\title{
Universidade de São Paulo Faculdade de Saúde Pública
}

\section{Uso de medicamentos e a segurança do paciente na interface entre hospital, atenção básica e domicílio}

Liete de Fátima Gouveia Marques

Dissertação apresentada ao Programa de Pós-Graduação em Saúde Pública para obtenção do título de Mestre em Ciências.

Área de Concentração: Serviços de Saúde Pública

Orientadora: Prof $^{\mathrm{a}} \mathrm{Dr}^{\mathrm{a}}$ Nicolina Silvana Romano Lieber

São Paulo 


\title{
Uso de medicamentos e a segurança do paciente na interface entre hospital, atenção básica e domicílio
}

\author{
Liete de Fátima Gouveia Marques
}

Dissertação apresentada ao

Programa de Pós-Graduação em Saúde Pública para obtenção do título de Mestre em Ciências.

Área de Concentração: Serviços de Saúde Pública

Orientadora: Prof ${ }^{a} \mathrm{Dr}^{\mathrm{a}}$ Nicolina Silvana Romano Lieber

São Paulo 
É expressamente proibida a comercialização deste documento, tanto na sua forma impressa como eletrônica. Sua reprodução total ou parcial é permitida exclusivamente para fins acadêmicos e científicos, desde que na reprodução figure a identificação do autor, título, instituição e ano da dissertação. 
Aos meus amores Suis, Ssabela e Diego, Gerônima e Sibertino

Pelo carinho, compreensão, apoio, estímulo e pela convivência sempre gratificante e especial, mesmo quando estamos distantes. 


\section{AGRADECIMENTOS}

À $\operatorname{Prof}^{a} \operatorname{Dr}^{\mathrm{a}}$ Nicolina Silvana Romano Lieber, minha orientadora, pela oportunidade de realizar este trabalho e pela confiança, incentivo e apoio durante todo o processo.

Às prof ${ }^{\mathrm{as}} \mathrm{Dr}^{\text {as }}$ Maria da Penha Costa Vasconcellos, Helaine Carneiro Capucho e Katia Grillo Padilha pelas valiosas sugestões ao trabalho.

À prof $^{\mathrm{a}} \mathrm{Dr}^{\mathrm{a}}$ Augusta Thereza de Alvarenga e colegas da disciplina de Fundamentos da Investigação Científica - turma 2011, pelas importantes contribuições durante a elaboração do projeto de pesquisa.

Aos amigos Donadio, Lenir, Mariluce e Zenilda, do Hospital Universitário Regional de Maringá, pela contribuição no aperfeiçoamento do roteiro de entrevista.

À equipe do Hospital Universitário da Universidade de São Paulo, pela participação receptiva e sincera nas entrevistas, por entenderem a importância de compartilhar tanto as experiências bem sucedidas como as dificuldades e problemas vivenciados.

Ao Conselho Nacional de Desenvolvimento Científico e Tecnológico (CNPq), pelo apoio financeiro para a realização deste trabalho. 
"Cada sonho que você deixa para trás é um pedaço do seu futuro que deixa de existir".

Steve Jobs 
MARQUES, L. F. G. Uso de medicamentos e a segurança do paciente na interface entre hospital, atenção básica e domicílio. 2013. Dissertação (Mestrado em Ciências) - Faculdade de Saúde Pública, Universidade de São Paulo, São Paulo.

\section{RESUMO}

A segurança do paciente e a qualidade da assistência à saúde, no uso de medicamentos, têm sido foco de preocupação e estudos em nível mundial. Os pacientes podem estar especialmente vulneráveis a danos imediatamente após alta hospitalar, e a ocorrência de eventos adversos relacionados a medicamentos pode resultar em atendimento em serviços de urgência ou em readmissão hospitalar. Este estudo teve como objetivo compreender a dinâmica e os desafios do cuidado fornecido ao paciente, pela equipe de saúde do hospital, visando à segurança no processo de uso de medicamentos após alta hospitalar. Foi realizada pesquisa exploratória por meio de entrevistas junto a médicos, enfermeiros, farmacêuticos e assistentes sociais do Hospital Universitário da Universidade de São Paulo. Atualmente, a principal estratégia adotada pelo hospital visando à segurança do paciente, com foco no processo de uso de medicamentos após alta hospitalar, é a orientação de alta ao paciente e/ou cuidador, realizada de forma estruturada, em casos selecionados, principalmente envolvendo pacientes pediátricos. A reconciliação medicamentosa está em fase de implantação na instituição e, em situações específicas, ocorre mobilização da equipe multidisciplinar para viabilização do acesso a medicamentos prescritos na alta hospitalar. Visita domiciliar é desenvolvida junto a pacientes críticos com problemas de locomoção, e não conta com a participação de farmacêuticos. As principais barreiras para implantação, desenvolvimento e ampliação dessas atividades são a falta de recursos humanos e de tecnologias da informação e a necessidade de alterações no procedimento de alta. Entre os fatores facilitadores estão características da 
equipe, como iniciativa, comprometimento, responsabilidade por resultados e qualificação, além do apoio da alta administração. O desenvolvimento de atividades acadêmicas junto à atenção básica facilita o estabelecimento de "pontes" entre o hospital e demais serviços de saúde, contribuindo para a transposição da barreira da falta de contato entre as equipes. No entanto, as limitações das atividades desenvolvidas e a falta de articulação adequada para a continuidade do cuidado, com foco no processo de uso de medicamentos, podem comprometer a segurança do paciente na interface entre hospital, atenção básica e domicílio.

Palavras-chave: segurança do paciente, alta hospitalar, eventos adversos, erros de medicação, medicamentos, saúde pública. 
MARQUES, L. F. G. Uso de medicamentos e a segurança do paciente na interface entre hospital, atenção básica e domicílio / Medication use and patient safety at the interface of hospital, primary care and the home setting. 2013. Dissertação (Mestrado em Ciências) - Faculdade de Saúde Pública, Universidade de São Paulo, São Paulo.

\begin{abstract}
Patient safety and quality of health care on medication use have been a central topic of discussion and focused in studies worldwide. Patients can be particularly vulnerable in the period immediately following their discharge from hospital and the occurrence of adverse drug events may require emergency care and hospital readmission. The present study aimed to understand the dynamics and challenges of care provided to patients by hospital providers focusing on safe use of medications after discharge. An exploratory study was conducted. Data was collected through interviews with physicians, nurses, pharmacists and social workers at the Hospital Universitário da Universidade de São Paulo, Brazil. The hospital's current main strategy for safe use of medications after hospital discharge is to provide structured counseling to selected patients and/or their caregivers especially pediatric patients. Medication reconciliation is being implemented and a multidisciplinary team can help ensure access to prescription drugs at discharge in some cases. Home visits are paid to patients with severe conditions and mobility problems but pharmacists are not involved. The main barriers to implementation, development, and expansion of these activities include limited human and information technology resources and changes required to patient discharge procedures. The main facilitators are a skilled team of care providers, committed to improving care and accountable for results and support from senior management. Care provided by students and residents at a primary care setting helps create "bridges" to integrate hospital
\end{abstract}


care and other care services and overcome the interaction barrier between care teams. However, limited actions and inadequate coordination of followup care focused on medication use may compromise patient safety at the interface of hospital, primary care and the home setting.

Keywords: patient safety, hospital discharge, adverse events, medication errors, drugs, public health. 


\section{ÍNDICE}

Sobre a escolha do tema

1 INTRODUÇÃO

1.1 MEDICAMENTO, SAÚDE E SOCIEDADE 16

1.2 RISCOS RELACIONADOS AO USO DE MEDICAMENTOS 19

1.3 A (IN)SEGURANÇA DO PACIENTE NA ASSISTÊNCIA À 22 SAÚDE E A QUESTÃO DOS MEDICAMENTOS: MAGNITUDE DO PROBLEMA

1.4 ALTA HOSPITALAR E OS RISCOS ASSOCIADOS AO 28 PROCESSO DE USO DE MEDICAMENTOS

1.4.1 Especificidades da alta hospitalar

1.4.2 Estratégias hospitalares para gerenciamento da 33 segurança do paciente no processo de uso de medicamentos após alta hospitalar

1.5 ARTICULAÇÃO ENTRE HOSPITAL, ATENÇÃO BÁSICA E DOMICÍLIO: O GRANDE DESAFIO PARA A SEGURANÇA NO PROCESSO DE USO DE MEDICAMENTOS

2 OBJETIVOS

3 PROCEDIMENTO METODOLÓGICO 53

3.1 SOBRE A PESQUISA 54

3.2 SOBRE OS PARTICIPANTES 58

3.3 SOBRE O LOCAL DO ESTUDO 59

4 RESULTADOS E DISCUSSÃO 64

4.1 ASPECTOS GERAIS RELACIONADOS À SEGURANÇA 65 DO PACIENTE NA INSTITUIÇÃO

4.1.1 Cultura de segurança 65

4.1.2 Atividades de farmacovigilância 70 
4.2 ATIVIDADES RELACIONADAS AO CUIDADO AO 78 PACIENTE EM ALTA HOSPITALAR

4.2.1 O cuidado ao paciente durante a hospitalização $\quad 78$

4.2.2 O cuidado ao paciente após alta hospitalar 114

4.2.3 O acesso a medicamentos prescritos na alta 126 hospitalar

4.3 ARTICULAÇÃO ENTRE O HOSPITAL E DEMAIS 134 SERVIÇOS DE SAÚDE

4.4 FATORES FACILITADORES E BARREIRAS PARA 140 IMPLANTAÇÃO E DESENVOLVIMENTO DAS ESTRATÉGIAS E PARA ARTICULAÇÃO ENTRE OS SERVIÇOS

5 CONCLUSÕES 150

6 CONSIDERAÇÕES FINAIS 154

7 REFERÊNCIAS 157

APÊNDICES E ANEXOS

GLOSSÁRIO

CURRÍCULO LATTES 


\title{
LISTA DE SIGLAS E ABREVIATURAS
}

\author{
ANVISA - Agência Nacional de Vigilância Sanitária \\ EA - Evento adverso \\ EAM - Evento adverso relacionado a medicamento \\ HU/USP - Hospital Universitário da Universidade de São Paulo \\ PAD - Programa de Assistência Domiciliária \\ PRO - Projeto Região Oeste \\ RAM - Reação adversa a medicamento \\ UBS - Unidade Básica de Saúde \\ USF - Unidade de Saúde da Família
}




\section{Sobre a escolha do tema}

Meu interesse sobre a segurança do paciente no processo de uso de medicamentos é decorrente de atuação na área hospitalar, como farmacêutica, onde prevenção e resolução de problemas associados ao uso de medicamentos fazem parte da rotina diária. Tive oportunidade de desenvolver trabalhos relacionados à segurança do paciente, em cursos de especialização: Farmacovigilância da Carbamazepina no Hospital das Clínicas da Universidade de São Paulo (1996), Farmacovigilância Hospitalar: uma pesquisa sobre programas desenvolvidos em hospitais universitários (2002), e Alta Hospitalar: um enfoque farmacêutico (2010). Na experiência investigativa mais recente, a riqueza da literatura, notadamente de publicações internacionais, possibilitou o conhecimento de estratégias desenvolvidas em nível das práticas dos serviços de saúde visando à segurança do paciente no processo de uso de medicamentos após alta hospitalar. Foi possível verificar que várias atividades - orientação ao paciente, reconciliação medicamentosa, seguimento do paciente após alta hospitalar, entre outras - podem ser utilizadas, pelos hospitais, como estratégias para minimizar os riscos de ocorrência de eventos adversos relacionados ao uso de medicamentos, após retorno ao domicílio, especialmente quando são realizadas de forma articulada com demais serviços de saúde, contribuindo para evitar danos ao paciente. Em contrapartida, os levantamentos bibliográficos, então realizados, apontaram para escassez de literatura brasileira em relação à segurança do paciente no processo de uso de medicamentos após alta hospitalar, dificultando o conhecimento sobre a atuação de hospitais brasileiros sobre questão tão relevante para a saúde pública. Esse processo permitiu ampliar indagações e pressupostos sobre o tema, mobilizando-me para avançar nesse tipo de investigação. Nessa linha é que se coloca a proposta de trabalho de mestrado, na qual parto das seguintes indagações sobre a situação no Brasil: Como está sendo tratada a questão da segurança do paciente no 
processo de uso de medicamentos após alta hospitalar? Que estratégias estão sendo empregadas por hospitais? Existe articulação entre hospitais e demais serviços de saúde para evitar descontinuidade no cuidado ao paciente após alta hospitalar? 
$I_{\text {nkrodução }}$ 


\subsection{MEDICAMENTO, SAÚDE E SOCIEDADE}

O uso de medicamentos representa uma importante estratégia terapêutica e tem sido fundamental para a prevenção, controle e cura de doenças, contribuindo não somente para o aumento da expectativa de vida como para a qualidade de vida. Porém, existe uma valorização excessiva do alcance desta e outras tecnologias de saúde. A medicalização - elevada dependência e consumo intensivo de bens e serviços médico-assistenciais ocorre até mesmo em situações fisiológicas ou de natureza sócioeconômica, que passam a ser consideradas como doenças (BARROS, 2002), acentuando a realização de procedimentos profissionalizados, diagnósticos e terapêuticos, desnecessários e muitas vezes até danosos aos usuários (TESSER et al., 2010). Além disso, existe uma tendência a reduzir adoecimentos a problemas da "máquina humana" que medicamentos ou cirurgias irão resolver (TESSER e BARROS, 2008).

O uso simbólico do medicamento implica "a fantasia de redução mágica do complexo, do complicado, do frustrante, do arriscado, do trabalhoso, ao uno, ao simples, ao fácil, ao acessível, ao visível, ao concreto, ao 'aqui e agora', ao imediato" (LEFĖVRE, 1987, p.65). Ainda segundo este autor, haveria um provável interesse de indivíduos ao que chama de subclasses de "saúde imediata", tais como alívio de dor ou desconforto (analgésicos e afins), potência ou vida (vitaminas, estimulantes), morte, no sentido figurado (calmantes e algumas drogas que levam a "paraísos artificiais"), além de proteção (vacinas e antibióticos). Vale ressaltar que os analgésicos geralmente ocupam lugar de destaque na lista de medicamentos utilizados sob prescrição ou por automedicação (SILVA et al., 2011; SÁ et al., 2007; SOUZA e LOPES, 2007; BERTOLDI et al., 2004; ROZENFELD, 2003). De fato, no topo da lista de medicamentos com maior faturamento no Brasil, no período entre agosto de 2010 e agosto de 2011, 
estão os analgésicos Dorflex® ( $1^{\circ}$ lugar, $R \$ 321$ milhões) e Neosaldina ${ }^{\circledR}\left(3^{\circ}\right.$ lugar, $R \$ 209$ milhões), segundo dados do IMS Health (2011).

Na década de 70, em seu livro $A$ expropriação da saúde: nêmesis da medicina, Ivan Illich, citado por TESSER (2006), afirmou que a medicina institucionalizada havia se transformado numa ameaça à saúde devido à difusão de vários tipos de iatrogenias, entre elas, a iatrogenia clínica - danos ao indivíduo ocasionados pelo uso da tecnologia médica, diagnóstica e terapêutica.

Nos últimos anos, a preocupação com a segurança do paciente, entendida como "redução do risco, a um mínimo aceitável, de danos desnecessários associados ao atendimento em saúde" (RUNCIMAN et al., 2009, p.19), tem reforçado a questão do manejo dos riscos associados ao uso de medicamentos.

Para BECK (2011), a preocupação com riscos é antiga, embora apresente características diferentes ao longo do tempo. Os riscos por causas naturais, aos quais estavam expostos os indivíduos, por exemplo, nas antigas expedições náuticas, eram de caráter pessoal, e associados à ousadia e à aventura. Os riscos fabris e profissionais, no século XIX e início do século $X X$, eram limitados geograficamente ou em função de grupos específicos. Ainda segundo o autor, na atualidade, ao contrário, destacamse os riscos decorrentes do desenvolvimento científico e tecnológico, que contêm uma tendência globalizante, sendo a sociedade contemporânea definida como "sociedade de risco".

Esta sociedade, ao mesmo tempo em que gera os riscos, passa a naturalizar sua convivência com eles e suas consequências (ZANIRATO et al., 2008), adotando práticas específicas a partir de reflexão sobre seu estilo de vida e riscos associados. Para NAVARRO e CARDOSO (2005), a questão do risco exige posicionamento constante da sociedade quanto a escolhas em ações cotidianas, como expor-se, ou não, aos riscos do 
consumo de alimentos geneticamente modificados ou alimentos contaminados com agrotóxicos; confiar, ou não, no elo de fidelidade com o parceiro, diante das doenças sexualmente transmissíveis, especialmente a AIDS; adotar ou não novos hábitos em função da insegurança em ambientes públicos. Além das citadas pelos autores, outras situações podem envolver escolhas motivadas pela perspectiva de risco, tais como mudar o estilo de vida ou utilizar medicamentos em função de fatores de risco como obesidade, hipercolesterolemia ou tabagismo, e buscar formas alternativas de tratamentos de saúde devido aos riscos dos tratamentos habituais.

Segundo Douglas, citada por ZANIRATO et al. (2008), o risco não pode ser interpretado como um conceito objetivo e mensurável, mas sim como algo construído social, cultural e politicamente, cuja definição é fundamental para os debates sobre políticas públicas. Para LIEBER e ROMANO-LIEBER (2002, p.12), "risco é uma relação que pode ser estabelecida sob argumentos objetivos, mas a percepção e a aceitação desta relação objetivamente dada estão sujeitas aos aspectos culturais e pessoais". Assim, de acordo com estes autores, na avaliação do risco devem ser incluídos não apenas componentes clássicos, como probabilidade de ocorrência de um evento/acontecimento relativo a uma dada magnitude de consequência, ou probabilidade de dano potencial, mas, também, uma abordagem de riscos em uma perspectiva cultural. Para Douglas, esse enfoque permite entender como são (ou não) estabelecidas as estratégias de prevenção, pois estas são orientadas pelo contexto cultural, no qual os sujeitos se encontram inseridos.

ZANIRATO et al. (2008) destacam que a convivência com os riscos não implica na sua compreensão pela população. Muitos dos novos riscos podem até mesmo fugir por completo à percepção humana imediata (BECK, 2011), dificultando o manejo do potencial iatrogênico das tecnologias, incluindo o medicamento. 


\subsection{RISCOS RELACIONADOS AO USO DE MEDICAMENTOS}

Os riscos de ocorrência de danos associados ao uso de medicamentos podem ser decorrentes de problemas em várias etapas do ciclo do medicamento, e são aqui brevemente apresentados:

Limitações dos estudos clínicos pré-comercialização

Segundo LAPPORTE e TOGNONI (1989), quando um novo medicamento é comercializado, dispõe-se de pouca informação sobre a natureza e a quantidade dos seus possíveis efeitos indesejáveis, devido às limitações próprias dos ensaios clínicos controlados exigidos no período précomercialização (pequeno número de pacientes selecionados, curta duração, ausência de tratamentos concomitantes). Assim, somente a partir do uso dos medicamentos pela população é possível conhecer seus efeitos na "vida real", como as reações adversas raras ou que ocorrem apenas após uso por períodos prolongados, como em tratamentos crônicos, ou ainda efeitos indesejáveis decorrentes de interação com outros medicamentos.

Além da existência de regulamentação para pesquisa e desenvolvimento de medicamentos, para seu uso seguro é fundamental o desenvolvimento de atividades relativas à detecção, avaliação, compreensão e prevenção dos efeitos adversos e quaisquer outros problemas relacionados a medicamentos - objeto dos programas de farmacovigilância (OMS, 2005). Daí a necessidade que profissionais de saúde notifiquem qualquer suspeita de evento adverso relacionado ao uso de medicamentos, especialmente com relação a medicamentos novos.

Problemas relacionados à produção e controle de qualidade de medicamentos 
Eventos adversos podem ser decorrentes do uso de medicamentos com problemas de qualidade, tais como teor do fármaco fora das especificações, instabilidade do fármaco e do medicamento, excesso de impureza da matéria-prima, dissolução inadequada, contaminação do produto, além de problemas na bula, no material de acondicionamento e na embalagem.

A garantia da qualidade dos medicamentos disponíveis no mercado é responsabilidade da indústria farmacêutica e de órgãos regulatórios, uma vez que o fabricante deve atender aos requisitos de registro, fabricação, controle de qualidade, e vigilância pós-comercialização, segundo normatização da Vigilância Sanitária. A utilização de medicamentos que apresentam problemas decorrentes de falhas na produção e controle de qualidade é uma situação que tem potencial de causar danos ao paciente (relacionados à efetividade ou à segurança), devido à disponibilização de produtos de baixa qualidade no mercado, não somente em países em desenvolvimento, por falta de recursos ou expertise, como em países desenvolvidos, nos quais, de tempos em tempos, ocorrem problemas semelhantes (MEREDITH, 1996). Portanto, é de fundamental importância a realização periódica de inspeção e fiscalização das indústrias farmacêuticas, pela Vigilância Sanitária, além do monitoramento da qualidade de medicamentos disponíveis no mercado. Igualmente importante é a notificação de desvios de qualidade de medicamentos, pelos profissionais de saúde, a fim de orientar as ações das autoridades sanitárias para regular o comércio de medicamentos.

\section{Erros de medicação}

Erro de medicação pode ser definido como "uma falha no processo terapêutico que leva ou tem potencial para levar dano ao paciente" (FERNER e ARONSON, 2006, p. 1013). Os erros podem ocorrer nas etapas de prescrição, dispensação, administração e monitorização do uso de 
medicamentos, e resultar, ou não, em danos ao paciente, com vários níveis de gravidade, incluindo danos irreversíveis e morte.

Embora erros possam ocorrer devido à violação voluntária de normas e procedimentos, a maioria dos erros de medicação está relacionada a falhas sistemáticas e organizacionais. Por essa razão, HUGHES e ORTIZ (2005) sugerem que, além de treinamento de pessoal, algumas medidas podem ser úteis para o manejo de erros de medicação, tais como uso de tecnologias da informação, avaliação das práticas em uso, e notificação e avaliação de erros de medicação, para promover alterações que previnam erros semelhantes. São exemplos de erros de medicação (ASHP, 1993; ANACLETO et al., 2010):

- Erros de prescrição: escolha incorreta de medicamentos quanto às indicações, contraindicações, alergias conhecidas, uso concomitante de medicamentos; prescrição incorreta de dose, via de administração, duração do tratamento; prescrição de medicamento desnecessário e prescrição ilegível ou com uso inadequado de abreviaturas ou siglas.

- Erros de dispensação: omissão de medicamento prescrito, dispensação de medicamento não prescrito, troca de medicamentos, dispensação de medicamento em concentração, forma farmacêutica ou dose errada, e dispensação de medicamentos com desvios de qualidade passíveis de detecção visual.

- Erros de administração: omissão de medicamento, administração de medicamento não prescrito, administração de medicamento deteriorado e administração inadequada quanto à dose, horário, via de administração, velocidade ou taxa de administração.

- Erros de monitorização: falha na revisão do esquema farmacoterapêutico prescrito, quanto à adequabilidade e detecção de problemas, ou falha no uso de dados laboratoriais e clínicos para avaliação da resposta do paciente ao tratamento, quanto à efetividade e segurança. 
Presença de fármacos ativos no meio ambiente

\begin{abstract}
Este é outro aspecto relacionado à segurança no uso de medicamentos que, mais recentemente, tem gerado preocupação de autoridades sanitárias e pesquisadores. As principais fontes de contaminação são a eliminação de fármacos ativos nas fezes e urina, a partir de medicamentos utilizados em humanos e animais, além do descarte de medicamentos vencidos ou sobras, no vaso sanitário ou lixo comum, resultando na dispersão dos fármacos no esgoto, água e solo. Os fármacos geralmente não persistem no meio ambiente, mas a dispersão contínua mantém concentrações relativamente constantes, mesmo que extremamente baixas (ng/L, mcg/L), de antibióticos, hormônios, analgésicos, antiinflamatórios, entre outros, havendo preocupação quanto ao potencial de desenvolvimento de resistência microbiana, danos ao sistema reprodutor e desenvolvimento de câncer, entre outros agravos, em função da ingestão de água e alimentos contaminados (GUALTERO, 2005; RAHMAN et al., 2007; CRESTANA e SILVA, 2011).
\end{abstract}

Há, também, riscos de danos decorrentes de uso indevido ou abusivo de medicamentos; riscos de exposição acidental a medicamentos, especialmente envolvendo crianças; riscos de uso de medicamentos deteriorados ou falsificados, entre outros.

Enfim, a segurança no uso de medicamentos é um tema importante para saúde pública, e requer atuação integrada de órgãos reguladores, indústrias farmacêuticas, instituições de saúde, instituições de ensino e pesquisa, organizações governamentais e não governamentais envolvidas com a segurança, além de profissionais de saúde, pacientes e cuidadores.

\title{
1.3 A (IN)SEGURANÇA DO PACIENTE NA ASSISTÊNCIA À SAÚDE E A QUESTÃO DOS MEDICAMENTOS: MAGNITUDE DO PROBLEMA
}


Nos últimos anos, a preocupação com a segurança do paciente foi fortemente influenciada pela divulgação dos dados do relatório do Instituto de Medicina norte-americano (IOM), de 1999 (KOHN et. al, 2000): anualmente, os erros associados à assistência à saúde seriam a causa de morte de 44.000 a 98.000 pacientes norte-americanos; mesmo utilizando a estimativa mais baixa, ultrapassaria o número de mortes por acidentes de veículo a motor, câncer de mama, ou AIDS. Sete mil mortes seriam resultantes de erros relacionados ao uso de medicamentos, em nível hospitalar ou ambulatorial.

Ainda segundo estimativas do IOM, o custo nacional total dos eventos adversos evitáveis (erros associados à assistência à saúde que resultam em dano ao paciente) seria de 17 a 29 bilhões de dólares, sendo $50 \%$ deste valor destinado ao atendimento em serviços de saúde. Os eventos adversos evitáveis relacionados a medicamentos, como também são chamados os erros de medicação, aumentariam os custos hospitalares em 2 bilhões de dólares, anualmente, nos EUA.

A divulgação do relatório do IOM contribuiu para a mudança da visão de que erro associado à assistência à saúde seria "um 'subproduto' inevitável da medicina moderna ou infortúnio advindo de maus prestadores desses serviços" (WACHTER, 2010, p. 23). Também resultou em estímulo para a mobilização de profissionais, instituições de saúde, organizações governamentais e não governamentais, em vários países, como há muito tempo não se observava, visando ao desenvolvimento de estratégias para promover a melhoria da qualidade do atendimento em saúde, e, consequentemente, da segurança do paciente (CLASSEN e METZGER, 2003).

A publicação de vários estudos, nas ultimas décadas, tem auxiliado na compreensão da dimensão do problema. MENDES et al. (2005) realizaram revisão sistemática de nove estudos de avaliação da ocorrência de eventos adversos (EA) em hospitais, por meio de revisão retrospectiva de 
prontuários. A análise dos estudos desenvolvidos em 7 países (EUA, Canadá, Inglaterra, Austrália, Nova Zelândia, França e Dinamarca), envolvendo 92063 prontuários de 158 hospitais, demonstrou que a incidência de EA variou de 2,9 a 16,6 por 100 pacientes. Do total de eventos adversos, $38 \%$ estavam relacionados a procedimentos cirúrgicos e $19 \%$ a medicamentos.

VRIES et al. (2008) realizaram revisão sistemática de oito estudos desenvolvidos no Canadá, EUA, Reino Unido, Austrália e Nova Zelândia, sobre a incidência e natureza dos eventos adversos hospitalares, e envolveu revisão retrospectiva de prontuários de aproximadamente 75 mil pacientes de 144 hospitais. A incidência de eventos adversos entre os pacientes foi de $3,2 \%$ a $16,6 \%$ (média de $9,2 \%$ ), sendo que o percentual médio de EA considerados evitáveis foi de $43,5 \%$. Com relação aos desfechos, $56,3 \%$ dos EA não resultaram em incapacidade ou esta foi considerada leve; porém, $7 \%$ resultaram em incapacidade permanente, e 7,4\% dos eventos causaram a morte dos pacientes. Os eventos eram, principalmente, relacionados a procedimentos cirúrgicos $(40 \%)$ ou medicamentos (15\%). Cerca de $80 \%$ dos EA foram detectados no hospital e $15 \%$ fora do hospital, antes da admissão ou após alta hospitalar.

Estudo que envolveu aproximadamente $12 \mathrm{mil}$ indivíduos, da Austrália, Canadá, Alemanha, Holanda, Nova Zelândia, Reino Unido e EUA, demonstrou que a taxa de erros associados à assistência à saúde (erros médicos, laboratoriais e de medicação), verificada a partir de autorrelato, variou de $12 \%$ a $20 \%$, e que 1 a cada 6 canadenses tinha vivenciado pelo menos um erro nos dois últimos anos (O'HAGAN et al., 2009).

MENDES et al. (2009), em estudo realizado em três hospitais brasileiros, verificaram que a incidência de pacientes com EA foi de $7.6 \%$ (84 de 1103 pacientes), sendo que 35,2\% estavam relacionados a procedimentos cirúrgicos e 5,6\% a medicamentos. A taxa de incidência foi considerada similar à encontrada em outros estudos: Canadá $(7,5 \%)$, 
Dinamarca (9\%), Espanha (9,3\%), Reino Unido (10,8\%), Nova Zelândia (11,3\%), França (14,5\%) e Austrália (16.6\%). Entretanto, no estudo brasileiro a proporção de EA evitáveis $(66,7 \%)$ foi mais elevada que a de Nova Zelândia (61.6\%), Reino Unido (52\%), Austrália (50\%), Dinamarca (40.4\%), Espanha (42,6\%), Canadá (36,9\%) e França (27.6\%).

Com base em dados coletados neste mesmo estudo brasileiro, MARTINS et al. (2011) demonstraram que a taxa de mortalidade geral foi de $8,5 \%$, mas subiu para $38,1 \%$ no subgrupo de casos com ocorrência de um evento adverso. Os autores demonstraram associação estatisticamente significante entre morte e evento adverso. Este estudo também demonstrou que pacientes idosos apresentaram maior risco de morrer, e que parte desse risco estava relacionada à ocorrência de eventos adversos.

O impacto econômico da ocorrência de eventos adversos tem sido demonstrado em estudos realizados em diversos países. Na Holanda, os custos diretos dos EA, estimados em 2004, foram de 355 milhões de euros, sendo 161 milhões gastos com EA evitável, correspondendo a $1 \%$ do orçamento nacional destinado aos cuidados de saúde (HOONHOUT et al., 2009). Na Nova Zelândia, o tratamento de eventos adversos foi responsável por $30 \%$ dos gastos dos hospitais públicos (BROWN et al., 2002).

Para estimar o volume de recursos financeiros gastos com pacientes com eventos adversos em hospitais no Brasil, PORTO et al. (2010) analisaram 622 prontuários de pacientes de dois hospitais públicos de ensino do Estado do Rio de Janeiro, em 2003. Trinta e nove pacientes $(6,3 \%)$ apresentaram EA, $64 \%$ deles considerados evitáveis. Os custos foram avaliados em relação aos dias adicionais de hospitalização decorrentes de EA. O valor médio pago pelo atendimento aos pacientes com EA foi $200,5 \%$ superior ao valor pago aos pacientes sem EA. Considerando o total de internações nos dois hospitais, os eventos adversos implicaram um gasto superior a 1 bilhão de reais, representando $2,7 \%$ do reembolso feito pelo Ministério da Saúde aos hospitais pesquisados. 
Vários estudos abordaram o impacto clínico e econômico especificamente dos eventos adversos relacionados a medicamentos (EAM). Em revisão realizada por CANO e ROZENFELD (2009) sobre EAM durante a hospitalização foram analisados 29 estudos conduzidos em 13 países da América do Norte, Europa, América do Sul e Ásia - sendo 10 estudos realizados nos EUA e 2 no Brasil. A proporção de pacientes com EAM durante a hospitalização variou de $1,6 \%$ a $41,4 \%$, e as taxas variaram de 1,7 a 51,5 eventos por 100 hospitalizações e de 4,4 a 7,0 eventos por 100 pacientes-dia. Houve predominância de eventos classificados como leves ou moderados (mais de $80 \%$ do total), e 14,8\% a $59 \%$ dos eventos foram considerados evitáveis. Três grupos de medicamentos foram responsáveis por mais de $50 \%$ dos eventos (agentes antiinfecciosos, cardiovasculares e antineoplásicos), sinalizando áreas para intervenção e prevenção de EAM.

Em estudo sobre agravos provocados por medicamentos em pacientes internados em hospitais do Sistema Único de Saúde, no Rio de Janeiro, entre 1999 e 2002, foram identificados 3.421 casos, equivalentes a 1,8 casos/1000 internações, sendo a maioria de efeitos adversos (1,4 e 2,3 por 1000 internações, em 1999 e 2002, respectivamente), seguido de intoxicações (ROZENFELD, 2007).

Fora do ambiente hospitalar, também existe preocupação com a segurança no uso de medicamentos, pois, embora o número de medicamentos utilizados por paciente, em geral, seja menor, o processo envolve a maior parcela da população e ocorre sem a supervisão direta da equipe de saúde. Revisão sistemática da literatura realizada para estimar a ocorrência de EAM em atendimento ambulatorial demonstrou taxa de prevalência de 3,3\% em estudos retrospectivos e de 9,65\% em estudos prospectivos, sendo que $16,5 \%$ dos eventos poderiam ter sido evitados. A distribuição das taxas conforme a faixa etária foi de 2,45\% para crianças, $5,27 \%$ para adultos, e 16,1\% para pacientes idosos (TACHE et al., 2011). 
Em revisão sistemática sobre admissão hospitalar associada com reações adversas a medicamentos (RAM), KONGKAEW et al., (2008), identificaram 25 estudos prospectivos observacionais, envolvendo cerca de 100 mil pacientes. A taxa de admissão hospitalar devido à reação adversa a medicamentos variou conforme faixa etária, sendo de $4,1 \%$ para crianças, $6,3 \%$ para adultos e $10,7 \%$ para idosos.

Quanto a estudos desenvolvidos no Brasil, RAM foi responsável ou teve participação em 6,6\% (9/135) das internações analisadas em hospital universitário do interior de São Paulo (PFAFFENBACH et al., 2002).

No estudo realizado por VARALLO (2010), também no Estado de São Paulo, a prevalência de internações hospitalares por RAM foi de $46,4 \%$ (115/248). Neste estudo, a maioria das reações adversas foi classificada como possível $(66,3 \%)$ ou provável $(30,3 \%)$.

Em estudo desenvolvido em quatro hospitais de ensino de Salvador, a taxa de admissão hospitalar devida à RAM foi de 0,56\% (212/37658). A maioria dos pacientes teve recuperação sem sequelas (94,3\%), e houve um caso fatal devido a acidente vascular cerebral causado pelo uso de varfarina (NOBLAT et al., 2011).

Estudo realizado em serviço de emergência no sul do Brasil (ANDREAZZA et al., 2011) verificou que, de 335 pacientes, 106 (31,6\%) foram atendidos devido a problemas relacionados com medicamentos. Os problemas mais comuns foram RAM $(28,5 \%)$ e inefetividade terapêutica devido a doses inadequadas $(17,9 \%)$.

$\mathrm{Na}$ Inglaterra, a estimativa do custo anual de admissões hospitalares decorrentes de reações adversas a medicamentos foi de $£ 466$ milhões (PIRMOHAMED et al., 2004).

O panorama apresentado demonstra que a ocorrência de eventos adversos representa uma importante causa de morbidade e mortalidade, 
resultando em sofrimento e aumento dos custos do atendimento em serviços de saúde. Ao demonstrar a dimensão do problema, esses dados reforçam a relevância da utilização de estratégias para evitar a ocorrência de eventos adversos, tanto pelo impacto social como econômico, permitindo melhor utilização dos recursos financeiros destinados ao atendimento à saúde da população. Assim, os dados justificam a necessidade de inclusão deste tema na agenda nacional de assistência à saúde.

A questão da segurança do paciente assume particular importância em períodos de transição do atendimento - como a alta hospitalar - onde os pacientes encontram-se mais vulneráveis a danos, e são comuns os problemas relacionados ao uso de medicamentos.

\subsection{ALTA HOSPITALAR E OS RISCOS ASSOCIADOS AO PROCESSO DE USO DE MEDICAMENTOS}

\subsubsection{Especificidades da alta hospitalar}

A experiência de adoecimento e hospitalização implica em separação de familiares, amigos e objetos significativos, mudança de rotina, limitação do espaço físico, restrição de atividades, submissão a novos horários, realização de procedimentos invasivos e dolorosos, dependência em situações básicas como alimentação, higiene e movimentação, além de sofrimento com a solidão e o medo da morte - uma realidade constante nos hospitais (MORO et al., 2007; SILVA e GRAZIANO, 1996).

O momento da alta hospitalar costuma trazer, ao paciente, sentimentos ambíguos, como satisfação e medo. Satisfação por estar se recuperando e por voltar para casa, e medo por sentir-se inseguro sem o suporte da equipe de saúde, já que, geralmente, deverá dar continuidade ao processo de recuperação (MARRA et al., 1989). Comumente, os pacientes 
retornam para a família e comunidade ainda com uma gama de problemas que demandam assistência, pois recebem alta logo após a resolução de problemas mais agudos, devido à grande demanda pelos leitos hospitalares, à necessidade de redução de custos, bem como devido aos riscos que a hospitalização prolongada pode oferecer, especialmente infecção hospitalar (CESAR e SANTOS, 2005). Frequentemente, os pacientes recebem alta no processo de convalescença, mais que em seu estado de saúde basal (CUA e KRIPALANI, 2008), podendo, ainda, apresentar deficiências funcionais.

Os pacientes podem estar especialmente vulneráveis a danos imediatamente após alta hospitalar, por várias razões: falta de preparo para o autocuidado'; falta ou inadequação de orientação; falta de acesso a profissionais de saúde que tenham conhecimento de seu plano de cuidado, quando as dúvidas surgem; falta de seguimento adequado (COLEMAN et al., 2006), descontinuidade do cuidado na interface do atendimento hospitalar e ambulatorial, por mudança do local de atendimento ou dos profissionais de saúde; além da transferência incorreta ou incompleta de informações (BARNSTEINER, 2005) e ausência de sistema integrado de informações nos diferentes serviços de atendimento à saúde do paciente (BAYLEY et al., 2007).

Estima-se que $11 \%$ a $23 \%$ dos pacientes apresentam eventos adversos relacionados a medicamentos após alta hospitalar, sendo que $6 \%$ a $27 \%$ dos eventos poderiam ter sido evitados, e $6 \%$ a $33 \%$ poderiam ter severidade e duração reduzidas (FOSTER et al., 2003, 2004, 2005). Além disso, estima-se que $6 \%$ a $12 \%$ dos eventos adversos relacionados a medicamentos que ocorrem após alta resultam em atendimento em serviços de urgência e 5\% em readmissão hospitalar (SCHINIPPER et al., 2006).

\footnotetext{
${ }^{1}$ Autocuidado é a atividade que os indivíduos praticam em seu benefício próprio para manutenção da vida, da saúde e do bem estar. Envolve atividades do cotidiano (ingestão de água e alimentos, higiene, equilíbrio entre atividade e descanso, prevenção de riscos), assim como atividades exigidas em condições de desvio de saúde (OREM apud SILVA, 2009), como busca de assistência à saúde e execução de procedimentos relacionados ao tratamento proposto.
} 
Os principais fatores desencadeadores de eventos adversos relacionados ao processo de uso de medicamentos após alta hospitalar podem ser assim agrupados: prescrição inapropriada de medicamentos, falta ou insuficiência de orientação sobre o tratamento, ausência ou inadequação de seguimento do paciente, e falhas na comunicação e transferência de informações entre hospital e atenção primária.

A falta de informações acuradas e completas sobre quais medicamentos o paciente estava utilizando antes da internação pode levar à interrupção ou inadequação da terapia medicamentosa durante a hospitalização, ou resultar em falha na deteç̧ão de problemas relacionados a medicamentos como causa da admissão hospitalar, afetando adversamente a segurança do paciente. $\mathrm{Na}$ alta hospitalar, a manutenção destes erros pode resultar na prescrição de terapia farmacológica inapropriada, seja pela omissão de medicamentos anteriormente utilizados pelo paciente, ou devido à duplicação de medicamentos, presença de interações medicamentosas, manutenção de medicamentos desnecessários, desencadeando eventos adversos que podem resultar em sofrimento e custos adicionais no atendimento (CORNISH et al., 2005).

Vários estudos relatam a frequência, tipos e causas das discrepâncias detectadas nos tratamentos farmacológicos: mais da metade dos pacientes estudados apresentaram pelo menos uma discrepância na admissão hospitalar (CORNISH et al., 2005; GLEASON et al., 2004), enquanto que, na alta hospitalar, $41 \%$ a $49 \%$ dos pacientes apresentaram discrepâncias (SCHNIPPER et al., 2006; VIRA et al., 2006). O principal tipo de discrepância detectado nestes trabalhos foi a omissão de medicamentos anteriormente utilizados pelos pacientes (42\% a 60\% das discrepâncias), tanto na admissão como na alta hospitalar, seguida de diferenças na dose, frequência, horário, via e forma de administração. Em outro estudo, no momento da alta, $57 \%$ das alterações nos regimes farmacoterapêuticos foram devidas à descontinuidade do medicamento; $21 \%$, alteração na dose; 
e 7\%, substituições (BOOCKVAR et al., 2004). As discrepâncias não justificadas podem ser consideradas erros de medicação, que podem ter consequências clínicas, isto é, podem causar danos ou ter potencial para causar danos; portanto, tais discrepâncias podem ser consideradas eventos adversos reais ou potenciais (VIRA et al., 2006).

Estudos avaliaram o potencial de dano das discrepâncias detectadas: caso as discrepâncias não tivessem sido interceptadas em 24-48 horas e permanecessem durante a hospitalização, 22\% das discrepâncias causariam danos e $23 \%$ demandariam necessidade de monitorização ou intervenção; $59 \%$ das discrepâncias poderiam resultar em dano se o erro não fosse interceptado e continuasse após alta hospitalar (GLEASON et al., 2004); $23 \%$ foram consideradas graves, com risco de hospitalização ou alteração persistente da função (PIPPINS et al., 2008). Em estudo realizado com pacientes idosos, mais de um terço das discrepâncias tinham potencial de causar dano moderado $(32,9 \%)$ ou severo $(5,7 \%)$ (CORNISH et al., 2005$)$.

O conhecimento insuficiente sobre seus problemas de saúde e medicamentos é uma das principais causas da falta de adesão do paciente ao seu regime farmacoterapêutico e plano de monitorização. Estima-se que $20 \%$ a $50 \%$ dos pacientes não utilizam seus medicamentos da maneira como são prescritos; sem adequado conhecimento, os pacientes não podem ser parceiros efetivos no manejo de seu próprio tratamento. A não-adesão ao tratamento farmacológico pode resultar em comprometimento dos resultados do tratamento, deterioração do estado de saúde do paciente, além de aumento da utilização e dos custos do atendimento em saúde (ASHP, 1997; SILVA et al., 2000; KERZMAN et al., 2005). Muitos pacientes relatam que, durante hospitalização, não tiveram oportunidade de fazer perguntas sobre seus medicamentos para qualquer membro da equipe de saúde. Frequentemente, os pacientes recebem alta hospitalar com informação inadequada ou insuficiente sobre seus medicamentos ou mesmo 
não recebem qualquer orientação sobre seu tratamento (CALABRESE et al., 2003; KERZMAN et al., 2005).

A falta de seguimento adequado do paciente é uma das causas do comprometimento da segurança dos pacientes durante o período vulnerável da transição de atendimento (COLEMAN et al., 2006). Em geral, os hospitais não oferecem seguimento do paciente imediatamente após alta hospitalar, em seu domicílio, até seu retorno ao acompanhamento ambulatorial. Assim, pode ser comum a ocorrência de sentimento de abandono após alta, como demonstrado no depoimento de um paciente, após receber alta hospitalar:

Eu estava sozinho, com medo, desinformado e isolado. Não tinha orientação sobre como cuidar de mim mesmo e nenhuma maneira de conseguir informação, orientação, consolo, cuidado. Pensei que talvez fosse porque sou médico, mas, agora que sou sensível a isso, vejo que esta falha está acontecendo em toda parte (BISOGNANO e BOUTWELL, 2009, p. 3).

Além de falta ou deficiência do seguimento do paciente no domicílio, o seguimento ambulatorial pode ser comprometido por falhas na comunicação e transferência de informações entre os profissionais envolvidos no cuidado do paciente, devido à falta de articulação das ações e serviços em todos os níveis de complexidade do atendimento (GLINTBORG et al., 2007). Até pouco tempo, apesar de comuns e de grandes consequências para o paciente, os erros na troca de informações e na transferência de pacientes despertavam pouca atenção - em parte porque ocorrem nas interfaces das relações profissionais (WACHTER, 2010). Atualmente, porém, tem sido enfatizada a necessidade de transferência de informações acuradas, completas e dentro de período adequado para a continuidade do cuidado ao paciente (CUA e KRIPALANI, 2008).

Transições de cuidado efetivas dependem da colaboração entre as instituições de saúde, porém as instituições geralmente funcionam de forma isolada (COLEMAN e BERENSON, 2004). 
Estudos demonstram que algumas atividades desenvolvidas durante a hospitalização e após a alta hospitalar podem reduzir as discrepâncias entre regimes farmacoterapêuticos pré e pós-hospitalização, melhorar a adesão ao tratamento, reduzir a taxa de eventos adversos relacionados a medicamentos, além de reduzir a necessidade de novos atendimentos em serviços de saúde, tanto em emergência como readmissões hospitalares (NAYLOR et al., 1999; HUANG e LIANG, 2005; KABOLI et al., 2006; SCHNIPPER et al., 2006; COLEMAN et al., 2006).

1.4.2 Estratégias hospitalares para gerenciamento da segurança do paciente no processo de uso de medicamentos após alta hospitalar

O já citado relatório do Instituto de Medicina dos EUA, publicado como To err is human: building a safer health system (KOHN et al., 2000), estimulou as organizações de saúde a implementar iniciativas que melhoram a segurança do paciente, entre elas o desenvolvimento da cultura de segurança nas instituições de saúde.

A cultura de segurança de uma organização é o produto dos valores, atitudes, percepções, habilidades e padrões de comportamento, individuais e de grupo, que determina o comprometimento, além do estilo e a competência da organização, para o gerenciamento de segurança e saúde (ACSNI apud SAMMER et al., 2010, p. 156).

Segundo a Agency for Healthcare Research and Quality (AHRQ) ${ }^{2}$, a cultura de segurança engloba as seguintes características-chave:

- Reconhecimento de que as atividades da organização são de alto risco, e determinação em alcançar operações seguras de forma consistente;

- Comprometimento organizacional de recursos para atuação na resolução dos os problemas;

\footnotetext{
${ }^{2}$ Texto extraído dos arquivos da Agency for Healthcare Research and Quality, disponível em <http://psnet.ahrq.gov/primer.aspx?primerlD=5>. Acesso em 05/11/2012.
} 
- Incentivo à colaboração na busca de soluções para problemas relacionados à segurança do paciente;

- Ambiente onde os indivíduos são capazes de notificar erros reais ou potenciais sem medo de repreensão ou punição.

Atualmente, tem sido enfatizado que o foco dos esforços na abordagem do erro deve ser transferido do indivíduo para o sistema, ou seja, a abordagem tradicional - culpar o indivíduo pelo erro cometido - deve ser abandonada, pois não resolve o problema. A abordagem sistêmica parte do princípio de que humanos erram e, em função disto, a segurança depende da criação de sistemas que antecipem os erros, para que possam ser prevenidos ou interceptados antes que causem dano (WACHTER, 2010).

Em nível hospitalar, o gerenciamento da segurança do paciente após alta hospitalar requer atuação multiprofissional integrada e atendimento às necessidades específicas de cada paciente (POMPEO et al., 2007). Esforços coordenados entre os membros da equipe de saúde aumentarão a adesão aos regimes farmacoterapêuticos e a monitorização dos efeitos dos medicamentos (ASHP, 1997), contribuindo para seu uso seguro e efetivo.

Várias estratégias têm sido divulgadas para promover efetiva transição do cuidado na alta hospitalar, e há evidências de que algumas intervenções podem ter impacto positivo sobre a segurança do paciente, especialmente aquelas com componentes educacionais e aquelas que combinam intervenções pré e pós-alta (MISTIAEN et al., 2007).

As principais estratégias direcionadas à prevenção e manejo da ocorrência de eventos adversos relacionados ao uso de medicamentos são: reconciliação medicamentosa, orientação ao paciente, seguimento domiciliar do paciente após alta hospitalar, e articulação do cuidado entre o hospital e os demais serviços de atendimento à saúde do paciente.

\subsubsection{Reconciliação medicamentosa}


A reconciliação medicamentosa é um dos procedimentos operacionais recomendados pelo High 5's Project - projeto internacional lançado pela Organização Mundial da Saúde, em 2006, com a missão de facilitar a implantação e avaliação de soluções padronizadas para a segurança do paciente (WILLIAMS, 2012). Segundo MORIEL et al. (2008), a reconciliação medicamentosa representa uma importante estratégia para reduzir erros de medicação e custos no atendimento.

Reconciliação medicamentosa é a avaliação global do regime de medicação do paciente, sempre que ocorre alteração no tratamento, em um esforço para evitar erros de medicação tais como, omissões, duplicações, erros de dose, ou interações medicamentosas, assim como para observar padrões de adesão ao tratamento (CHEN e BURNS, 2007, p. 4).

A reconciliação medicamentosa permite detectar, interceptar e corrigir discrepâncias entre o tratamento prévio e o tratamento proposto, suspender medicamentos desnecessários, e revisar a segurança e adequabilidade do regime farmacoterapêutico (KRIPALANI, 2007a). Deve ser realizada reconciliação sempre que novos medicamentos são prescritos ou são refeitas prescrições já existentes, incluindo mudanças de setor, serviço, médico ou nível de atendimento e compreende as seguintes etapas (BARNSTEINER, 2008; MORIEL et al., 2008): desenvolvimento de uma lista dos medicamentos em uso, como resultado da obtenção da história medicamentosa; desenvolvimento de uma lista de medicamentos a serem prescritos; comparação entre as duas listas; tomada de decisão baseada na comparação; além de comunicação da nova lista ao paciente e ao cuidador, e ao médico que dará continuidade ao atendimento do paciente fora do hospital.

O resultado da reconciliação deve ser claramente documentado, contendo todas as alterações do tratamento, suas justificativas (independente de quão óbvias sejam), e se as alterações são temporárias ou permanentes, a fim de fundamentar as prescrições subsequentes (CUA e KRIPALANI, 2008). 
Uma das etapas críticas da reconciliação medicamentosa é a obtenção da história medicamentosa. Segundo TAM et al. (2005) e FITZGERALD (2009), há várias razões para a obtenção de uma história medicamentosa acurada:

- O conhecimento dos tratamentos que o paciente já utilizou ou está utilizando, com informações sobre resultados vivenciados relacionados à efetividade e segurança, auxiliará no planejamento de tratamentos futuros;

- Ajuda a evitar erros de prescrição, uma vez que uma história inexata na admissão hospitalar pode resultar na ocorrência de eventos indesejáveis resultantes da duplicação de medicamentos, interações medicamentosas, interrupção no tratamento com medicamentos de uso contínuo;

- Permite considerar o medicamento como possível causa de problemas de saúde, inclusive da própria hospitalização, como resultado de reação adversa prévia (os efeitos dos medicamentos deveriam estar sempre na lista de diagnóstico diferencial), ou de outros eventos adversos relacionados a medicamentos, tais como aqueles decorrentes de erros de medicação no domicílio;

- Auxilia no diagnóstico, pois medicamentos podem mascarar sinais clínicos e interferir em exames laboratoriais;

- É uma excelente oportunidade para orientar pacientes sobre seus medicamentos.

Entretanto, o problema de listas de medicamentos inexatas, tanto na admissão hospitalar como na alta, é frequente e tem sido foco de atenção, nos últimos anos, devido à preocupação com a segurança do paciente (HELLSTRÖM et al., 2012). Revisão sistemática da literatura sobre a frequência, tipo e importância clínica de erros de história medicamentosa na admissão hospitalar (TAM et al., 2005) revela que os erros de prescrição 
relacionados a história medicamentosa são comuns e potencialmente danosos para o paciente:

- De todos os erros de prescrição, $27 \%$ foram atribuídos a histórias de medicação incompletas no momento da admissão.

- Entre $10 \%$ e $67 \%$ dos pacientes apresentaram pelo menos um erro de prescrição relacionado à história medicamentosa. Quando medicamentos isentos de prescrição foram incluídos, a frequência de erros subiu para $27 \%$ a $83 \%$; quando informações sobre alergias a medicamentos ou outras reações adversas a medicamentos prévias foram adicionadas, a frequência foi de $34 \%$ a $95 \%$ dos pacientes com pelo menos um erro.

- Entre $10 \%$ e $61 \%$ dos pacientes tiveram pelo menos um erro de omissão, ou seja, medicamentos utilizados anteriormente pelo paciente não foram prescritos, apesar de necessários.

- Entre $11 \%$ e $59 \%$ dos erros de história medicamentosa eram clinicamente importantes.

Estudo realizado cinco anos após a publicação da revisão sistemática revelou que o problema ainda é atual e preocupante. Mais de um terço dos pacientes apresentaram erros de prescrição, sendo que $85 \%$ dos pacientes apresentaram erros originados nas histórias medicamentosas, sendo metade deles erros de omissão (GLEASON et al., 2010).

Após alta hospitalar, a manutenção de erros de prescrição resultantes de falhas na coleta da história medicamentosa pode resultar em eventos adversos e, consequentemente, em sofrimento humano e custos adicionais no atendimento (CORNISH et al., 2005).

Apesar da maioria das alterações de medicamentos implicadas em EAM ocorrer na admissão hospitalar, a maior parte de EAM ocorre após alta (BOOCKVAR et al., 2004). Este fato é compreensível, pois o período de 
hospitalização é menor e melhor monitorado que o período póshospitalização. Assim, o mesmo erro pode ter um potencial pequeno para causar dano ao paciente quando prescrito na admissão, pela possibilidade de ser interceptado e corrigido ou suas consequências monitoradas e controladas, enquanto que pode expor o paciente a riscos desnecessários quando prescrito na alta hospitalar (PIPPINS et al., 2008).

Revisão sistemática sobre reconciliação medicamentosa em hospitais (MUELLER et al., 2012), envolvendo 26 estudos realizados em 10 países, demonstrou consistente redução nas discrepâncias de medicamentos (17 de 17 estudos), nos potenciais eventos adversos relacionados a medicamentos (5 de 6 estudos), e em eventos adversos relacionados a medicamentos ( 2 de 2 estudos). Porém, apenas 2 de 8 estudos demonstraram redução na utilização de serviços de saúde após alta hospitalar. Os autores concluíram que as evidências disponíveis apoiam intervenções que utilizam de forma intensiva a equipe da farmácia (farmacêuticos, residentes ou técnicos de farmácia) e que têm foco em pacientes com alto risco de apresentar eventos adversos.

Nos dois estudos da revisão que demonstraram melhoria na utilização dos serviços de saúde, a equipe do serviço de farmácia foi intensivamente envolvida na obtenção de história medicamentosa abrangente na admissão hospitalar, reconciliação medicamentosa na admissão e na alta hospitalar, orientação ao paciente, comunicação com profissionais responsáveis pelo atendimento ambulatorial subsequente, e comunicação com paciente após a alta hospitalar.

Nos seis estudos que tiveram como foco o uso de tecnologia de informação para a realização de reconciliação houve melhoria no acesso a fontes de informação disponíveis eletronicamente sobre o uso de medicamentos antes da hospitalização, como prontuários ambulatoriais. Nestes estudos, houve redução no número de discrepâncias (3 de 3 estudos), de potenciais eventos adversos relacionados a medicamentos (1 
de 1) e de eventos adversos relacionados a medicamentos (1 de 1), mas não demonstraram melhoria no uso de serviços de saúde.

Entre os estudos da revisão sistemática, os elementos comuns das intervenções que obtiveram sucesso foram: foco em subgrupos de alto risco, realização de intervenção em uma população definida (por exemplo, em unidade de cirurgia eletiva), e evidência de apoio institucional (MUELLER, 2012).

\subsubsection{Orientação ao paciente}

A orientação ao paciente tem por objetivo ajudá-lo a obter os maiores benefícios com o uso de seus medicamentos; auxiliar na resolução de problemas existentes; prevenir a ocorrência de problemas futuros, e desenvolver a capacidade do indivíduo em lidar com problemas relacionados ao uso de medicamentos que possam vir a ocorrer em seu domicílio (RANTUCCI, 2007).

CUA e KRIPALANI (2008) recomendam que, no momento da alta, sejam destacadas as alterações no tratamento que o paciente fazia antes da hospitalização, detectadas no processo de reconciliação medicamentosa na alta hospitalar, para que não haja dúvidas quanto ao tratamento que deverá realizar no domicílio, especialmente se deve ou não continuar a fazer uso de seus medicamentos.

Deve ser fornecida cópia do resultado da reconciliação, com informações claras sobre quais medicamentos foram excluídos, incluídos ou tiveram o esquema posológico alterado, incluindo as justificativas.

Estudo realizado em hospital universitário norteamericano com cerca de 200 pacientes, com média de idade de 60 anos, revelou que $96 \%$ dos pacientes tinham apresentado, na alta hospitalar, pelo menos uma alteração no regime farmacoterapêutico, com relação ao tratamento utilizado antes da hospitalização. Entretanto, apenas $44 \%$ foram alertados explicitamente 
sobre novos medicamentos prescritos ou alterações de doses, e $12 \%$ receberam instruções por escrito para parar de utilizar medicamentos que faziam uso antes da hospitalização e que foram suspensos (UNROE et al., 2010).

A orientação, com base no resultado da reconciliação de alta, visa assegurar que os pacientes não tenham dúvidas se devem ou não continuar o tratamento com os medicamentos que utilizavam antes da hospitalização. A orientação adequada, após reconciliação, possibilita evitar erros de medicação, especialmente por meio da abordagem cuidadosa quanto à identificação dos medicamentos prescritos na alta e dos medicamentos em uso anterior à hospitalização, em função da possibilidade de estoque remanescente no domicílio do paciente. Assim, recomenda-se atenção em duas situações específicas:

- Medicamentos de uso contínuo podem ter sido substituídos durante a hospitalização, em função de adaptação ao formulário terapêutico do hospital (lista de medicamentos padronizados para uso na instituição). $\mathrm{Na}$ alta, deve ser avaliada a possibilidade de retorno ao medicamento que o paciente estava utilizando antes da hospitalização (BOOCKVAR et al., 2004; CUA e KRIPALANI, 2008), e proceder a orientação adequada ao paciente.

- O nome do medicamento na prescrição pode confundir o paciente, podendo levar ao uso em duplicidade ou omissão do medicamento, se receber prescrição de determinado medicamento pelo nome comercial e já estiver utilizando um produto genérico do mesmo medicamento, ou viceversa (CUA e KRIPALANI, 2008). Uma vez que em hospitais públicos a prescrição deve ser realizada pela Denominação Comum Brasileira do fármaco, apesar de os medicamentos de referência e produtos genéricos apresentarem os mesmos fármacos, eles podem parecer completamente diferentes para o paciente, o qual, sem orientação, pode fazer uso inadequado dos medicamentos. Além disso, os produtos disponíveis no comércio podem ter diferenças na apresentação, por exemplo na 
concentração do fármaco, propiciando erros de dose (STUFFKEN e EGBERTS, 2004).

Adicionalmente, recomenda-se que, durante 0 período de hospitalização, sejam realizadas sessões de orientação abordando informações sobre cada medicamento que deverá ser utilizado após alta, incluindo tratamentos prévios com medicamentos de uso contínuo. Sugerese abordar os seguintes tópicos (ASHP, 1997):

i. Nome do medicamento (comercial e genérico), sinônimo, e quando apropriado sua classe terapêutica e eficácia;

ii. Indicação, benefícios esperados e ação. Pode incluir se o medicamento deverá curar a doença, eliminar ou reduzir os sintomas, interromper ou retardar o processo da doença, ou prevenir uma doença ou sintoma;

iii. A expectativa de início de ação e o que fazer se a ação não ocorrer;

iv. A via de administração, a apresentação, a dose e esquema de administração (incluindo a duração do tratamento);

v. Orientações para preparo e uso ou administração (pode incluir adaptação ao estilo de vida ou ambiente de trabalho);

vi. O que fazer se perder uma dose;

vii. Precauções a serem observadas durante 0 uso ou administração do medicamento e riscos potenciais em relação aos benefícios;

viii. Potenciais efeitos adversos (os comuns e os graves) que podem ocorrer, e como prevenir ou minimizar sua ocorrência;

ix. Técnicas de auto-monitorização da farmacoterapia; 
x. Interações potenciais (com medicamentos, alimentos e doenças), contra-indicações;

xi. Interferência com a interpretação de resultados laboratoriais;

xii. Informações para obtenção dos medicamentos prescritos;

xiii. Instruções para acesso 24 horas a um farmacêutico;

xiv. Armazenamento adequado do medicamento;

xv. Descarte adequado;

xvi. Qualquer outra informação específica sobre o tratamento para aquele paciente.

No caso de pacientes pediátricos, os cuidadores devem ser orientados quanto a técnicas de preparo e diluição; informações sobre estabilidade; sistemas de medidas (doses fracionadas, uso de dosadores orais); técnicas de administração segura; além de informações sobre medicamentos com revestimentos que não podem ser fracionados, triturados ou mastigados; como mascarar sabor de medicamentos não palatáveis, e formas de prevenção de ingestão acidental, entre outros (ASHP,1994; RICCI, 2008).

\subsubsection{Seguimento domiciliar do paciente após alta hospitalar}

O hospital pode oferecer seguimento ao paciente por um período de tempo após alta hospitalar, especialmente durante os primeiros dias da transição do atendimento. Telefonar ao paciente poucos dias após a alta oferece a ele a oportunidade de esclarecer dúvidas sobre o regime farmacoterapêutico, relatar novos sintomas que podem estar relacionados ao uso de medicamentos, ou ainda relatar dificuldades na aquisição de medicamentos (KRIPALANI et al., 2007a). 
Outro recurso é a visita domiciliar pós-alta, que possibilita esclarecer dúvidas, observar como os medicamentos estão sendo utilizados e armazenados, descartar medicamentos antigos (CUA e KRIPALANI, 2008), reforçar orientações, monitorar progresso e aparecimento de eventos adversos, realizar ajustes no regime farmacoterapêutico, e encaminhar o paciente a serviços necessários antes que ocorra piora do quadro (NAYLOR et al., 1999).

Para paciente de alto risco, recomenda-se que seja realizada uma visita de seguimento após 48 horas da alta; para paciente de risco moderado, seguimento por telefone dentro de 48 horas e visita domiciliar dentro de 5 dias (BISOGNANO e BOUTWELL, 2009).

O seguimento do paciente no domicílio logo após alta - associado à reconciliação medicamentosa e orientação ao paciente - resulta em muitos benefícios ao paciente, além do sistema de saúde, pois este contato transmite segurança ao paciente e seus familiares de que suas dúvidas e necessidades, durante esse período vulnerável, serão conhecidas e resolvidas pela equipe de saúde (COLEMAN et al., 2006).

Iniciativas como a Estratégia Saúde da Família, o programa "Melhor em Casa" ${ }^{3}$ e serviços de atendimento domiciliar oferecidos por convênios de saúde podem contribuir para evitar a descontinuidade do atendimento ao paciente após alta hospitalar, especialmente quando integrados ao atendimento hospitalar.

\subsubsection{Comunicação entre hospital e demais serviços de saúde}

Para a efetividade e segurança do tratamento do paciente é essencial que o desenvolvimento das estratégias ocorra de forma articulada entre a equipe hospitalar e a equipe da atenção primária à saúde, com realização de

3 Programa recém-lançado pelo governo federal que objetiva ampliar o atendimento domiciliar do Sistema Único de Saúde, levando atendimento multiprofissional a pessoas com necessidade de reabilitação motora, idosos, pacientes crônicos sem agravamento ou em situação pós-cirúrgica (MINISTÉRIO DA SAÚDE, 2011). 
contato para o compartilhamento de informações sobre o paciente, esclarecimento sobre ocorrências durante a hospitalização, e formulação de plano de seguimento do paciente (KRIPALANI et al., 2007a).

O plano estruturado de alta hospitalar é uma estratégia para estreitar a comunicação entre o hospital e o cuidado fornecido em serviços de atenção primária e deve conter as seguintes informações: motivo da admissão hospitalar e intervenções realizadas durante a hospitalização; tratamento proposto (nome, dose, frequência e via de administração, duração planejada de uso e razão de uso de cada medicamento), orientações sobre monitorização (o que fazer, quando fazer e o que esperar dos procedimentos de monitorização), além das justificativas de exclusões, inclusões e substituições de medicamentos e/ou alterações de doses, resultantes da reconciliação; esclarecimentos sobre em quais circunstâncias o paciente deve contatar um profissional, para quem ou onde telefonar para esclarecer dúvidas (MAMON et al.,1992; RATLIFF, 1981; ROMANO, 1982).

Informações do plano de alta relevantes à continuidade do tratamento devem ser encaminhadas ao profissional de saúde que realizará seguimento do paciente, por meio de relatório de alta, resumo de alta, carta de alta ou cartão de alta, em tempo adequado para possibilitar prosseguimento ao tratamento e sua monitorização, conforme planejado.

Vários estudos avaliaram o impacto das estratégias apresentadas sobre o gerenciamento da segurança dos pacientes após alta hospitalar. SCHNIPPER et al. (2006) demonstraram que, por meio de orientação farmacêutica e seguimento por telefone, 3 a 5 dias após alta, foi possível interceptar discrepâncias no uso de medicamentos comparado à prescrição de alta, em $71 \%$ dos pacientes: em $42 \%$ as discrepâncias ocorreram por conta de alterações pelo médico que realizou seguimento ambulatorial, mudança quanto ao uso "se necessário" ou uso de medicamentos sem prescrição médica. Nos 29\% restantes, as discrepâncias não apresentavam justificativa. Trinta dias após alta, o grupo sob intervenção apresentou menor 
número de eventos adversos relacionados a medicamentos que o grupo controle ( $1 \%$ versus $11 \%$ ) e menor número de atendimentos em serviços de urgência (1\% versus $8 \%)$.

Em estudo onde a transição de pacientes idosos foi acompanhada por enfermeira, cujas funções incluíram reconciliação medicamentosa, orientação e capacitação do paciente, visitas domiciliares e contatos telefônicos, os pacientes sob intervenção tiveram menores taxas de readmissão hospitalar quando comparados ao grupo controle, aos 30, 90 e 180 dias após alta (COLEMAN et al., 2006).

Em outro estudo, o responsável pela transição foi um farmacêutico e suas funções foram: realizar reconciliação medicamentosa, fornecer recomendações aos médicos sobre a terapêutica farmacológica, elaborar lista de medicamentos para alta, orientar pacientes, transmitir informações ao médico da atenção primária sobre medicamentos prescritos na alta, incluindo plano de monitorização, e realizar contato telefônico com os pacientes dentro de 3 a 5 dias. A média de intervenções realizadas pelo farmacêutico foi de 9,4 intervenções por paciente, com taxa de aceitação das recomendações pelos médicos de 96\% (BAYLEY et al., 2007).

Excelentes resultados foram obtidos em dois estudos clínicos, realizados com idosos após alta hospitalar, nos quais enfermeiras especializadas em gerontologia realizaram visitas clínicas logo após admissão e durante hospitalização, elaboraram plano de alta especializado, realizaram visitas domiciliares e contato telefônico semanal com o paciente ou seus familiares, e disponibilizaram um número de telefone durante sete dias por semana para esclarecimentos de dúvidas. No estudo realizado por HUANG e LIANG (2005), os resultados do grupo sob intervenção em comparação com o grupo controle foram: média do período de hospitalização $(8,17$ versus 10,06$)$, número de readmissão hospitalar após três meses (4 versus 13), mortes após alta (zero versus 4), melhor habilidade para realização de atividades diárias, e maior pontuação em 
testes de avaliação da qualidade de vida, especialmente quanto à função social, função física, dor corporal, vitalidade, saúde mental, e percepção de saúde em geral.

O outro estudo foi realizado nas mesmas condições, com foco sobre medicamentos utilizados, manejo de sintomas, dieta, atividades, sono, acompanhamento médico, e estado emocional de pacientes e cuidadores. Os pacientes que receberam intervenção durante quatro meses após alta apresentaram, após um ano, menor taxa de readmissão hospitalar $(20 \%$ versus 37\%), menor taxa de readmissões múltiplas (6,2\% versus 14,5\%), menor número de casos de readmissões relacionadas à admissão hospitalar no início do estudo (30 versus 64). Além disso, 35\% dos pacientes do grupo controle foram readmitidos dentro de 48 dias após alta, enquanto $25 \%$ dos pacientes que receberam intervenção foram readmitidos dentro de 133 dias. O custo total no atendimento do grupo controle foi maior que o custo do grupo que recebeu intervenção - cerca de USD\$1.200.000 versus USD\$ 600.000 (NAYLOR et al., 1999).

Considerando, ainda, as diversas atividades preconizadas para proporcionar segurança no processo de uso de medicamentos após hospitalização, vale destacar o estudo de GOUVÊA (2011), realizado no Brasil, sobre o desenvolvimento de indicadores de segurança do paciente para hospitais de pacientes agudos. São propostos vários indicadores, entre os quais alguns relacionados às atividades aqui abordadas, tais como:

- Taxa de reconciliação de medicamentos antes da alta.

- Porcentagem de pacientes que receberam alta em uso de varfarina e receberam informações escritas sobre o gerenciamento da varfarina antes da alta.

- Porcentagem de pacientes cujo resumo medicamentoso de alta foi encaminhado ao médico do paciente, em até 72 horas após alta.

O uso de indicadores permite avaliação de resultados de estratégias implantadas, podendo alertar para potenciais problemas e indicar a 
necessidade de realização de análise mais detalhada dos processos envolvidos.

A Carta dos Direitos dos Usuários da Saúde (BRASIL, 2006) assegura, como direito do cidadão, vários aspectos abordados nas estratégias aqui apresentadas, tais como: direito ao recebimento de informações completas sobre o tratamento; treinamento em autocuidado visando à autonomia; acesso à continuidade da atenção com apoio domiciliar, quando pertinente, ou acompanhamento em outros serviços de saúde.

O conjunto de atividades desenvolvidas pela equipe hospitalar é essencial para o fornecimento de cuidado diferenciado ao paciente em alta hospitalar, contribuindo para a segurança do paciente, especialmente quando ocorre de forma articulada com demais serviços de saúde, evitando a descontinuidade do atendimento.

\subsection{ARTICULAÇÃO ENTRE HOSPITAL, ATENÇÃO BÁSICA E DOMICÍLIO: O GRANDE DESAFIO PARA A SEGURANÇA NO PROCESSO DE USO DE MEDICAMENTOS}

Para alcançar melhores níveis de saúde para a população brasileira devem ser promovidas iniciativas que melhorem a qualidade do cuidado e a segurança dos pacientes (VICTORA et al., 2011). Após avanços conseguidos em termos de acesso ao sistema público de saúde, os esforços se concentram na questão da qualidade dos serviços prestados.

O cumprimento da integralidade, um dos pilares do Sistema Único de Saúde, pode ter grande contribuição para garantir a qualidade da atenção à saúde. A efetivação da integralidade em seus vários aspectos pressupõe a abordagem integral do indivíduo, levando em consideração as dimensões 
biológica, psicológica e social; a articulação de ações de promoção, prevenção, cura e recuperação; além de garantia da atenção nos três níveis de complexidade da assistência médica - atenção básica, secundária e hospitalar (CAMPOS, 2003), visando a assegurar continuidade do cuidado. Uma vez que nenhum dos níveis de atendimento, isoladamente, possui a totalidade dos recursos e competências necessárias para resolver as necessidades de saúde de uma população - existindo, portanto, interdependência - é imperativa a constituição de redes integradas (GIOVANELLA et al., 2009).

Os serviços de atenção básica vêm se configurando como importantes fontes de cuidado regular e porta de entrada preferencial no sistema de saúde e, segundo NORMAN e TESSER (2009), o desenvolvimento de prevenção quaternária - relacionada ao risco de adoecimento iatrogênico, ao excessivo intervencionismo diagnóstico e terapêutico, e à medicalização desnecessária - pode contribuir para a redução da medicalização e da iatrogenia do cuidado. Entretanto, apesar de relatos sobre investimentos em tecnologias de informação e comunicação visando à integração da rede (GIOVANELLA et al., 2009), em geral, observa-se fragmentação e desarticulação do cuidado, as quais contribuem para perda da efetividade e aumento da iatrogenia e dos custos dos serviços de saúde, além de resultar na diluição da responsabilidade sanitária sobre os resultados dos atendimentos realizados (CAMPOS e DOMITTI, 2007).

Um dos elementos essenciais para a integração das redes de saúde, e para as práticas de trabalho da Estratégia Saúde da Família, é a existência de um efetivo sistema de referência e contrarreferência - mecanismo de encaminhamento mútuo de pacientes entre os diferentes níveis de complexidade dos serviços. Porém, em geral, o que se observa é a inexistência ou precariedade da contrarreferência (SERRA e RODRIGUES, 2010; SIMINO et al., 2010; PERRECHI e RIBEIRO, 2009; MARIN et al., 
2010), demonstrando a desarticulação entre os níveis de atenção básica, secundária e hospitalar.

Além disso, a contrarreferência não basta para garantir continuidade do cuidado. É necessário haver responsabilização do profissional e do sistema pela saúde do usuário e, segundo CECILIO e MERHY (2003, p. 6)

O momento de alta de cada paciente deve ser pensado como um momento privilegiado para se produzir a continuidade do tratamento em outros serviços, não apenas de forma burocrática, cumprindo um papel da contra-referência, mas pela construção ativa da linha de cuidado necessária àquele paciente específico.

A linha de cuidado deve ter início na entrada do usuário em qualquer ponto do sistema que opere a assistência - unidade básica de saúde (UBS), Unidade de Saúde da Família (USF), serviço de urgência - prosseguindo por serviços de apoio diagnóstico e terapêutico, especialidades, atenção hospitalar e outros, com acompanhamento da equipe da atenção básica durante todo o percurso, de forma a garantir fluxo seguro a todos os serviços que atendam às necessidades dos usuários, evitando interrupção e segmentação do cuidado, de forma a proporcionar cuidado integral (MALTA e MERHY, 2010; FRANCO e MAGALHÃES JÚNIOR, 2004).

Para MALTA e MERHY (2010, p. 597), "cada serviço pode ser repensado como um componente fundamental da integralidade do cuidado, como uma 'estação' no circuito que cada indivíduo percorre para obter a integralidade de que necessita", e, além de acesso e resolutividade, é necessário conectar esses serviços.

Portanto, o desenvolvimento de atividades de cuidado ao paciente em alta, pela equipe hospitalar, e a existência de efetiva articulação entre os diferentes níveis de complexidade do atendimento em saúde podem representar importantes aliados neste grande desafio para a saúde pública, que é a segurança do paciente no processo de uso de medicamentos após alta hospitalar. 
Com o objetivo de analisar a produção científica brasileira sobre segurança do paciente em alta hospitalar, visando verificar tendências de abordagem temática e identificar estudos com foco na segurança no processo de uso de medicamentos, MARQUES e ROMANO-LIEBER (2012) realizaram revisão da literatura publicada no período entre 2000 e 2012. Foram analisados 45 estudos relacionados ao processo de alta hospitalar, baseados em pesquisa de campo, sendo que a maioria se refere às etapas de diagnóstico da situação e planejamento de estratégias, sendo ainda pouco frequentes os relatos e avaliações de estratégias implantadas. Do total de estudos, apenas três foram direcionados ao processo de uso de medicamentos, sendo que todos detectaram falhas na orientação ao paciente em alta, e um deles detectou, também, dificuldades financeiras afetando a continuidade do tratamento. A escassez de publicações com foco no processo de uso de medicamentos e a ausência de abordagem de estratégias específicas - reconciliação medicamentosa, seguimento do paciente e articulação efetiva entre os serviços de saúde de diferentes níveis de complexidade - podem ser reflexo da incipiente atuação profissional nesta área, e apontam a existência de vasto campo de pesquisa visando à segurança do paciente em alta hospitalar.

Neste contexto - onde a segurança do paciente e a qualidade da assistência à saúde, no uso de medicamentos, têm sido foco de preocupação e estudos em nível mundial, especialmente na transição do atendimento, contrastando com a escassez de informações sobre estratégias desenvolvidas em nosso país - é que se insere o presente estudo. 
Objetivos 


\section{OBJETIVO GERAL}

Compreender a dinâmica e os desafios do cuidado fornecido ao paciente, pela equipe de saúde do hospital, visando à segurança no processo de uso de medicamentos após alta hospitalar.

\section{OBJETIVOS ESPECÍFICOS}

1. Identificar estratégias empregadas por hospitais para a segurança do paciente no processo de uso de medicamentos após alta hospitalar;

2. Verificar articulações entre hospitais e demais serviços de saúde que possibilitem continuidade do cuidado ao paciente;

3. Identificar fatores facilitadores e barreiras para implantação e desenvolvimento de estratégias, assim como para articulação com demais serviços de saúde, analisando alcance e limitações para a segurança de pacientes. 
Procedimento metodológico 


\subsection{SOBRE A PESQUISA}

Em função da natureza do problema de investigação apresentado, optou-se pela realização de uma pesquisa exploratória.

Para GIL (2007), pesquisas exploratórias são realizadas especialmente quando o tema escolhido é pouco explorado, a fim de proporcionar uma visão geral de determinado fato ou fenômeno, e têm como principal finalidade desenvolver, esclarecer, modificar conceitos e ideias, tendo em vista a formulação de problemas mais precisos ou hipóteses pesquisáveis para estudos posteriores.

Foram utilizadas entrevistas como técnica para coleta de dados. Segundo MINAYO (2007), as entrevistas podem resultar em dados objetivos ou concretos, e dados subjetivos - tais como opiniões, ideias, crenças, razões de determinadas atitudes e comportamentos, projeções para o futuro, maneiras de pensar, sentir e atuar.

Atendendo aos requisitos para tramitação do projeto de pesquisa junto ao Comitê de Ética em Pesquisa da instituição hospitalar escolhida para realização deste estudo, foi solicitada autorização para coleta de dados por meio de entrevistas junto ao Departamento de Medicina, Departamento de Enfermagem, Divisão de Farmácia, Serviço Social, Programa de Assistência Domiciliária, e Gerência de Risco. Para tanto, foram encaminhadas cartas à Superintendência e aos respectivos diretores ou coordenadores, acompanhadas de cópia do projeto de pesquisa.

Após autorização, foi realizado contato telefônico com as secretarias das áreas para agendamento de entrevistas com médicos, enfermeiros, farmacêuticos e assistentes sociais envolvidos em atividades relacionadas ao cuidado ao paciente em alta hospitalar, além de representante da Gerência de Risco. Nos casos em que não houve contato pessoal direto ou 
telefônico com o profissional a ser entrevistado, foi realizado contato eletrônico onde a pesquisadora colocou-se à disposição para complementar as informações constantes no projeto de pesquisa encaminhado.

A seleção inicial das unidades de internação e funções dos profissionais a serem entrevistados foi realizada pela pesquisadora, buscando-se obter informações representativas do atendimento realizado nas unidades de internação do hospital, e destacando-se as particularidades, quando necessário. Quando havia mais de um profissional na função e setor selecionados, foi solicitada indicação de participante ao responsável pelo acompanhamento da pesquisa designado pela respectiva área.

Foram incorporados novos participantes conforme necessidade observada durante o desenvolvimento da pesquisa, para esclarecimento do tema, como no caso de solicitação de entrevista junto ao Serviço Social, uma vez que durante a realização das entrevistas foram frequentes as referências sobre a atuação de assistentes sociais em atividades relacionadas à alta hospitalar. Vale destacar que, após o primeiro contato para expor os objetivos da pesquisa, foi realizada uma reunião prévia, por iniciativa do próprio serviço, entre todos os assistentes sociais e a diretora do serviço, para identificação das atividades relacionadas ao cuidado ao paciente em alta hospitalar, com foco no processo de uso de medicamentos, realizadas na instituição, de forma a reunir informações obtidas a partir das experiências vivenciadas pelos assistentes sociais nas várias unidades de internação, e para a definição do profissional que seria entrevistado, representando o serviço.

Também foi solicitada entrevista com uma das enfermeiras representantes do hospital na Rede Brasileira de Enfermagem e Segurança do Paciente (REBRAENSP), citada em algumas das entrevistas realizadas, em função de atuação especificamente relacionada ao tema da pesquisa, nas diversas áreas do hospital. 
Todas as entrevistas foram realizadas no próprio hospital, em data, horário e local definidos pelos entrevistados.

Nas entrevistas, foram exploradas questões previamente definidas pela pesquisadora, abordando atividades desenvolvidas na instituição visando à segurança do paciente no processo de uso de medicamentos após alta hospitalar, ocorrência de articulação com demais serviços de saúde visando à segurança do paciente na continuidade do tratamento, bem como as barreiras e fatores facilitadores vivenciados na implantação e desenvolvimento dessas atividades, e os desafios para alcançar avanços no processo.

Como orientação, foi utilizado roteiro de entrevista (Apêndice 1) submetido a pré-teste com profissionais envolvidos em atividades similares, nas mesmas funções, em outro hospital universitário, permitindo realizar adequações do instrumento antes de sua utilização na pesquisa de campo. Nas entrevistas com profissionais que atuam nas unidades de internação, outras questões foram adicionadas ao roteiro original, durante 0 desenvolvimento da pesquisa, e mesmo durante cada entrevista, seja para esclarecimento de novos questionamentos ou aprofundamento de aspectos já abordados.

Além disso, o roteiro foi adaptado às atividades desenvolvidas pelos representantes da Gerência de Risco, Programa de Assistência Domiciliária e Serviço Social. Dessa forma, na entrevista com o representante da Gerência de Risco não foram abordadas questões específicas relativas ao detalhamento de procedimentos desenvolvidos nas unidades de internação. No caso da entrevista sobre o programa de assistência domiciliária, priorizou-se a descrição do programa e do atendimento realizado, com foco no processo de uso de medicamentos após alta hospitalar. Quanto à entrevista junto ao Serviço Social, teve como principal enfoque as atividades desenvolvidas visando ao acesso, pelos pacientes, a medicamentos prescritos na alta. 
As entrevistas foram realizadas no período entre 23 de Julho de 2012 e 02 de Outubro de 2012, iniciando-se com representantes da Gerência de Risco e do Serviço de Farmácia, pela possibilidade de obtenção de uma visão geral da abordagem da segurança no processo de uso de medicamentos desenvolvido nas diversas unidades do hospital, e para obtenção de informações iniciais sobre semelhanças e particularidades entre as unidades de internação, especificamente relacionadas ao processo pesquisado, apontando caminhos para a continuidade da investigação, os quais foram continuamente reavaliados durante 0 desenvolvimento da pesquisa.

Foram realizadas onze entrevistas, totalizando aproximadamente 12 horas de gravação, transcritas em 258 páginas. Após transcrição, todo o conteúdo foi revisado para garantir a exatidão da transcrição de todos os depoimentos na produção do material a ser analisado. Após várias leituras de cada material, foi realizada leitura horizontal, agrupando-se as respostas às perguntas comuns, buscando verificar semelhanças, complementaridades e particularidades, além de acrescentar informações obtidas a partir de questões específicas ao contexto pesquisado.

A análise dos dados ocorreu em torno de quatro eixos preestabelecidos:

1. Aspectos gerais relacionados à segurança do paciente na instituição

Compreende os subeixos: cultura de segurança e atividades de farmacovigilância.

2. Atividades relacionadas ao cuidado ao paciente em alta hospitalar

Compreende os subeixos: o cuidado ao paciente durante a hospitalização, o cuidado ao paciente após alta hospitalar, e o acesso a medicamentos prescritos na alta hospitalar.

3. Articulação entre o hospital e demais serviços de saúde 
4. Fatores facilitadores e barreiras para implantação e desenvolvimento das estratégias e para articulação entre os serviços

Em atendimento à Resolução 196 do Conselho Nacional de Saúde de 1996, a pesquisa foi aprovada pelo Comitê de Ética em Pesquisa da Faculdade de Saúde Pública da Universidade de São Paulo, sob o parecer de número 65433 (Anexo 1), e pelo Comitê de Ética em Pesquisa do Hospital Universitário da Universidade de São Paulo, sob parecer de número 51394 (Anexo 2). Após leitura, esclarecimento e assinatura do Termo de Consentimento Livre e Esclarecido, foi fornecida uma cópia, devidamente assinada pela pesquisadora e pela orientadora, a cada participante das entrevistas (Apêndice 2).

\subsection{SOBRE OS PARTICIPANTES}

Foram entrevistados quatro médicos, representando as clínicas Pediátrica, Médica e Cirúrgica, além do Programa de Assistência Domiciliária, sendo três indicados pela área; três enfermeiras, entre as quais duas com atuação nas clínicas Pediátrica e Médica , e uma enfermeira com atuação em segurança do paciente junto às diversas unidades de internação do hospital, sendo duas indicadas pela área; três farmacêuticos, representando a Gerência de Risco, o Serviço de Farmácia e a equipe de farmacêuticos clínicos, sendo um deles indicado pela área, por atuar em unidade de internação onde é desenvolvida uma das estratégias preconizadas para a segurança do paciente após alta, além de realizar supervisão direta da equipe de farmacêuticos clínicos que atua nas diversas unidades de internação do hospital; e uma assistente social, indicada pela equipe do Serviço Social.

Dessa forma, foram entrevistados profissionais atuantes nas unidades de Clínica Médica, Clínica Cirúrgica e Clínica Pediátrica, além de 
profissionais que supervisionam atividades desenvolvidas em todas as unidades de internação. Dessa forma, buscou-se obter informações representativas de todos os setores de internação em que ocorre alta do paciente para o domicílio, excluindo-se, portanto, as unidades de terapia intensiva e semi-intensiva.

Para preservar a identidade dos participantes, as falas foram codificadas com as iniciais da categoria profissional de cada um, seguidas por número, segundo a ordem de realização das entrevistas com cada grupo: médicos ( $M 1, M 2, M 3, M 4)$, enfermeiros (E1, E2, E3), farmacêuticos (F1, F2, F3) e assistente social (AS).

\subsection{SOBRE O LOCAL DO ESTUDO}

O Hospital Universitário da Universidade de São Paulo (HU/USP) foi escolhido para a realização desta pesquisa com base no critério de desenvolvimento de atividades reconhecidamente estratégicas para a segurança do paciente após alta hospitalar, com relação ao processo de uso de medicamentos. Além do atendimento a este requisito básico, o HU/USP é considerado serviço de referência na área e constitui-se em importante centro de formação de recursos humanos nas várias áreas de atendimento à saúde. Este conjunto de características justifica a intencionalidade da amostra.

Caracterização do HU/USP

O HU/USP, localizado na região oeste da cidade de São Paulo, é um hospital de média complexidade, com 236 leitos (Tabela 1), e média mensal 
de 1014 internações, 1004 altas, 393 cirurgias e 306 partos. A taxa de ocupação é de $81 \%$ e a média de permanência é de 6 dias $^{4}$.

Tabela 1: Distribuição dos leitos do Hospital Universitário da Universidade de São Paulo. São Paulo, 2012.

\begin{tabular}{|c|c|}
\hline UNIDADES DE INTERNAÇÃO & $\mathbf{N}^{\circ}$ DE LEITOS \\
\hline CLÍNICA MÉDICA & 44 \\
\hline CLÍ́NICA CIRÚRGICA & $44^{\mathrm{a}}$ \\
\hline CLÍNICA PEDIÁTRICA & 36 \\
\hline GINECOLOGIA/OBSTETRÍCIA & $52^{\mathrm{b}}$ \\
\hline BERÇÁRIO (NEONATOLOGIA) & 24 \\
\hline UTI NEONATAL & 06 \\
\hline UTI PEDIÁTRICA & 10 \\
\hline UTI ADULTO & 12 \\
\hline SEMI INTENSIVO ADULTO & 08 \\
\hline TOTAL & 236 \\
\hline
\end{tabular}

a Sendo oito leitos para Clínica Ortopédica

${ }^{\mathrm{b}}$ Sendo cinco leitos para Ginecologia

Além da equipe de médicos e de enfermeiros, cada unidade de internação conta com a atuação de farmacêuticos clínicos e assistentes sociais, entre outros profissionais. Do total de 15 farmacêuticos do quadro de recursos humanos do Serviço de Farmácia, sete atuam nas unidades de internação, sendo cinco no período da manhã, responsáveis pela Clínica Médica, Clínica Cirúrgica, Clínica Pediátrica, UTI adulto, e pela UTI Neonatal, Berçário e Ginecologia/ Obstetrícia. Dois farmacêuticos clínicos atuam no período da tarde, sendo um responsável pelas unidades de internação de pacientes adultos e o outro, de pacientes pediátricos ${ }^{5}$. Dos 10 assistentes sociais do hospital, quatro atuam nas unidades de internação, diariamente, acumulando responsabilidade de mais de uma unidade ${ }^{6}$.

O HU/USP mantém Residência Médica, Residência de Farmácia, Residência de Bucomaxilofacial, além de Residência Multiprofissional,

\footnotetext{
${ }^{4}$ Fonte: Seção de Arquivo, Estatística e Laudos do HU/USP, com base nos dados do $1^{\circ}$ semestre de 2012. Em 04 de Outubro de 2012.

${ }^{5}$ Fonte: Serviço de Farmácia do HU/USP, em 23 de Julho de 2012.

${ }^{6}$ Fonte: Serviço Social do HU/USP, em 02 de Outubro de 2012.
} 
vinculada ao Departamento de Fonoaudilogia, Fisioterapia e Terapia Ocupacional (FOFITO) e à Faculdade de Ciências Farmacêuticas. O hospital é, também, campo de estágio para os cursos de graduação da Faculdade de Medicina, Escola de Enfermagem, Faculdade de Ciências Farmacêuticas, Faculdade de Saúde Pública, Instituto de Psicologia, FOFITO, além da Escola de Artes, Ciências e Humanidades $(\mathrm{EACH})$, que mantém os cursos de Ciências da Atividade Física, Licenciatura em Ciências da Natureza, Gerontologia, Gestão Ambiental, Gestão de Políticas Públicas, Lazer e Turismo, Marketing, Obstetrícia, e Sistemas de Informação ${ }^{7}$.

\section{Projeto Região Oeste ${ }^{8}$}

O Hospital Universitário da Universidade de São Paulo, o Hospital das Clínicas da Faculdade de Medicina da USP e o Centro de Saúde-Escola Butantã são parceiros do Projeto Região Oeste (PRO) - contrato de gestão entre a Secretaria Municipal de Saúde e a Organização Social Fundação Faculdade de Medicina, firmado em 2008. O PRO, além de contribuir para o aprimoramento do Sistema Único de Saúde na cidade de São Paulo, devido à integração entre atenção básica e a atenção secundária e terciária, permite uma maior articulação entre ensino, pesquisa e assistência, por meio do desenvolvimento de atividades de graduação e pós-graduação dos cursos da área de saúde da USP.

O contrato de gestão prevê a reorganização e o gerenciamento dos equipamentos públicos municipais da microrregião Butantã/Jaguaré, que é composta por seis Distritos Administrativos (Butantã, Morumbi, Raposo Tavares, Rio Pequeno, Vila Sônia e Jaguaré), e tem uma população total de

\footnotetext{
${ }^{7}$ Fonte: Comissão de Ensino e Pesquisa do HU/USP, em 29 de Outubro de 2012.

${ }^{8}$ Fontes: http://pro.fm.usp.br/organizacao/
}

http://www.pro.fm.usp.br/arquivos/informativo-setembro-outubro-2011.pdf http://extranet.ffm.br/atuacaodaffm/projetos/ContratoGestaoButanta.ashx 
cerca de 420 mil habitantes, dos quais 90 mil cadastrados na Estratégia Saúde da Família. Em outubro de 2011, o PRO encontrava-se em sua quarta etapa de expansão, e contava com os seguintes serviços: 7 Unidades Básicas de Saúde (UBS), 4 Unidades de Atendimento Médico Ambulatorial (AMA), 31 Equipes de Saúde da Família (ESF), 2 Núcleos de Apoio à Saúde da Família (NASF), 1 Ambulatório de Especialidades (AE) e 2 Pronto Socorros Municipais (PSM).

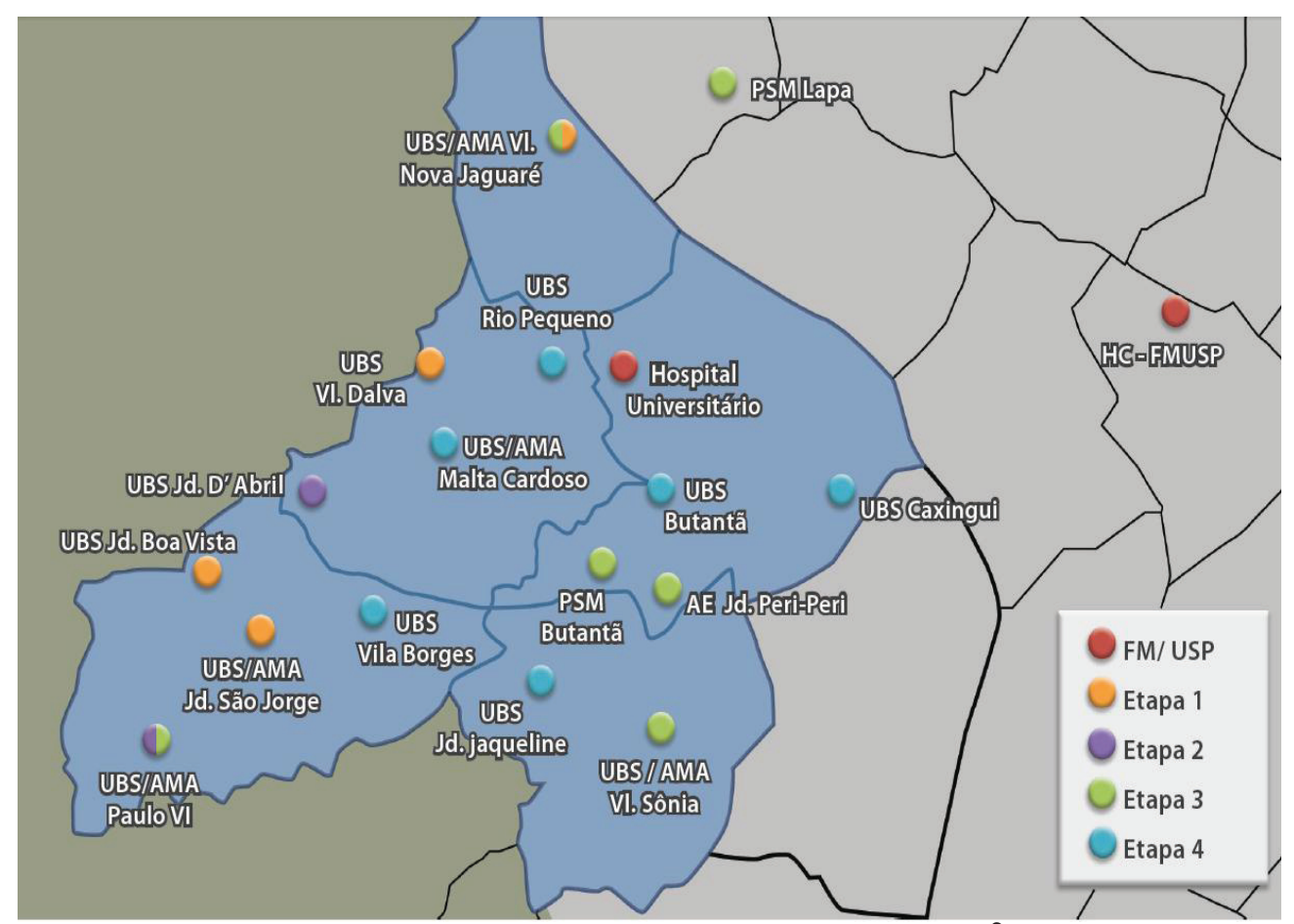

Fonte: Informativo Projeto Região Oeste, Set/Out $2011^{9}$.

O Projeto Região Oeste deve implantar uma plataforma de prontuários eletrônicos para permitir atuação on line de referência e contrarreferência, para integração dos três níveis de atenção à saúde. Atualmente, está em fase de implantação, na atenção básica, um sistema de informação georreferenciado (GeoHealth), desenvolvido para smartphones, por meio dos quais formulários digitais preenchidos pelos agentes comunitários de saúde são cadastrados no Sistema de Informação da Atenção Básica (SIAB) e os dados são transmitidos diretamente a um banco

\footnotetext{
${ }^{9}$ Disponível em http://www.pro.fm.usp.br/arquivos/informativo-setembro-outubro-2011.pdf
} 
de dados central. Após o término da implantação em todas as unidades de saúde com Programa de Saúde da Família, geridas pelo PRO, os dados obtidos serão disponibilizados para os demais sistemas de informação. 
Resultados e discussão 


\subsection{ASPECTOS GERAIS RELACIONADOS À SEGURANÇA DO PACIENTE NA INSTITUIÇÃO}

\subsubsection{CULTURA DE SEGURANÇA}

A segurança do paciente é uma das seis dimensões definidas pelo Instituto de Medicina norte-americano (IOM) para a qualidade em sistemas de saúde, além da efetividade, eficiência, oportunidade, equidade, e objetivos centrados no paciente (WACHTER, 2010). A busca pela segurança do paciente e, consequentemente, qualidade da assistência prestada, é prática compatível com a atuação esperada de um hospital de ensino que, geralmente, procura se manter na vanguarda dos acontecimentos.

Os hospitais universitários são unidades de saúde que prestam serviços à população e são importantes centros de formação de recursos humanos nas várias áreas de atendimento à saúde. Espera-se que os hospitais universitários sejam modelos de serviço, traduzindo o conhecimento científico em práticas capazes de incidir sobre a saúde da população (MACHADO e KUCHENBECKER, 2007), além de local onde a equipe hospitalar, docentes e profissionais em formação desenvolvam atividades que contribuam com a qualidade da assistência ao paciente.

No HU/USP, parece haver esse entendimento sobre o papel dos hospitais universitários acerca da cultura de segurança, uma vez que o vínculo com instituição de ensino foi apontado como contribuidor ao desenvolvimento de atividades relacionadas à segurança do paciente.

Por ser um hospital escola da universidade, onde você tem um grupo de profissionais qualificado, você vê que isso (a segurança do paciente) já vem sendo o objetivo do hospital há muito tempo (F1). 
(...) como uma cultura de segurança, isso tem crescido muito nos últimos tempos. (...) em tudo que é evento, congresso, isso tem sido mais bem divulgado. (...) como é um hospital escola, sempre que tem alguma mudança... por exemplo, a cultura de segurança, a OMS traz como uma das suas diretrizes, é um eixo. Então, sempre que tem alguma coisa maior, alguma coisa acadêmica envolvida, isso é trazido para cá, discutido, e inclusive há mudanças em processos (E3).

No entanto, quanto ao questionamento sobre a contribuição de docentes às atividades realizadas na instituição, por meio de projetos acadêmicos relacionados à segurança do paciente, foram citados três projetos desenvolvidos, no HU/USP, vinculados à enfermagem (análise de indicadores, uso de medicamentos injetáveis, e segurança do paciente em terapia intensiva), além de um projeto sob coordenação médica (duração de tratamento com antimicrobianos). Há, portanto, ainda, vasto campo de atuação e pesquisa nesta área, na instituição.

Para PROVONOST et al. (2005), além de melhoria nos sistemas que inclui as tecnologias, práticas, procedimentos e políticas - a cultura de segurança é reconhecida como importante estratégia para melhoria da segurança do paciente. Isso porque os profissionais são guiados por um comprometimento com a segurança do paciente que permeia todos os níveis de uma organização, em um ambiente no qual o trabalho em equipe, a comunicação clara e a abertura para discussão e análise sobre a ocorrência de erros são operacionalizados (PRONOVOST et al., 2005; PRONOVOST e SEXTON, 2005; WACHTER, 2010).

O modelo de trabalho em equipe já é uma realidade consolidada no HU/USP, conforme avaliação dos entrevistados:

Em relação ao trabalho em equipe, eu não vejo mais essa instituição trabalhando de outra forma. Isso a gente já conquistou há muito tempo (F1).

Nunca foi uma barreira conversar com outro profissional aqui dentro do $\mathrm{HU}$. A gente sempre teve muita facilidade de questionar conduta e de trocar ideia para tentar melhorar. (....) 
não existe uma hierarquia em equipe. Equipe é equipe, cada um tem a sua competência dentro da equipe e ela é respeitada. Então acho que isso, aqui, é melhor trabalhado que em outras instituições que eu conheço (E3).

O trabalho em equipe aqui é excelente, (...) os alunos acham, sempre falam isso. (...) todos têm lugar no mundo, e o seu lugar não é o maior, então fica mais fácil (M2).

Acho que no Hospital Universitário isso até que está bem desenvolvido porque a gente tem essas visitas (...) que participam a enfermeira, o nutricionista, o farmacêutico, então está todo mundo junto lá, exatamente com a ideia de discutir essas coisas. E, a rigor, tudo gira em torno da segurança do paciente que é o fim, o propósito final de todo mundo (M1).

Esse trabalho multidisciplinar é um exemplo, o hospital inteiro considera isso um exemplo, (...) vem gente de fora para ver como é que funciona. É um serviço muito forte, e de muitos anos. Isso não começou ontem, começou há quase trinta anos, quando começou o hospital (M3).

Estudo brasileiro que avaliou a percepção dos profissionais de enfermagem sobre o clima de segurança em um hospital de ensino revelou que a maioria dos entrevistados considera que existe apoio de outros membros da equipe para cuidar dos pacientes, e que médicos e enfermeiros trabalham como equipe bem coordenada (RIGOBELLO et al., 2012).

No HU/USP, observa-se que a substituição de medidas punitivas por revisão de processos, em casos de erros assistenciais, iniciou-se já há algum tempo.

Antes de toda essa onda de segurança, por exemplo, na enfermagem (...) mais ou menos há uns quinze anos, existia muito a tendência da punição: errou, você que fez, você que administrou, você vai ser advertido. Então era muito focado na pessoa, o erro era da pessoa, individual, não era o processo (...). Há quase dez anos, começou a mudar essa cultura, o erro não é individual, vamos verificar o que aconteceu antes. Então, pararam as punições, (...) alguns é claro, inevitável, quando era negligência ou alguma coisa, eram punidos. Então acho que o hospital já estava propício para essa cultura, para essa mudança, não teve uma quebra tão grande de paradigma, de 
repente, 'agora nos últimos dois anos é que eu parei de punir', não, isso é algo que já vem lá de trás (E3).

Nós chamamos o assistente, ou quem fez a prescrição, e chamamos atenção para o erro. Essa é a medida, não existe nenhuma coisa punitiva. (...). É só uma questão de ir lá, ensinar e conversar para que aquilo não se repita (M2).

A gente vai analisar para ver se foi um erro de processo (...) a gente traça qual foi o processo, quais os caminhos e quais foram as pessoas envolvidas. $E$ a gente vai tomar a medida de acordo com isso. (...) a gente sempre analisa o todo e não só a ponta, porque nem sempre a ponta é o verdadeiro responsável por todo o processo de erro (E3).

Quando a gente detecta um problema no processo, a gente altera o processo. Na maioria das vezes, altera com o aval dos funcionários e pede ajuda (...) para olhar aquele processo e refazer. A gente não pune funcionário, a não ser que ele tenha feito o procedimento pulando etapas do processo, aí é diferente. Para ele, saber que o paciente tomou o medicamento errado, é uma grande punição. A gente vê até que o funcionário fica aqui, ele permanece aqui até saber se 0 paciente melhorou ou não (F1).

A busca por uma transformação na cultura organizacional de segurança, substituindo o enfoque individual pela abordagem sistêmica do problema, é uma das mais importantes recomendações dos especialistas em segurança (CASSIANI, 2010a).

Embora erros não sejam as únicas causas de ocorrência de problemas na assistência à saúde que podem repercutir sobre a segurança do paciente, a mudança de abordagem sobre os erros tem sido enfatizada, pois os eventos adversos decorrentes são passíveis de prevenção. E, segundo SAMMER (2010), em uma cultura de segurança amadurecida, além da aprendizagem a partir dos erros, estimula-se a pró-atividade na identificação e melhoria de processos potencialmente inseguros, para evitar erros.

A partir do relato dos participantes deste estudo, verifica-se que no HU/USP ocorre mescla do enfoque sistêmico com a responsabilidade 
individual e institucional apropriadas, conforme recomendado por WACHTER (2010), no sentido de que a instituição, ao mesmo tempo em que analisa possíveis causas dos erros e busca soluções para os problemas encontrados, não é condescendente com indivíduos que adotam conscientemente comportamentos imprudentes, são descuidados, erram com frequência, ou não seguem rotinas mínimas de segurança.

No estudo realizado por RIGOBELLO (2012), para a maioria dos entrevistados, os profissionais 'problemáticos' não são tratados de modo construtivo. Segundo os autores, predomina a percepção de que falhas na segurança do paciente resultam apenas em ações punitivas.

No HU/USP, a abertura para discutir erros assistenciais parece representar um dos importantes desafios, especialmente entre setores ou equipes.

É claro que, como tem muitas pessoas, isso não é homogêneo, mas eu acho que grande parte tem um entendimento bom interdisciplinar. Grande parte, não todo mundo. Mas do ponto de vista institucional, acho que como mentalidade da instituição, sim, aí existe esta preocupação de discutir os erros e tudo (M1).

Abertura, sim, para você relatar que houve evento, claro que com dificuldades (...) isso aqui não é um mar de rosas, mas é possível, há abertura para isso, existem comissões para discutir isso, a gente discute essas coisas, tanto internamente, (...) com a minha equipe, o que aconteceu, o que nós podemos rever neste caso que a gente fez e que nós podíamos fazer diferente. E existem questões também que envolvem as outras áreas, que a gente comenta também, não vou dizer que seja fácil, mas existe sim (...) a gente muda procedimento (...) em função do que aconteceu (M3).

Dentro dos grupos, com certeza. Mas, entre os grupos... eu não vejo isso como uma grande discussão, não, cada um resolve isso dentro do seu espaço (F2).

A comunicação é boa, um pede e aceita, agora, não é uniforme, por parte de todos, a facilidade em aceitar crítica, 
entendeu? Talvez esse ponto pudesse ser melhor desenvolvido, ninguém gosta muito de ser criticado (M2).

Dificuldades semelhantes foram encontradas no estudo de RIGOBELLO et al. (2012), onde $62 \%$ dos profissionais de enfermagem afirmaram ser difícil falar abertamente quando percebem algum problema com o cuidado do paciente.

Vale ressaltar a importância da abertura para discussão de erros entre setores e grupos, em se tratando de processo de uso de medicamentos (prescrição, dispensação e administração de medicamentos, e monitorização dos resultados de seu uso), pois o erro em uma etapa impacta na etapa seguinte, e envolve diferentes categorias profissionais (médicos, farmacêuticos e enfermeiros). E o objetivo da discussão, na cultura de aprendizagem com os erros, é prevenir a ocorrência de eventos semelhantes e evitar danos ao paciente.

\subsubsection{ATIVIDADES DE FARMACOVIGILÂNCIA}

O HU/USP faz parte da Rede de Hospitais Sentinela, da Agência Nacional de Vigilância Sanitária (ANVISA). A rede foi criada com o objetivo de proporcionar à ANVISA informação qualificada sobre desempenho dos produtos de saúde utilizados no Brasil, entre eles medicamentos, por meio da notificação de eventos adversos e queixas técnicas sobre desvios de qualidade. Dessa forma, hospitais contribuiriam com ações de vigilância sanitária para garantir melhores produtos no mercado, além de mais segurança para pacientes. Nos hospitais da rede, o foco ampliou-se para o gerenciamento de riscos de processos e implementação de estratégias para criação da cultura de segurança (CASSIANI, 2010b).

Pesquisa realizada em 2002 constatou que, entre os 43 hospitais universitários brasileiros vinculados a instituições federais de ensino, apenas 
três hospitais desenvolviam programas de farmacovigilância, e 16 citaram a existência de projetos em fase de elaboração, em função da participação no Projeto Hospitais Sentinela (PHS) da ANVISA (MARQUES, 2002). À época recém-implantado, o PHS acenava com apoio técnico-científico e subsídios ao desenvolvimento de projetos hospitalares na área de farmacovigilância, entre outras, além de contribuir com a implantação de Gerência de Risco, nos hospitais, por ser esta uma das exigências para participação na Rede Sentinela.

Observa-se que a expectativa de mudança no cenário brasileiro da farmacovigilância hospitalar foi concretizada, tanto por influência do PHS como de legislações nesta área. Segundo CASSIANI (2010b), a maioria dos serviços de farmacovigilância era encontrada em hospitais da Rede Sentinela da ANVISA e em hospitais que participavam de algum programa de certificação de qualidade. A partir de 2007, o desenvolvimento de atividades de farmacovigilância tornou-se pré-requisito para a certificação de hospitais de ensino, no Brasil (BRASIL, 2007). Atualmente, todos os estabelecimentos de saúde devem realizar monitorização e gerenciamento de risco das tecnologias em saúde, entre elas, os medicamentos (BRASIL, 2010).

Em função da importância da detecção, análise, registro e comunicação de eventos adversos relacionados a medicamentos que ocorram durante a hospitalização e após a alta hospitalar, para a segurança do paciente e para o desenvolvimento da cultura de segurança, alguns aspectos gerais relacionados ao manejo de reações adversas a medicamentos e erros de medicação, no HU/USP, foram abordados nas entrevistas, e os procedimentos descritos por vários profissionais são, então, apresentados:

- Atualmente, quando são identificadas suspeitas de reações adversas a medicamentos, as equipes das unidades de internação tomam as providências necessárias quanto ao atendimento ao paciente, e 
comunicam, verbalmente, a ocorrência à farmacêutica responsável pela farmacovigilância, que realiza a coleta de dados, registra os casos e faz notificação à ANVISA. A farmacêutica não é exclusiva para a atividade de farmacovilância, uma vez que também realiza atendimento às unidades de internação. Recentemente, esta atividade passou a contar com a participação de estagiários do curso de Farmácia.

- Quanto à busca ativa de reações adversas a medicamentos, durante a hospitalização, esta atividade é facilitada pela utilização de rastreadores em atividades desenvolvidas diariamente pelos farmacêuticos clínicos, como análise de resultados alterados de exames laboratoriais obtidos on line e alterações no tratamento verificadas por meio da triagem da prescrição, além do contato direto com o paciente nas unidades de internação. Um projeto de pesquisa para detecção de eventos adversos relacionados a medicamentos por meio de rastreadores está em fase de aprovação.

- Quando são detectados erros de administração de medicamentos nas unidades de internação, primeiramente são tomadas as providências junto ao paciente, quando necessárias. O profissional envolvido é comunicado e a ocorrência é registrada em formulário, disponível nos setores, que contém várias opções de não-conformidades, como administração de medicamento errado, dose errada, via de administração errada, medicamento não prescrito, entre outras, além de espaço para descrição da ocorrência e das medidas tomadas.

- Quando a ocorrência envolve a equipe de enfermagem, o formulário é encaminhado para a Educação Continuada da enfermagem, mensalmente, onde são calculados indicadores de não-conformidades, por unidade de internação. Caso a ocorrência envolva problema de dispensação de medicamentos, esse registro de ocorrência é encaminhado para o Serviço de Farmácia, que registra, também, as ocorrências de erros de dispensação detectados pelos próprios 
funcionários. Os indicadores são analisados por enfermeiros e farmacêuticos, nos respectivos setores, podendo desencadear reavaliação e mudança de processos, ou indicar necessidade de treinamento de pessoal, ou outra medida para evitar recorrência do erro.

- Os indicadores de erros de medicação também são analisados e discutidos por um grupo interdisciplinar, como atividade de projeto de pesquisa desenvolvido na instituição, e conta com representantes de todas as unidades do hospital, resultando em propostas de melhorias nos processos.

- Com relação aos erros de prescrição detectados antes da administração do medicamento ao paciente (denominados 'near misses', quase erros ou erros potenciais), quando interceptados durante triagem de prescrição realizada pelos farmacêuticos clínicos, são registrados e calculados como um dos indicadores de intervenções farmacêuticas. Quanto aos erros de prescrição interceptados pela enfermagem, passaram a ser registrados à época da realização desta pesquisa. Estes indicadores de erros potenciais passarão a ser apresentados à equipe médica das unidades de internação.

- Dependendo da gravidade, os registros de ocorrência de erros de medicação podem ser encaminhados à Comissão de Avaliação de Óbitos e Intercorrências, de composição multidisciplinar, que pode recomendar modificação da rotina envolvida. Caso tenham sido feridos princípios éticos, são encaminhados à Comissão de Ética.

- O formulário para registro de ocorrências será disponibilizado no sistema, para notificação on line de suspeitas de reações adversas a medicamentos e erros de medicação.

- Após alta hospitalar, não há canais para contato direto do paciente com a Farmacovigilância do hospital, para comunicação de possíveis 
eventos adversos relacionados a medicamentos, sejam eles suspeitas de reações adversas a medicamentos ou resultado de erros de medicação.

- Eventualmente, pacientes procuram o Serviço Social, com queixas de alergia a medicamento ou com suspeita de que o tratamento "não está fazendo bem", inclusive comunicando interrupção do tratamento. Nestes casos, o paciente é orientado a comparecer no ambulatório da instituição, no dia de atendimento do médico que realizou o atendimento durante a hospitalização, ou é encaminhado à unidade de internação em que esteve hospitalizado.

- O registro e acompanhamento dos eventos adversos relacionados a medicamento que ocorrem após alta, pela Farmacovigilância do hospital, dependem da detecção do evento durante atendimento realizado no ambulatório ou no Pronto Socorro, e do encaminhamento do caso à Farmácia.

Com base nos procedimentos operacionais descritos, verifica-se que no HU/USP o manejo de reações adversas a medicamentos, em geral, envolve medidas clínicas (suporte ao paciente), além das medidas administrativas (registro e notificação) centralizadas em um único profissional, não exclusivo para a atividade. Alguns hospitais brasileiros contam com equipe multidisciplinar de farmacovigilância para estruturação do serviço e desenvolvimento de rotinas direcionadas à detecção e avaliação dos casos de suspeitas de RAM, desenvolvimento de medidas corretivas e preventivas, divulgação de informações relacionadas ao tema, além de realização de discussão de casos, palestras e cursos para sensibilização e capacitação da equipe de saúde. Também existem projetos de ensino direcionados à farmacovigilância, em desenvolvimento em hospitais, onde as atividades contam com a participação de docentes e de acadêmicos estagiários dos cursos de farmácia, medicina e enfermagem. 
Com relação à análise de erros assistenciais, ressalte-se a ocorrência de retorno dos indicadores aos setores do HU/USP. Embora seja mecanismo essencial para análise e busca por melhorias, por parte dos envolvidos, nem sempre os dados retornam aos setores e sua análise pode ficar restrita à alta administração, conforme observado por ROTTA (2004).

A iniciativa de elaboração de formulário para notificação on line de suspeitas de reações adversas a medicamentos e erros de medicação, a ser disponibilizado no sistema, representa um importante passo para estimular o envolvimento da equipe do HU/USP no processo de notificação.

Uma das barreiras ao processo de notificação é a existência de sistemas de notificação trabalhosos e lentos e de formulários complexos e nem sempre disponíveis prontamente. Estudo comparativo entre sistema manuscrito e sistema informatizado para notificação de incidentes demonstrou aumento de $62,3 \%$ na taxa de notificações após implantação de sistema informatizado que possibilita preenchimento e envio on line do formulário. Segundo a autora, além do acesso facilitado aos formulários, o estímulo à notificação pode ter sido decorrente do fato de que o envio do relato é realizado sem intermediários, gerando maior confiabilidade no processo, especialmente quanto à garantia do sigilo sobre a identificação do notificador (CAPUCHO, 2012).

A segurança dos usuários de medicamentos é o principal objetivo da farmacovigilância, a qual, por meio da prevenção e monitoramento de eventos adversos relacionados ao uso de medicamentos, possibilita redução de sofrimento para o paciente e de custos para a instituição. A participação nestas atividades aumenta o grau de conscientização dos profissionais e estudantes sobre a ampla gama de riscos relacionados à farmacoterapia aos quais os pacientes estão expostos, possibilitando exercer um nível mais alto de atenção sanitária. Além disso, o desenvolvimento de atividades de farmacovigilância aumenta o senso crítico dos profissionais para a identificação de falhas nos processos internos e execução de ações 
preventivas e corretivas, e amplia a cultura pela qualidade e segurança dos pacientes (CAPUCHO, 2011).

A participação multiprofissional integrada em atividades de gerenciamento de risco desenvolvidas na instituição é uma importante estratégia para a segurança do paciente no processo de uso de medicamentos. A constituição, recentemente, de grupo de trabalho interdisciplinar na Gerência de Risco do HU/USP foi destacada, em várias entrevistas, como um marco importante para o desenvolvimento de estratégias relacionadas à segurança do paciente na instituição. Este grupo está realizando revisão de todas as etapas do processo de uso de medicamentos - de forma interdisciplinar, promovendo a integração de avaliações que eram, anteriormente, realizadas de forma setorizada e geralmente isolada - visando à identificação dos pontos críticos que devem ser trabalhados para melhorar a segurança do paciente.

Acho que, com esse grupo, que é interdisciplinar, a tendência é que a gente consiga mexer no processo inteiro, e não só em algumas partes (E3).

Alguns dos desafios que despontaram da revisão de processos realizada pela Gerência de Risco incluem aspectos que apresentam impacto no cuidado ao paciente em alta hospitalar, como necessidade de implantação e/ou ampliação de atividades específicas.

A gente ainda faz muito pouco, eu acho, em relação ao cuidado ao paciente em alta hospitalar, (...) e recursos humanos é o nosso grande problema para não avançar (F1).

(...) é o ponto, senão mais frágil, um dos mais frágeis, a alta. Então precisa ser revista por todos os profissionais, porque tem falha em todo o processo de alta, com relação às medicações. Reconhecer que existe falha, e tentar melhorar este processo, já é algo que está em curso aqui no hospital (E3).

Outros estudos realizados em hospitais brasileiros também apontam falhas, como falta de planejamento e de sistematização do processo de alta e falta de atuação interdisciplinar no preparo do paciente para o retorno ao 
domicílio (CARDOZO-GONZALES et al., 2001; PEREIRA et al., 2007; POMPEO et al., 2007; BARRETO et al., 2008), bem como falha na orientação sobre uso de medicamentos após alta hospitalar (MIASSO e CASSIANI, 2005; SILVA e RUIZ, 2006; BARBOSA et al., 2007). 


\subsection{ATIVIDADES RELACIONADAS AO CUIDADO AO PACIENTE EM ALTA HOSPITALAR}

\subsubsection{O CUIDADO AO PACIENTE DURANTE A HOSPITALIZAÇÃO}

\subsubsection{Conhecendo o uso prévio de medicamentos}

$\mathrm{Na}$ admissão hospitalar, os pacientes são abordados com questionamentos visando à obtenção de uma ampla gama de informações que subsidiem o diagnóstico e o planejamento de seu cuidado. Entre as informações, o uso de medicamentos é abordado, nestas entrevistas, para que possam ser providenciadas a prescrição e administração dos medicamentos.

No HU/USP, na admissão do paciente, a entrevista para a coleta da história medicamentosa é feita por duas fontes independentes: pela enfermagem e pelo interno de medicina ou médico residente, sob a supervisão do médico assistente. Eventualmente, a coleta da história medicamentosa junto ao paciente ou cuidador é, também, realizada pelo farmacêutico, a partir da verificação de necessidade de complementação de dados, em casos específicos.

À época da pesquisa, farmacêuticos residentes estavam iniciando a coleta sistemática de história medicamentosa em entrevistas, na admissão de pacientes na clínica cirúrgica e clínica médica, devido à implantação de reconciliação medicamentosa nestes setores.

No HU/USP, as histórias medicamentosas coletadas pela equipe médica, pela enfermagem e por farmacêuticos são independentes e registradas em locais diferentes no prontuário do paciente. Assim como na maioria dos hospitais, as entrevistas ocorrem de forma paralela e, 
geralmente, sem integração, levando o paciente a repetir as mesmas informações para vários profissionais e, às vezes, também para estagiários. Essa situação pode gerar incômodo e frustração ao paciente (GEBHART, 2005), como também foi apontado na pesquisa:

A gente já está pensando num instrumento onde possa armazenar no mesmo instrumento, talvez, todas as informações, para não ficar várias pessoas perguntando a mesma coisa, na hora da internação (...) porque chega no terceiro ela já não quer falar mais (E2).

Essa situação também pode resultar em diferenças entre as informações obtidas pelas diferentes fontes. Segundo ETCHELLS (2010), a história medicamentosa "perfeita" é uma meta ilusória, sendo preferível empenhar-se na obtenção da melhor história possível. Além disso, sugere que a equipe de saúde contribua para, e trabalhe a partir de, uma única lista de medicamentos acurada, eliminando as dúvidas geradas por diferenças entre as listas obtidas por diferentes profissionais da equipe. No entanto, para o autor "integrar as atividades clínicas em torno de uma lista é o principal desafio para os programas de reconciliação medicamentosa" ( $p$. 370).

A obtenção de histórias medicamentosas acuradas é um importante elemento do uso seguro de medicamentos, uma vez que as informações são posteriormente utilizadas para elaboração de prescrições durante a hospitalização e na alta hospitalar. Portanto, se esta etapa do processo de admissão do paciente apresentar falhas, poderá haver reflexos negativos no cuidado ao paciente.

Embora geralmente subutilizados nesta etapa essencial para a continuidade da farmacoterapia (GEBHART, 2005; MEYER, 2011), deve-se considerar que os farmacêuticos são especialmente adequados para obter histórias medicamentosas e reconciliar discrepâncias devido à sua formação, experiência, conhecimento sobre medicamentos, e habilidades 
para orientar pacientes (GLEASON et al., 2004; CUA e KRIPALANI, 2008; WINTER et al., 2010 ).

Segundo REEDER e MUTNICK (2008), histórias medicamentosas obtidas pelos farmacêuticos são mais minuciosas e resultam em menor número de discrepâncias que as histórias obtidas pelos médicos. Para os autores, podem ser perdidas informações específicas e pertinentes sobre medicamentos, doses, posologias e alergias, quando o farmacêutico não é envolvido no processo.

Para CUA e KRIPALANI (2008), a responsabilidade profissional pela obtenção de histórias medicamentosas nos hospitais deve ser bem definida, dependendo dos recursos de cada instituição.

No HU/USP, a entrevista de admissão segue roteiros padronizados por cada uma das categorias profissionais envolvidas, e a anamnese farmacológica inicia-se pela verificação do nome e posologia dos medicamentos que estavam sendo utilizados pelo paciente até o momento da hospitalização. Eventualmente, no caso de informações incompletas ou confusas, solicita-se que familiares tragam ao hospital a última receita ou os medicamentos que o paciente estava fazendo uso até o momento da hospitalização, para complementar e/ou esclarecer as informações da entrevista inicial.

Além da identificação dos medicamentos em uso pelo paciente, foram apontadas outras informações que podem ser coletadas na entrevista de admissão hospitalar, tais como: início do tratamento, conhecimento do motivo da utilização do medicamento, além de problemas prévios de adesão ao tratamento, e ocorrência de resultados negativos relacionados ao uso dos medicamentos, como alergias e outras reações adversas a medicamentos.

Verificou-se, pela descrição do procedimento, que o registro de informações sobre alergias prévias é realizado de maneira não uniforme nas unidades, sendo mais rigorosa nas unidades de internação de pacientes 
pediátricos. No caso de pacientes pediátricos, além de registro da alergia em prontuário e na folha diária de prescrição, é colocada, no leito do paciente pediátrico, uma placa com o nome do medicamento, além do uso de uma pulseira vermelha, identificando o paciente alérgico, a fim de evitar que seja prescrito ou administrado o medicamento envolvido. Os farmacêuticos clínicos também registram as alergias no formulário de seguimento farmacoterapêutico de cada paciente, para subsidiar a triagem diária das prescrições.

$\mathrm{Na}$ entrevista para obtenção da história medicamentosa, alguns tópicos são imprescindíveis, segundo FITZGERALD (2009):

- Medicamentos sob prescrição, em uso pelo paciente: além do nome, concentração e forma farmacêutica, a formulação (ex. comprimidos de liberação modificada), dose, via de administração (oral, tópica, transdérmica, inalação), frequência (incluindo o horário da última dose administrada), e início do tratamento (tempo de tratamento);

- Medicamentos isentos de prescrição, suplementos nutricionais, plantas medicinais;

- Medicamentos utilizados recentemente (importante para fármacos de meia-vida longa);

- Reação adversa prévia, sua natureza e tempo de curso;

- Adesão ao tratamento (reconhecendo que a informação pode não ser acurada).

Segundo RANTUCCI (2007), deve-se perguntar ao paciente se ele sabe de algum medicamento ao qual ele possa ser alérgico. A autora recomenda que o paciente seja, também, questionado de uma forma mais geral se já apresentou uma reação indesejável a medicamento, pois pode não estar ciente sobre alergias específicas. Caso responda positivamente, deve-se solicitar descrição dos efeitos apresentados, pois pode haver 
confusão entre alergia e efeitos colaterais (efeitos decorrentes do próprio mecanismo de ação do medicamento). Vale ressaltar que informações sobre alergia prévia a contrastes radiológicos e anestésicos também devem ser questionadas.

A partir de queixas dos pacientes sobre experiências indesejáveis durante tratamento farmacológico, é possível, ainda, incluir questionamentos que permitirão detectar eventos adversos decorrentes de utilização inadequada dos medicamentos. Dessa forma, o momento é propício para a educação em saúde.

Uma vez que as informações fornecidas pelo paciente e seus familiares podem ser incompletas e inexatas (por falta de conhecimento, por esquecimento ou confusão devido ao stress da situação) os pacientes devem ser encorajados a trazer uma sacola contendo todos os seus medicamentos em cada consulta, atendimento de emergência ou hospitalização (BARNESTEINER, 2005). Embora este procedimento ocorra apenas eventualmente no HU/USP, é recomendável que faça parte da rotina hospitalar e da orientação prestada ao paciente em qualquer unidade de atendimento em saúde, pois o acesso a todos os medicamentos em uso pelo paciente possibilita complementação de dados obtidos na entrevista para a prescrição segura dos esquemas farmacoterapêuticos subsequentes. Além da identificação dos medicamentos, o procedimento propicia a coleta de dados para avaliar adesão, reações adversas prévias, resposta aos tratamentos, entre outros. No Reino Unido, essa orientação é fornecida até mesmo durante atendimento telefônico em casos de urgência, quando é solicitada a separação dos medicamentos em uso pelo paciente, para que sejam transportados em sacolas (as green bags), junto ao paciente, nas ambulâncias. ${ }^{10}$

\footnotetext{
${ }^{10}$ Palestra sobre "Medication reconciliation - an English perspective", proferida por Bryony Dean Franklin, durante o IV Fórum Internacional sobre Segurança do Paciente: erros de medicação, em Belo Horizonte, em 18 de Agosto de 2012.
} 
Medicamentos com grafias ou pronúncias semelhantes podem dificultar a obtenção de história medicamentosa acurada, especialmente se o paciente não tiver condições de informar qual a indicação de uso (GLEASON, 2010; MEYER et al., 2011). Assim, pacientes devem ser orientados a levar, ao hospital e ao atendimento ambulatorial, as receitas de medicamentos em uso, além de manter lista atualizada contendo nome e posologia dos medicamentos utilizados sem prescrição médica, levando-a consigo aos atendimentos nos serviços de saúde. No entanto, as informações devem ser confirmadas com o paciente, pois este pode adicionar medicamentos, interromper o uso ou utilizar os medicamentos de forma diferente da prescrita, com relação à dose ou frequência de administração.

No caso das listas trazidas de casa ou de informação verbal memorizada, é recomendável que a informação seja validada, questionando ao paciente o motivo de sua utilização. Em estudo conduzido por GIZZI et al. (2010) analisando listas trazidas por 300 pacientes idosos, verificou-se que $38 \%$ dos pacientes relataram o uso de pelo menos um medicamento sem diagnóstico ou condição correspondente documentada, sendo que a classe de medicamentos mais frequentemente envolvida foi a de supressor da secreção gástrica, em uso por $21 \%$ destes pacientes, sem esclarecimento de indicação. Segundo os autores, os resultados do estudo sugerem que a obtenção de história medicamentosa de forma mais rigorosa pode diminuir o uso desnecessário de medicamentos pelos idosos.

Com relação à forma de registro, a história medicamentosa obtida deve ser registrada em prontuário, seja de forma manuscrita, impressa ou em formato eletrônico. A lista de medicamentos utilizados antes da admissão hospitalar deve ser colocada num local bem visível para facilitar a comparação com as prescrições subsequentes (KRIPALANI et al., 2007a).

O tempo necessário para a realização de entrevista com todos os pacientes na admissão hospitalar frequentemente representa dificuldade 
para a atuação de farmacêuticos do HU/USP neste procedimento, levando à necessidade de priorização de casos e delegação da atividade, sob supervisão, aos farmacêuticos residentes, nas unidades onde está sendo implantada a reconciliação medicamentosa.

O conhecimento de fatores de risco para erros de história medicamentosa pode auxiliar na priorização de casos. GLEASON et al. (2010) demonstraram que idade superior a 65 anos e número de medicamentos são significativamente associados com erros que potencialmente requerem monitorização ou causam dano ao paciente. Assim, os esforços para melhorar a acurácia de histórias medicamentosas deveriam ter como foco os pacientes idosos em uso de grande número de medicamentos.

Estudo realizado por HELLSTRÖM et al. (2012) apresentou limitado potencial em predizer quais pacientes estão em maior risco de apresentar erros em sua história medicamentosa. No entanto, os autores sugerem que seja realizada reconciliação medicamentosa a todos os pacientes admitidos ao hospital, e que pacientes mais idosos com vários medicamentos prescritos podem ser especialmente beneficiados pelo procedimento.

A obtenção de história medicamentosa de pacientes selecionados é uma alternativa frequentemente apresentada (ETCHELLS, 2010; FITZGERALD, 2009; BARNSTEINER, 2005; MORIEL et al., 2008; TAM et al., 2005), sendo que a seleção prévia de pacientes pode ser baseada em idade (especialmente crianças e idosos), número de medicamentos prescritos, atendimento fornecido por mais de um médico, número de enfermidades, e pacientes com deficiência cognitiva utilizando múltiplos medicamentos.

Segundo MORIEL et al. (2008) podem ser priorizados os pacientes de serviços cirúrgicos, pois nestes casos a equipe de saúde não é familiarizada com os medicamentos geralmente utilizados pelos pacientes, medicamentos 
estes mais relacionados às comorbidades que ao motivo da hospitalização. No HU/USP, a rotina de entrevista na admissão do paciente para obtenção de história medicamentosa pelos farmacêuticos residentes iniciou-se na Clínica Cirúrgica, em função da implantação da reconciliação medicamentosa. Dados preliminares sugerem potencial contribuição para evitar erros de prescrição, especialmente omissão de medicamentos utilizados até o momento da hospitalização.

A situação ideal para obtenção de história medicamentosa envolve a utilização de sistemas informatizados e integrados que permitam uma conexão rápida e confiável para transferir histórias de medicação e informações sobre prescrição entre os profissionais de diversos locais de atendimento ao paciente (CORNISH et al., 2005; MORIEL et al., 2008). No entanto, GLEASON et al. (2004) alertam que o sucesso da tecnologia de informação depende primordialmente da entrada de dados acurados no sistema pelo profissional de saúde; portanto, seu uso não evita erros decorrentes de falhas na obtenção de histórias medicamentosa.

A importância do compartilhamento de histórias clínicas entre profissionais de saúde que cuidam do paciente, independente do local onde o atendimento esteja sendo realizado, foi manifestada nas entrevistas, inclusive com grande expectativa quanto à implantação de prontuário eletrônico, em curso no Projeto Região Oeste, para integração das unidades de saúde.

\subsubsection{Definindo o momento da alta}

No HU/USP, diariamente, são realizadas visitas médicas (médico assistente, residentes e internos de medicina) nas unidades de internação, visando à avaliação e discussão de casos, definição de condutas diagnósticas e terapêuticas, além de seleção de pacientes que receberão alta no dia. Dependendo do setor, as discussões de caso podem ocorrer à 
beira do leito ou em salas separadas. Em geral, as visitas contam com participação multidisciplinar.

No entanto, na maioria das unidades de internação, o farmacêutico não tem condições de acompanhar todos os dias as visitas a todos os pacientes da unidade em que atua. Essa dificuldade é decorrente da dinâmica das visitas, uma vez que as equipes são divididas em grupos e as visitas ocorrem simultaneamente, em uma mesma unidade. Além disso, há farmacêuticos responsáveis por várias unidades.

A dinâmica das visitas foi considerada um fator limitante para a organização de atividades relacionadas ao cuidado ao paciente, tanto durante a hospitalização como na alta hospitalar.

Ocorrem várias visitas ao mesmo tempo. (...) cada enfermaria tem a sua peculiaridade (F1).

(...) uma dinâmica que impossibilita a participação (E3).

Em função da dificuldade de participação nas visitas e por falha de comunicação, geralmente, enfermeiros, farmacêuticos e outros membros da equipe do HU/USP tomam conhecimento da alta no dia em que ela ocorre.

Verificou-se que a percepção da complexidade do procedimento de alta pode ocorrer de forma diferenciada.

Rotineiramente, um procedimento num hospital secundário ou de média complexidade como é o Hospital Universitário, ele tem procedimentos relativamente simples, e pacientes também relativamente simples. Então, este processo de alta geralmente não é complicado, ele é feito no mesmo dia. Dificilmente demanda um planejamento de vários dias. Isso seria uma exceção (M1).

A alta programada ocorre mais frequentemente na Clínica Pediátrica, em situações mais complexas, geralmente envolvendo pacientes com hospitalização de longa permanência, questões sociais importantes e tratamentos complexos. Segundo o médico entrevistado, nestes casos, o 
planejamento de alta é realizado na reunião semanal multiprofissional, onde são discutidas questões como local de seguimento, recursos disponíveis na comunidade, acesso aos medicamentos necessários, entre outros.

Após definição de quais pacientes receberão alta hospitalar, geralmente em visita médica pela manhã, o interno ou o médico residente faz a receita de alta, e preenche o formulário de resumo de alta no computador. O médico assistente confere a receita e o resumo de alta e, com sua senha, libera a alta no sistema informatizado, geralmente no período da tarde.

O planejamento de alta é um processo direcionado a assegurar a continuidade do atendimento ao paciente que se move entre sua casa e os diversos serviços que compõem o sistema de atendimento em saúde (ROMANO, 1982). O planejamento deve ser iniciado logo após admissão hospitalar, por equipe multidisciplinar, sendo recomendável contar com um profissional designado para coordenar o processo. Deve compreender avaliação das necessidades do paciente para o período pós-alta, avaliação dos recursos disponíveis na comunidade, além de elaboração de plano de alta estruturado, incluindo orientação ao paciente e seus familiares, visando à manutenção da saúde do paciente e à prevenção de atendimentos desnecessários em serviços de saúde (RATLIFF, 1981; ROMANO, 1982; MAMON et al., 1992; MISTIAEN, 2007).

É recomendável o envolvimento do paciente e seus familiares no processo, pois suas necessidades podem ser diferentes das prioridades delimitadas pelos profissionais de saúde. Pacientes demonstram satisfação com planejamentos de alta em que são envolvidos, devido ao atendimento de suas expectativas e favorecimento da continuidade do cuidado (GANZELLA e ZAGO, 2008).

No HU/USP, o planejamento de alta conforme recomendado ocorre especialmente para pacientes pediátricos, enquanto que nas demais 
unidades a situação é semelhante à descrita em outro estudo brasileiro (PEREIRA et al., 2007) e observada na prática clínica habitual: falta de participação multidisciplinar na visita diária ao paciente e comunicação da alta aos membros da equipe de saúde apenas no dia em que ela ocorre, inviabilizando o planejamento de forma interdisciplinar e, consequentemente, dificultando a atuação multiprofissional integrada no preparo do paciente para retorno ao domicílio.

No Brasil, são mais frequentes estudos relacionados ao planejamento de alta envolvendo pacientes com atendimentos de maior grau de complexidade, por exemplo, em caso de transplante de medula óssea (SILVA, 2001), lesão medular (CARDOZO-GONZALES et al., 2001), prostatectomia (NAPOLEÃO et al., 2009), e para pacientes com sequelas neurológicas (CESAR e SANTOS, 2005) ou pacientes ostomizados (GEMELLI e ZAGO, 2002).

No entanto, independente do grau de complexidade, frequentemente os pacientes recebem alta com prescrição de medicamentos e estão, portanto, sujeitos a eventos adversos relacionados ao seu uso. Para RATLIFF (1981, p.138), "nem todo paciente necessita de um plano de alta aprofundado; entretanto, cada paciente pode se beneficiar de alguma maneira com os esforços profissionais para facilitar sua transição de paciente dependente a indivíduo autônomo".

Um aspecto que deve ser ressaltado é a disponibilização de infraestrutura, em termos de recursos humanos, para o planejamento da alta hospitalar. No Brasil, ainda são escassas informações sobre desenvolvimento de programas ou serviços permanentes relacionados ao planejamento de alta. GLANZNER et al. (2006) descrevem experiência de programa desenvolvido em unidade cirúrgica de hospital de ensino brasileiro, desde 1999, onde enfermeiras realizam acolhimento do paciente quando da admissão hospitalar e fornecem orientações relacionadas ao procedimento cirúrgico, além de informações e treinamento sobre os 
cuidados domiciliares relativos ao pós-operatório, como resultado de planejamento individualizado do cuidado necessário após alta hospitalar. As autoras destacam que a atuação das enfermeiras de maneira exclusiva na atividade proposta pelo programa permite acolhimento individualizado do paciente, ao mesmo tempo em que possibilita que a enfermeira do setor se dedique aos demais pacientes da unidade. Trata-se de um modelo de atendimento que pode abranger o preparo do paciente e cuidadores quanto ao uso de medicamentos após alta, especialmente com atuação interdisciplinar, envolvendo farmacêutico, enfermeiro e médico.

Em outros países, o planejamento de alta hospitalar é praticado há mais de três décadas, com registros de profissionalização das responsabilidades sobre atividades relacionadas à alta hospitalar, por meio da descrição da atuação de profissionais especializados, tais como "discharge planner" (RATLIFF, 1981), "case manager" (MAMON et al., 1992), "transition coach" (COLEMAN et al., 2006), "transitional care pharmacist" (BAYLEY et al., 2007), que inclui o cuidado quanto ao uso de medicamentos após alta hospitalar.

\subsubsection{Da prescrição diária à receita de alta}

No HU/USP, as prescrições diárias, são realizadas pelo interno de medicina ou pelo médico residente, e avaliadas pelo médico assistente, por enfermeiros e farmacêuticos.

Os vários "crivos" ou "filtros" foram citados pelos entrevistados como importantes barreiras de segurança para evitar danos ao paciente, contribuindo para a segurança no processo de uso de medicamentos:

O processo em si é bastante seguro, exatamente porque tem várias pessoas que checam essa prescrição (M1).

Como é um hospital escola, aqui, graças a Deus, a gente tem alguns filtros, para que não cause dano (M2). 
Por outro lado, a existência dos vários "filtros" na etapa de prescrição de medicamentos foi, também, citada como dificuldade, por favorecer a ocorrência de menor comprometimento da equipe médica na observação de normas e orientações, no momento da prescrição, exigindo, assim, maior tempo das equipes de enfermagem e de farmacêuticos na identificação e resolução de problemas no dia a dia.

Rotineiramente eles sabem que a enfermagem vai ver, que o farmacêutico vai ver, então não tem uma prática de ter tanta atenção (E3).

Houve referência de que durante o aprazamento, quando os horários de administração dos medicamentos são definidos pelos enfermeiros, alguns problemas relacionados à prescrição, como omissão de medicamentos, prescrição de medicamento suspenso ou em duplicidade, entre outros, são detectados, comunicados ao médico prescritor e, então, corrigidos.

No HU/USP, diariamente, os farmacêuticos clínicos atuam junto às equipes nas unidades de internação, onde, além de fornecer informações relacionadas à prescrição e administração de medicamentos, também realizam triagem da prescrição, como uma das atividades do seguimento farmacoterapêutico, que visa monitorar a eficácia e a segurança do tratamento.

A triagem farmacêutica da prescrição realizada na instituição envolve verificação de adequabilidade às normas e padrões de prescrição, dose prescrita, interação medicamento/medicamento e medicamento/alimento, possibilidade de trituração para administração por sonda nasogástrica, disponibilidade do medicamento na instituição, possibilidade de substituição de medicamentos não-padronizados na instituição, bem como sugestões de alterações em medicamentos e esquemas posológicos, como resultado do seguimento farmacoterapêutico realizado. As sugestões e observações resultantes da triagem farmacêutica das prescrições são registradas em 
campo específico da prescrição diária e, a partir das intervenções farmacêuticas realizadas, são calculados indicadores.

Em geral, as intervenções farmacêuticas são bem aceitas pela equipe hospitalar.

A gente tem um indicador de farmácia clínica, que é o número de intervenções farmacêuticas aceitas, e ele é esmagadoramente grande. São raras as intervenções não aceitas, porque a interação da equipe é boa, (...) ele (o farmacêutico) está ali todo dia e é muito consultado (F3).

De fato, todos os médicos entrevistados ressaltaram a importância da triagem da prescrição realizada diariamente pelos farmacêuticos, nas unidades de internação:

A gente tem um serviço de farmácia que atua em conjunto (...) o último crivo é do farmacêutico, que também analisa e pode alertar se tiver alguma prescrição com algum problema (M1).

Depois tem a farmacêutica hospitalar que é excelente, que pega todas as prescrições, lê todas e vê não só se existe erro na prescrição com relação à posologia, mas também checa a interação (M2).

Se o médico não viu, por alguma razão, ou não prestou atenção (...) - ele vê tantas prescrições - a enfermeira também não viu... quem vai barrar isso é a farmácia. A farmácia é que sempre barra esse tipo de coisa e traz de volta para o médico, para discutir com o médico que prescreveu (M3).

Problemas na elaboração das prescrições diárias podem resultar em erros nas receitas de alta, caso não sejam detectados e interceptados.

No HU/USP, existem normas e orientações para a prescrição segura de medicamentos, tais como não utilizar abreviaturas e siglas; não colocar 'zero' após vírgula, quando a dose for um número inteiro; prescrever doses em unidades de peso, e não em $\mathrm{mL}$, para pacientes pediátricos, entre outras. A divulgação é realizada de várias formas: por meio de manual distribuído aos residentes e internos; em campanhas, como a colocação de material informativo nos elevadores e em murais; além de apresentação em 
reuniões de recepção de novas equipes de internos e residentes, especialmente na clínica pediátrica. No entanto, segundo enfermeiros e farmacêuticos entrevistados, é frequente a detecção de não-conformidades nas prescrições diárias, em todos os setores.

Embora durante a hospitalização a liberação de medicamentos às unidades de internação, pelo Serviço de Farmácia, seja precedida pela triagem da prescrição pelos farmacêuticos, geralmente a receita de alta não é encaminhada ao farmacêutico, para conferência, com exceção dos casos em que ocorre orientação de alta pelo farmacêutico.

A receita de alta geralmente é manuscrita, assim como as prescrições diárias, na maioria das unidades de internação do HU/USP. Durante a hospitalização, em geral, a segunda via (carbonada) da prescrição manuscrita é encaminhada à Farmácia, diariamente, para que ocorra a dispensação de medicamentos. No entanto, algumas unidades utilizam o computador para a realização das prescrições ("máscara" de Word) e, no decorrer do dia, realizam ajustes no plano terapêutico, utilizando o formulário padrão para prescrição manuscrita ou complementando manualmente a prescrição impressa. Assim, na mesma unidade, é comum a coexistência de prescrição digitada em computador, prescrição manuscrita, além de prescrição mista (parte digitada e parte manuscrita).

Segundo farmacêuticos e enfermeiros, a prescrição digitada trouxe melhorias quanto à legibilidade, mas introduziu novas situações de risco de erros em função do "copia e cola". Foram citados, como exemplos, a não atualização, no computador, das alterações feitas de forma manuscrita na folha impressa ou no formulário padrão (suspensão/inclusão de medicamentos ou alterações de doses, no decorrer do dia), além de digitação incompleta da identificação do paciente (associada à falta de utilização da etiqueta de identificação do paciente), entre outras. Em função deste risco, foi introduzida uma etapa adicional de trabalho para a enfermagem e farmacêuticos: a comparação diária da prescrição atual com 
a prescrição do dia anterior, e contato com médico para confirmação/alteração da informação ou complementação dos dados, seguida da alteração da prescrição, quando necessária.

Tem que checar tudo, item por item, com a prescrição anterior, para ver o que mudou e o que não mudou. Às vezes o item mudou naquele dia, mas na discussão do caso, no dia seguinte, eles resolveram retornar com aquela medicação. Então, não é só uma questão de mudar o que está ali do jeito que estava na anterior. Eu digo isso para a enfermagem ou para o farmacêutico, a gente tem que conferir com o assistente. Então, é bem cansativo e desgastante, nesse sentido, porque todo dia você tem que ir atrás do assistente para conferir essas mudanças (E3).

Ao receber a receita de alta, o enfermeiro verifica se foi realizada no receituário adequado e de forma clara, compara a receita de alta com a última prescrição do período de hospitalização, e questiona o médico prescritor em caso de não inclusão de medicamento prescrito durante a hospitalização ou a prescrição de doses diferentes, e ainda procura alertar sobre a falta de substituição de medicamento padronizado na instituição por equivalente terapêutico disponível na rede pública de saúde.

Apesar destes cuidados, foram citados casos eventuais de volta do paciente ou familiar, ao hospital, por não conseguir adquirir o medicamento devido a problemas com a receita, como uso de abreviatura em nomes de medicamento, apresentações não disponíveis nas UBSs ou no comércio, uso de receituário inadequado para prescrição de psicofármacos, e falta de carimbo do médico. Estes problemas, detectados por enfermeiros e assistentes sociais, não são registrados e, portanto, não geram indicadores.

Embora a receita de alta seja comparada à última prescrição de internação, pelo enfermeiro, não são registradas as justificativas das alterações de prescrição realizadas no momento da alta. Também não é realizada comparação entre a receita de alta e a lista de medicamentos que o paciente fazia uso até o momento da hospitalização, obtida em entrevista 
na admissão hospitalar, e, consequentemente não há registro de possíveis alterações e respectivas justificativas.

Especialmente em unidades pediátricas, foi citada como frequente a interceptação, pelo farmacêutico, de receitas de alta contendo medicamentos que deverão ser manipulados, devido à falta de dados como concentração, forma farmacêutica e duração do tratamento. Devido à complexidade de formulação destas receitas, o farmacêutico frequentemente é solicitado para auxiliar na sua elaboração, contribuindo com 0 fornecimento de informações sobre a formulação e sua estabilidade, bem como sobre a forma adequada de prescrição.

A prescrição médica é a primeira de várias etapas que compõem o processo de uso de medicamentos, até culminar com a administração ao paciente e a monitorização dos efeitos de seu uso. Vários fatores podem contribuir com a ocorrência de danos ao paciente decorrentes de falhas na prescrição, tanto relacionados à confecção da prescrição, como ilegibilidade ou ambiguidade, uso de abreviaturas, presença de rasuras, e falta de informações essenciais como dose, forma farmacêutica, via de administração ou duração do tratamento, como também devido a falhas na seleção do tratamento (medicamento, posologia, via de administração e duração).

Revisão sistemática revelou que erros de prescrição são frequentes em pacientes hospitalizados, afetando 7\% das prescrições e 50\% das admissões hospitalares. Os erros de dose foram os mais comuns, além de prescrições incompletas, omissão de medicamentos, ilegibilidade, erros em intervalos de doses, formulação incorreta, interações medicamentosas e erros de transcrição (LEWIS et al., 2009).

Estudos realizados em vários estados brasileiros (AGUIAR et al., 2006; SILVA et al., 2007; MIASSO et al., 2009; ROSA et al., 2009), envolvendo sete hospitais, demonstraram que são frequentes os problemas 
de ilegibilidade das prescrições, uso de abreviaturas e prescrições incompletas.

Trata-se, portanto, de uma etapa crítica, com riscos de danos, especialmente quando o paciente já não se encontra mais sob os cuidados da equipe hospitalar. Este fato justifica a tripla checagem da prescrição, que ocorre durante o período de hospitalização no HU/USP, bem como a necessidade de ampliação deste mecanismo de segurança no momento da alta, de forma sistematizada, incluindo a participação do farmacêutico na revisão de todas as receitas emitidas no momento da alta hospitalar.

O uso de tecnologia da informação é um recurso recomendado para evitar erros de prescrição, em especial a prescrição eletrônica com suporte para decisão clínica, que permite a padronização da nomenclatura dos medicamentos reduzindo o uso de abreviaturas e a emissão de alertas automáticos de doses inadequadas, interações medicamentosas e alergias prévias (WACHTER, 2010). No entanto, esta importante ferramenta ainda não faz parte da realidade do HU/USP, assim como da maioria dos hospitais brasileiros, geralmente devido a recursos financeiros limitados.

Por outro lado, a utilização da informática para gerar prescrições digitadas é uma estratégia acessível, além de útil, especialmente, para evitar ilegibilidade das prescrições. Entretanto, problemas detectados no HU/USP relacionados ao "copiar e colar", gerando repetição de prescrição do dia anterior, sem revisão, além de prescrições incompletas e coexistência de prescrições digitadas e manuscritas também foram descritos por CASSIANI et al. (2003). No estudo, realizado em hospital universitário brasileiro, foram analisadas 1351 prescrições digitadas, das quais 16,8\% continham medicamentos suspensos e, destes, apenas $3,2 \%$ foram suspensos digitalmente e não de forma manual, e $28,2 \%$ das prescrições apresentavam informações que poderiam resultar em dúvidas, como uso de abreviaturas, siglas ou decimais. As autoras destacam a necessidade de aperfeiçoamento do sistema e educação dos prescritores. 
A digitação de receitas na alta hospitalar, em substituição às receitas manuscritas, representa uma estratégia factível para evitar problemas decorrentes de ilegibilidade, porém ainda é exceção nas unidades de internação do HU/USP.

Para LEWIS et al. (2009), na revisão sistemática sobre erros de prescrição ficou aparente a importância dos profissionais de saúde no processo de detecção de erros, destacando a atuação de farmacêuticos. Segundo WACHTER (2010, p. 66), "de todas as estratégias para tentar diminuir os erros de prescrição de medicamentos, a inserção do farmacêutico clínico no processo de prescrição e administração de medicamentos é uma das mais poderosas". No HU/USP, essa estratégia é utilizada durante o período de hospitalização e tem boa receptividade junto à equipe de saúde, especialmente devido à atuação na revisão farmacêutica das prescrições e fornecimento de informações essenciais ao processo de uso de medicamentos. Entretanto, a atuação dos farmacêuticos na prescrição de alta é limitada, conforme demonstrado, em função da dinâmica do processo de alta e de recursos humanos restritos.

A contribuição da atuação de farmacêuticos do HU/USP está sendo ampliada com a implantação de outra importante estratégia para redução de erros de prescrição - a reconciliação medicamentosa - que tem por objetivo obter e manter informação acurada e completa sobre farmacoterapia para um paciente e usar essa informação durante e na interface do atendimento em saúde para assegurar o uso efetivo e seguro dos medicamentos (APhA ASHP, 2012).

Desde 2005, a reconciliação medicamentosa faz parte dos padrões de acreditação de serviços de saúde no Canadá (ISMP, 2006) e nos EUA (APhA - ASHP, 2012), embora haja registro de realização de reconciliação em hospitais norte-americanos desde 2001 (GEBHART, 2005). Pesquisa realizada em 2006, nos EUA, revelou que cerca de $70 \%$ dos hospitais que responderam à pesquisa nacional realizavam reconciliação medicamentosa. 
Segundo os autores da pesquisa, fatos como estes demonstram "o impacto e o valor que um padrão de acreditação pode ter para agilizar a adoção de uma prática segura de medicação" (PEDERSEN et al., 2007, p. 520).

No Brasil, alguns hospitais implantaram o processo de reconciliação medicamentosa, embora nem sempre ocorra em todas as fases de transição do atendimento hospitalar (admissão hospitalar, transferência de setor e alta hospitalar). ${ }^{11,12}$

A reconciliação medicamentosa está em fase de implantação no HU/USP, por meio da atuação de farmacêuticos residentes. O início do processo envolveu todos os pacientes da clínica cirúrgica e, em seguida, foi ampliado para a clínica médica. O Institute for Safe Medication Practices Canadá (ISMP, 2006) recomenda que o processo de reconciliação seja testado em um pequeno número de pacientes, modificando-se o processo conforme necessidade e, uma vez funcionando em pequena escala, seja testado em outros setores.

Embora o envolvimento intensivo de equipes do serviço de farmácia tenha sido considerado um dos elementos-chave para o sucesso das intervenções de reconciliação, em revisão sistemática realizada por MUELLER et al. (2012), a reconciliação medicamentosa pode ser realizada de forma eficiente, efetiva e consistente por farmacêuticos ou outros profissionais de saúde qualificados (APhA - ASHP, 2012). Além disso, é recomendável que a equipe multidisciplinar seja envolvida para desenvolver, testar e implementar, de forma colaborativa, um processo que seja efetivamente integrado ao fluxo de trabalho da instituição (ISMP, 2006).

\footnotetext{
${ }^{11}$ Palestra "Conciliação de medicamentos - experiência em hospital privado", proferida por Claudia Regina Laselva, durante o IV Fórum Internacional sobre Segurança do Paciente: erros de medicação, em Belo Horizonte, em 18 de Agosto de 2012.

12 Palestra "Conciliação de medicamentos - experiência em hospital público", proferida por Joice Zuckermann, durante o IV Fórum Internacional sobre Segurança do Paciente: erros de medicação, em Belo Horizonte, em 18 de Agosto de 2012.
} 
Dessa forma, vale ressaltar a necessidade de inclusão de enfermeiros e médicos do HU/USP no processo.

$\mathrm{Na}$ alta hospitalar, a reconciliação medicamentosa inclui duas etapas: comparação entre a receita de alta e a última prescrição realizada no período de hospitalização, e comparação da receita de alta com a lista de medicamentos que o paciente fazia uso até o momento da hospitalização (CUA e KRIPALANI, 2008). No HU/USP, embora os enfermeiros verifiquem, na receita de alta, se há continuidade de prescrição de medicamentos que foram utilizados até o momento da alta, este não é um processo formal, sistematizado, com documentação sobre ações subsequentes, e suas justificativas, em relação ao tratamento proposto na alta. Também não é realizada a segunda etapa. Estes procedimentos deverão ser realizados, e registrados, após implantação da reconciliação medicamentosa na alta hospitalar.

Especificamente com relação à reconciliação na alta hospitalar, além de evitar erros de prescrição por omissão de medicamentos prescritos durante a hospitalização e que necessitam ser mantidos após alta, possibilita evitar eventos adversos resultantes de uso de medicamentos em duplicidade, devido a problemas de comunicação. RODEHAVER e FEARING (2005) relatam o caso de paciente que apresentou severa rabdomiólise por superdosagem de estatina, devido ao uso concomitante da estatina receitada na alta e da estatina que fazia uso antes da hospitalização.

A reconciliação medicamentosa na alta possibilita, também, evitar eventos relacionados a tratamentos prévios com medicamentos de uso contínuo, decorrentes de omissão de medicamentos temporariamente suspensos durante a hospitalização e que deveriam ser retomados após alta. Coorte de base populacional realizada no Canadá com dados de prontuários do período de 1997 a 2009, envolvendo cerca de 400 mil pacientes em tratamento para doenças crônicas, revelou que pacientes que 
foram hospitalizados apresentaram maior risco de interrupção não intencional de seus tratamentos, com risco adicional para aqueles que foram atendidos em unidades de terapia intensiva durante a hospitalização. $O$ seguimento dos pacientes que interromperam o uso de estatinas e de antiagregantes plaquetários/agentes anticoagulantes demonstrou risco aumentado de morte, atendimento em pronto-socorro ou hospitalização (BELL et al., 2011).

Uma vez que o paciente e seus familiares são os únicos elementos constantes em cada transição do atendimento em saúde, recomenda-se envolvê-los no processo de reconciliação, especialmente estimulando-os a manter e atualizar a lista de medicamentos em uso (ISMP, 2006), sendo fundamental a realização de orientação específica sobre as alterações resultantes do processo de reconciliação na alta hospitalar.

\subsubsection{Orientando o paciente e/ou cuidador}

Geralmente, o momento da alta é carregado de ansiedade e stresse. Segundo MARRA et al. (1989), quanto maior a dependência de cuidados ou de medicamentos, maiores são os receios. Nestes momentos, o contato do paciente com os profissionais de saúde tem curta duração. Estes fatos dificultam o processamento de grande volume de informações pelos pacientes, na alta. Portanto, não é o momento ideal para recebimento de informações gerais e detalhadas sobre medicamentos.

A orientação realizada no momento da alta deve destacar alterações no regime farmacoterapêutico resultantes do processo de reconciliação de alta, como inclusões e exclusões de medicamentos ou mudança na dose (CUA e KRIPALANI, 2008).

No HU/USP, essa importante etapa do processo de orientação poderá ser incluída, de forma sistemática, com a implantação da reconciliação medicamentosa na alta hospitalar. 
Atualmente, no HU/USP, quando a alta não é programada, como ocorre na maioria dos casos, o conhecimento sobre os medicamentos que o paciente deve fazer uso no domicílio ocorre, geralmente, a partir do contato com a receita de alta, dificultando realizar orientação antecipada, durante o período de hospitalização. Portanto, na maioria das vezes, a orientação sobre utilização de medicamentos após alta hospitalar é realizada pelo enfermeiro, no período da tarde, imediatamente antes de o paciente deixar o hospital.

Após leitura do nome de cada medicamento e respectiva dose, a orientação fornecida ao paciente e ao acompanhante pelo enfermeiro pode incluir os seguintes tópicos: motivo de uso do medicamento e importância de seguir o tratamento, horário de administração (especialmente quando há necessidade de jejum), duração do tratamento (principalmente para antibióticos), e identificação de medicamentos distribuídos gratuitamente na rede pública de saúde.

Também ocorre orientação verbal pelo médico assistente ou residente, de forma pontual, como necessidade de jejum e duração do tratamento, além do registro de orientações específicas na própria receita.

Estudos realizados no Brasil demonstraram que, na prática clínica habitual, as orientações de alta, incluindo uso de medicamentos, se restringem a instruções fornecidas, na maioria das vezes, pelo médico e/ou enfermeiro no momento da alta hospitalar, de forma superficial e rápida, sem levar em consideração as necessidades individuais e sem verificar o entendimento das orientações pelo paciente (MIASSO e CASSIANI, 2005; PEREIRA et al., 2007 e POMPEO et al., 2007).

Verificou-se, entre os enfermeiros do HU/USP, reconhecimento da importância do desenvolvimento da autonomia do paciente para o autocuidado, e das limitações para a realização de orientação completa, em 
função da abrangência das necessidades de cuidado que apresentam, e de problemas relacionados ao planejamento de alta.

(...) pacientes mais dependentes, a gente começa orientações sobre outras questões de cuidado pessoal, (...) precisa treinar o cuidador para fazer curativo, para lidar com sonda ou alguma coisa que exija um pouco mais de complexidade. Nesses outros pontos que estão especificamente relacionados a cuidados, a gente já consegue fazer um planejamento mais adequado, mais próximo do ideal para alta (E3).

Cabe à enfermagem orientar o paciente sobre vários aspectos, tais como alimentação, repouso, atividade física, exames, cuidados especiais determinados pela enfermidade e pelas condições do paciente, agendamento de retornos, medicamentos, entre outros (MARRA et al., 1989), de forma que a orientação relacionada à terapia medicamentosa pode ser deficiente por falta de tempo, condições e conhecimento específico (MIASSO e CASSIANI, 2005).

Se a gente conseguisse planejar essa alta e saber qual o plano terapêutico depois da alta, acho que a gente poderia dar uma orientação ao longo da internação, com mais tempo, (...) na hora da alta elas estão morrendo de pressa, você sabe que não é o melhor momento para orientar (...). Acho que a gente precisa melhorar essa questão (E2).

O ideal seria que a gente começasse a fazer esse tipo de orientação desde o começo da internação, mas tem algumas medicações que a gente não sabe se ele vai sair com alta com aquelas medicações (...) talvez a gente tenha que criar alguma estratégia de comunicação com a equipe médica (E1).

Assim como ocorre no HU/USP, PEREIRA et al. (2007) relatam que, na visão dos enfermeiros, entre as principais dificuldades encontradas para a realização de adequada orientação na alta hospitalar sobre uso de medicamentos estão o conhecimento da alta do paciente apenas no momento em que ela ocorre e falta de participação nas visitas clínicas.

No HU/USP, além da orientação no momento da alta, ao paciente e cuidador, sobre o tratamento farmacológico que deverá ser realizado no 
domicílio, a orientação antecipada sobre o tratamento ocorre apenas nos casos de alta programada de pacientes pediátricos e em casos excepcionais envolvendo pacientes adultos, como no início de utilização de insulina durante a hospitalização ou em casos de grande dificuldade de entendimento do paciente ou familiar em tratamentos de maior complexidade. Nestes casos específicos, a alta pode ser postergada até que seja concluída a orientação ou treinamento.

Os casos de alta programada para pacientes pediátricos hospitalizados na Clínica Pediátrica e no Berçário do HU/USP, geralmente, envolvem situações com potencial impacto na segurança do uso de medicamentos, tais como:

- Avaliação sobre necessidade de orientação mais detalhada em função de esquemas terapêuticos complexos ou uso de psicofármacos;

- Grau de dificuldade da mãe ou cuidador em entender a forma correta de administração dos medicamentos;

- Necessidade de treinamento prático sobre a administração de medicamentos;

- Falta de condições financeiras da família para adquirir os medicamentos prescritos, necessitando intervenção do Serviço Social;

- Necessidade de a família buscar medicamento na rede pública de saúde para, então, receber orientação detalhada ou treinamento sobre administração do medicamento;

- Necessidade de manipular medicamentos em apresentações que não estão disponíveis comercialmente. 
Nos casos mais complexos, especialmente na Clínica Pediátrica e Berçário, o farmacêutico assume a orientação junto ao cuidador sobre os cuidados relacionados ao uso de medicamentos. São fornecidas orientações sobre vários aspectos relacionados ao tratamento, incluindo cuidados específicos na administração e precauções. Procura-se ajustar os horários de administração dos medicamentos à rotina diária. O cuidador é, também, orientado sobre a forma de obtenção da dose prescrita para cada horário, especialmente quanto à retirada correta de pequenas doses de formulações líquidas, com uso de dosadores orais. É realizado treinamento prático para administração correta do medicamento, buscando adaptar o método à melhor forma de aprendizado de cada cuidador.

Com relação aos riscos do tratamento, a orientação fornecida no HU/USP geralmente não inclui informações sobre potenciais efeitos adversos dos medicamentos prescritos, embora sejam fornecidas orientações sobre cuidados quanto aos riscos relacionados a tratamentos com insulina e anticoagulantes.

Não diria que é uma prática assim de se falar ativamente de eventos adversos sem o paciente questionar. Não é uma praxe (M3).

No geral, não, a não ser a hipoglicemia relacionada à insulina, então com isso se tem um cuidado grande. Agora possíveis outros problemas, sei lá, hepatotoxicidade, dificilmente isso é colocado para o paciente como possível (M1).

(...) então a gente diz 'esse remédio vai fazer com que o senhor sangre com mais facilidade. Se cair, se cortar, ou se notar que está sangrando a gengiva, notar que está sangrando a urina, notar que está saindo sangue nas fezes, venha para o hospital para fazer o exame'. Tem essa orientação (M2).

Pacientes e cuidadores recebem orientação geral para procurar atendimento no próprio HU/USP ou na UBS onde realiza acompanhamento, em caso de necessidade, incluindo suspeita de dano relacionado ao tratamento farmacológico. 
A preocupação da equipe quanto aos esclarecimentos sobre o manejo do uso de insulina e anticoagulantes é respaldada pelo estudo realizado por BUDNITZ et. al (2006), que revelou que eventos adversos relacionados a medicamentos foram a causa de $2,5 \%$ dos atendimentos em serviços de emergência, e insulina e anticoagulantes foram os medicamentos mais frequentemente envolvidos (1 a cada 7 eventos adversos) e implicados em $1 / 4$ das hospitalizações.

A falta de orientação sobre potenciais efeitos adversos dos medicamentos ocorre frequentemente. Vários estudos revelam que apenas $20 \%$ a $62 \%$ dos pacientes admitem ter recebido informações e conhecer possíveis efeitos colaterais dos medicamentos (FOSTER et al., 2005; KERZMAN et al., 2005; DONIHI et al., 2008).

Entretanto, em estudo qualitativo realizado no Canadá com 88 pacientes distribuídos em 19 grupos focais, sobre o que os pacientes querem saber sobre medicamentos, a necessidade de informação sobre riscos e efeitos colaterais foi mencionada em todos os grupos. Na maioria dos grupos, este foi o primeiro item mencionado (NAIR et al., 2002).

Segundo RANTUCCI (2007), alguns efeitos colaterais podem alarmar ou aborrecer o paciente suficientemente para que ele decida interromper o tratamento. Entretanto, se for alertado sobre a possível ocorrência e como gerenciá-la, poderá continuar o tratamento. As informações devem abordar os efeitos colaterais potenciais, precauções para evitar ou medidas para minimizar ou monitorar tais efeitos, o que fazer se eles ocorrerem, incluindo como tratar os sintomas, quando interromper o uso do medicamento, quando telefonar para o médico, e quando procurar atendimento em serviços de emergência (CUA e KRIPALANI, 2008). Se o paciente é orientado sobre sinais de possíveis efeitos adversos, sua detecção pode ocorrer em um estágio inicial e o médico pode ser notificado, possibilitando tomar medidas cabíveis antes que efeitos mais graves se instalem. Assim, o fornecimento adequado de informações relacionadas aos efeitos colaterais aumenta a 
sensação de controle do paciente sobre os efeitos dos medicamentos que está utilizando.

No HU/USP, especialmente em caso de pacientes pediátricos ou de pacientes adultos que receberam treinamento ou orientação mais detalhada, farmacêuticos e enfermeiros solicitam ao cuidador/paciente que repita as orientações recebidas ou demonstre a técnica aprendida, possibilitando avaliação do aprendizado.

A preocupação com o entendimento quanto às orientações recebidas é evidente:

Elas fazem perguntas, e as que não fazem a gente reforça 'você entendeu? Que horas você vai dar? Quantos $m L$ ?' A gente tenta reforçar e pedir essa devolutiva delas, para ver se entenderam (E2).

Explica, me mostra, lê para mim a receita, me mostra aqui aonde é a dose. Para você isso é claro? (F3).

Pedir ao paciente para repetir as instruções da forma como entendeu ou demonstrar uma nova técnica aprendida ("Teach-back") é o melhor recurso para confirmar o entendimento da orientação recebida. Este é considerado um dos métodos mais efetivos para melhorar a segurança do paciente (KRIPALANI et al., 2007a).

Ao final da orientação realizada pelo farmacêutico, no HU/USP, o cuidador recebe material informativo impresso, contendo informações específicas sobre determinados medicamentos, como cuidados especiais sobre administração e armazenamento (Anexo 3). Para facilitar o entendimento do esquema posológico, o farmacêutico elabora planilhas personalizadas, contendo nome dos medicamentos, doses e horários de administração, incluindo uso de símbolos e esquemas de cores (Anexo 4). Planilhas também estão disponíveis nas unidades para que possam ser preenchidas por enfermeiros ou médicos e fornecidas a pacientes que 
apresentam dificuldade de entendimento, especialmente em casos de vários itens de medicamentos prescritos, ou para pacientes não alfabetizados.

O uso isolado de informações impressas ou sessões educacionais não melhora a adesão do paciente ao tratamento, porém pode ser útil fornecer material educacional em combinação com orientação direta ou outras intervenções comportamentais (FOX et al., 2007), tais como ensinar ao paciente a adquirir habilidades, utilizar métodos de lembrança (calendários e estojos de medicamentos) e simplificar esquemas (TOUCHETTE e SHAPIRO, 2008).

No HU/USP não são realizadas sessões de orientação sobre 0 tratamento, ao longo do período de hospitalização, de forma sistematizada, embora os pacientes recebam orientações pontuais sobre seus medicamentos, fornecidas por médicos, farmacêuticos e enfermeiros.

Orientações detalhadas sobre o uso de medicamentos devem ser fornecidas aos pacientes e familiares ao longo do período de hospitalização (GREENWALD et al., 2007). Iniciar a orientação logo após admissão hospitalar possibilita adequar o procedimento às necessidades específicas de cada paciente, avaliar a compreensão do paciente e consequente necessidade de reforçar as informações, além de dar oportunidade ao paciente de esclarecer suas dúvidas (MARRA et al., 1989; PEREIRA et al., 2007).

CUA e KRIPALANI (2008) recomendam encaminhar para orientação e/ou treinamentos específicos pacientes para os quais foram prescritos medicamentos de alto risco (como anticoagulantes, antiarrítmicos, imunossupressores) ou medicamentos que requerem habilidades para administração (como insulina e inaladores).

Além do fornecimento de informações sobre tratamentos específicos, a orientação ao paciente é uma oportunidade para a realização de educação em saúde, com empoderamento do paciente para tomar decisões 
relacionadas à sua própria saúde e de seus familiares, cujas consequências podem afetar sua segurança e até mesmo a comunidade, como no caso do descarte inadequado de medicamentos com prazo de validade expirado e de sobras de medicamentos.

A adequada orientação sobre o uso de medicamentos após alta pode auxiliar no desenvolvimento de autonomia do paciente, contribuindo para a segurança do processo de uso de medicamentos no domicílio.

\subsubsection{Saindo de alta}

A transferência de informações inexatas entre os profissionais dos serviços de saúde no período pós-alta pode ter implicações negativas para a continuidade do cuidado $e$, consequentemente, para a segurança do paciente. Os resumos de alta são utilizados para documentar informações sobre exames diagnósticos e procedimentos realizados durante a hospitalização, além de fornecer informações necessárias ao seguimento do paciente após alta hospitalar (KRIPALANI, 2007b).

Estudo realizado por VAN WALRAVEN et al. (2002) demonstrou redução do risco de readmissão hospitalar para pacientes idosos cujos médicos tiveram acesso ao resumo de alta na consulta de seguimento após alta hospitalar.

$O$ resumo de alta do HU/USP (Anexo 5) foi referido, em algumas entrevistas, como documento obrigatório, utilizado pelo paciente como atestado médico, e não como um importante instrumento para estreitar a comunicação entre os serviços de saúde.

É um documento que serve, na maior parte das vezes, quando há necessidade de afastamento (M2).

É obrigatório, então sai a cópia do paciente e a cópia do prontuário. (...) o resumo de alta é utilizado como atestado (F3). 
Vale destacar a importância da valorização, pela própria equipe de saúde, do encaminhamento do resumo de alta ao médico que dará seguimento ao atendimento do paciente após alta hospitalar. Para KLÜCK e GUIMARÃES (1999), o recebimento de cópia do documento pelo paciente, com instruções de levá-lo em seus futuros atendimentos de saúde, possibilita ao paciente tornar-se um agente do processo, garantindo a continuidade da assistência com mais qualidade e menos riscos ao paciente.

Para garantir o direito do paciente ao acesso às informações relativas ao atendimento recebido durante a hospitalização e à transferência adequada de informações no encaminhamento para outras unidades de saúde, previsto na Carta dos Direitos do Usuário de Saúde (BRASIL, 2006), o resumo de alta deve conter informações claras relacionadas ao tratamento a ser seguido após alta hospitalar. Além de nome, dose, frequência/via de administração, duração planejada de uso, e razão de uso de cada medicamento, KRIPALANI et al. (2007b) e CUA e KRIPALANI (2008) recomendam que o resumo de alta explicite os motivos de inclusão de novos medicamentos e de alterações em tratamentos prévios, independente de quão óbvios sejam. Para garantir a continuidade do tratamento de forma segura, recomendam, também, que o resumo apresente informações sobre a realização de exames durante o seguimento do paciente, como a realização de monitorização de medicamentos (quais testes, em que frequência e o que esperar dos procedimentos de monitorização).

No resumo de alta do HU/USP, em geral, são registrados apenas os medicamentos, e respectivas posologias, que constam da receita entregue ao paciente. No entanto, em alguns casos, mesmo o registro destas informações é incompleto, por falta de inclusão de medicamento, falta de dose ou duração do tratamento.

Também houve referência a situações em que não são registrados, no resumo de alta, os medicamentos que o paciente fazia uso antes da hospitalização, especialmente quando é feita apenas orientação verbal ao 
paciente para continuar os medicamentos que já fazia uso, ou para voltar ao posto de saúde de origem e verificar com o médico se deve ou não continuar o uso de determinado medicamento, ou se haverá mudança na dose.

Quando da realização de orientação de alta aos pacientes, pelos farmacêuticos do HU/USP, é realizado preenchimento de impresso contendo todos os medicamentos prescritos na alta (Anexo 6), cuja cópia é anexada ao prontuário do paciente. Segundo um dos farmacêuticos entrevistados, os próprios médicos manifestam a valorização do documento, quando em novo atendimento a pacientes crônicos:

(...) "ah, quando a gente abre essa folha e vê (o impresso preenchido)... porque eu quero saber o que ele estava usando antes... fica tão fácil!" Porque a gente põe apresentação correta, quanto está usando de dose, os horários. É muito claro (F3).

Os registros de alterações nos tratamentos, e suas justificativas, no resumo de alta, ocorrem apenas em situações específicas, como substituição de hipoglicemiante oral por insulina, e substituição de antibióticos, ou seja, em situações, durante a hospitalização, em que houve necessidade de alteração da conduta por falta de resposta adequada ao tratamento, após avaliação do quadro clínico do paciente.

Tais registros não são resultado de rotina sistematizada de comparação entre a receita de alta e a lista de medicamentos em uso até a hospitalização (obtida na entrevista de admissão), embora haja reconhecimento de que o registro dessa informação possa ser aprimorado.

Talvez, poderia ser um pouco mais claro, mas isso acontece às vezes (M1).

Existe espaço para isso, é uma coisa livre, se quiser, se alguém quiser colocar pode colocar, mas isso não é rotina (M2).

A complementação dos dados no resumo de alta poderá ser incluída a partir da implantação da rotina de reconciliação de alta no HU/USP, uma 
vez que a comunicação do resultado da reconciliação ao profissional que dará sequência ao atendimento do paciente é etapa fundamental do processo.

Para cada medicamento analisado deve ser registrada uma ação (continuar, interromper ou alterar), como demonstra o exemplo de formulário de ROGERS et al. (2006) apresentado no Anexo 7 .

Revisão sistemática da literatura (KRIPALANI, 2007b) demonstrou que deficiências na comunicação e na transferência de informações na alta hospitalar são comuns. A disponibilidade do resumo de alta na primeira consulta após alta hospitalar foi baixa $(12 \%$ a $34 \%)$, afetando a qualidade do atendimento em aproximadamente $25 \%$ das consultas de seguimento. Frequentemente apresentaram falta de informações importantes, como medicamentos receitados na alta ( $2 \%$ a $40 \%)$ e planos de seguimento $(2 \%$ a $43 \%)$.

GRIMES et al. (2011), em estudo envolvendo 1245 episódios de atendimento ambulatorial de pacientes após hospitalização, verificaram que em $50,1 \%$ dos casos houve pelo menos um erro de prescrição ou falha em documentar ou comunicar alterações no tratamento, na receita de alta ou no resumo de alta. Os principais problemas encontrados estavam relacionados a erros na confecção da receita de alta (omissão de medicamento em uso até a alta $-18,7 \%$ do total de episódios) ou falha em comunicar ou documentar alterações no tratamento (interrupção de uso de medicamento $21,5 \%$, ou omissão de medicamento em uso antes da admissão hospitalar $11,2 \%$ ). Com relação ao impacto no cuidado ao paciente, as falhas apresentaram potencial para causar dano severo $(2 \%)$ ou moderado $(63 \%)$ ao paciente, além de alto (1\%) ou moderado (37\%) potencial para resultar em readmissão hospitalar não planejada. Pacientes com enfermidades crônicas e pacientes apresentando maior número de medicamentos foram identificados como os de maior risco para as falhas detectadas. 
CORRY et al. (2000) verificaram que as informações de cartas hospitalares encaminhadas à equipe da atenção básica são insuficientes para a adequada monitorização da farmacoterapia. Duzentos e vinte e quatro pacientes utilizavam medicamentos que requerem monitorização rigorosa, devido aos riscos associados ao seu uso, entre eles varfarina, digoxina, amiodarona, lítio, ciclosporina, azatioprina e estatinas. O tratamento havia sido iniciado no hospital para 173 destes pacientes. Apenas 30 cartas (17\%) indicavam que havia risco e que deveriam ser rotineiramente monitorizados. A informação sobre a frequência da monitorização estava presente em apenas 14 casos. Na maioria $(74,6 \%)$, não havia indicação se $o$ hospital ou a atenção primária faria a monitorização, e em $12 \%$ dos casos a carta não havia chegado dentro de 14 dias do início do tratamento. Em apenas 8 cartas havia indicação de que o paciente havia sido informado sobre possíveis riscos, e em 9, os pacientes haviam sido orientados sobre a necessidade de monitorização. Os autores sugerem o uso de documento de alta estruturado, com informações suficientes para a monitorização da farmacoterapia.

Independente do formato (resumo de alta, relatório de alta, carta ou cartão), o plano de alta deve ser encaminhado ao profissional de saúde que realizará seguimento do paciente (FOX et al., 2007), por meio de fax, correio eletrônico, entregue pelo próprio paciente, ou compartilhado por sistema eletrônico integrado.

KLÜCK e GUIMARÃES (1999) destacam os benefícios da emissão eletrônica de resumos de alta, quanto à agilização na elaboração e melhoria da qualidade destes documentos, uma vez que é frequente a existência de queixas dos médicos a respeito do excesso de documentos a serem preenchidos. Na experiência de implantação do resumo de alta eletrônico em hospital de ensino brasileiro, relatada pelos autores, os fatores críticos de sucesso identificados foram o apoio decisivo da Administração Central, a condução de caráter acadêmico e sua forma participativa. Além de facilitar o procedimento de alta hospitalar e possibilitar a melhoria da qualidade das 
informações necessárias ao seguimento do paciente, a emissão eletrônica de resumos de alta viabiliza a transferência virtual (e, portanto, imediata) destas informações, integrando os serviços de saúde.

No HU/USP, a substituição do resumo de alta digitado pelo formato eletrônico possibilitaria, no futuro, o compartilhamento do documento entre os serviços de saúde que fazem parte do Projeto Região Oeste.

Ensaio clínico controlado em que os pacientes receberam, além de orientação, um cartão com informações sobre os medicamentos que deveriam utilizar após alta, e foram orientados a mostrá-lo ao farmacêutico comunitário e ao médico da atenção primária, demonstrou que o grupo que recebeu intervenção apresentou melhor conhecimento sobre os medicamentos, maiores taxas de adesão ao tratamento, utilização de menor quantidade de medicamentos de seu estoque domiciliar, menor número de consultas na atenção primária, e menor número de admissões hospitalares (Al-RASHED et al., 2002).

MIDLÖV et al. (2008) demonstraram a importância do resumo de alta para a segurança do paciente. $O$ uso de relato de medicação, parte integrante do resumo de alta, reduziu significativamente o número (em mais de $50 \%$ ) e a gravidade dos erros de medicação. Em outro estudo, BERGKVIST et al. (2009) verificaram que alterações realizadas no resumo de alta, visando melhorar a qualidade do documento, reduziram em $45 \%$ os erros de medicação de pacientes após alta hospitalar. O modelo do documento utilizado no estudo é apresentado no Anexo 8.

Além da realização de transferência de informações acuradas e completas na transição do atendimento, ROMANO (1982) recomenda que a cópia do documento de alta entregue ao paciente contenha esclarecimentos sobre quais circunstâncias o paciente deve contatar um profissional, e para quem ou onde telefonar para esclarecer dúvidas. Embora seja uma recomendação feita há mais de 30 anos, essa não é uma prática corrente em hospitais brasileiros. 
No HU/USP, no momento da alta, não é rotina fornecer informação ao paciente ou cuidador sobre número de telefone e profissional de contato no hospital para esclarecimento de dúvidas ou orientação específica, após retorno ao domícilio, devido à falta de estrutura para realizar este tipo de atendimento, segundo os profissionais entrevistados.

Um número de telefone para contato é fornecido, com orientação para ligar quando necessário, apenas em situações específicas, como tratamento com insulina e, também, no caso de orientação de alta realizada pelo farmacêutico, uma vez que esta informação consta do impresso específico entregue ao final da sessão de orientação.

O número de telefone do HU/USP consta, também, do manual que o paciente recebe quando é hospitalizado. No entanto, são raros os casos de contato telefônico realizado pelo paciente, e ocorrem especialmente com pacientes diabéticos ou devido a dificuldades em encontrar medicamentos prescritos na alta. As ocorrências não são registradas.

POMPEO et al. (2007), em estudo realizado no Brasil junto a pacientes em alta, também verificaram que não há forma de contato rápido com a equipe hospitalar para esclarecimento de dúvidas que ocorrem após retorno ao domicílio.

Com relação às atividades desenvolvidas no HU/USP, verifica-se que várias atividades contribuem para a segurança do processo de uso de medicamentos durante o período de hospitalização, tais como visitas clínicas multiprofissionais, tripla checagem da prescrição, realização de seguimento farmacoterapêutico por farmacêuticos clínicos, além de rotinas específicas relacionadas à dispensação de medicamentos durante o período de hospitalização. Vale destacar que tais atividades não são frequentemente desenvolvidas na maioria dos hospitais brasileiros, conforme contatos na área e pela escassez de estudos realizados no Brasil abordando experiências bem sucedidas. 
No entanto, verifica-se que no HU/USP há limitações com relação ao desenvolvimento, durante a hospitalização, de atividades preconizadas para a promoção da segurança do processo de uso de medicamentos após alta hospitalar.

\subsubsection{O CUIDADO AO PACIENTE APÓS ALTA HOSPITALAR}

Em geral, ao receber alta hospitalar após hospitalização no HU/USP, o paciente é encaminhado para acompanhamento ambulatorial ou domiciliar, realizado pelo próprio hospital ou pela rede pública de saúde, conforme o caso.

\subsubsection{Acompanhamento ambulatorial no HU/USP}

Para acompanhamento ambulatorial no próprio HU/USP geralmente é agendada consulta dentro de sete a dez dias, após alta, para pacientes cirúrgicos, e em até duas ou três semanas para demais pacientes, sendo que pode ser antecipado retorno para um a dois dias após a alta, em casos onde se verifique necessidade de abreviar este intervalo.

Esta agilização, segundo médicos e enfermeiros entrevistados, é facilitada pela peculiaridade do hospital em agendar acompanhamento ambulatorial com o próprio médico (em caso de procedimento cirúrgico) ou equipe que assistiu o paciente durante a hospitalização. Dependendo do caso, o retorno ambulatorial do paciente pode ser agendado para o médico residente, o interno de medicina ou a enfermeira da equipe que acompanhou o paciente na unidade de internação.

A facilidade do agendamento e o conhecimento de detalhes do atendimento realizado durante a hospitalização no HU/USP foram citados 
como fatores que contribuem para o acompanhamento ambulatorial adequado do paciente após alta hospitalar.

Eu diria que a estratégia maior nossa de dar continuidade ao tratamento é o retorno (ambulatorial) mais rápido (M3).

No momento da alta, o agendamento de retorno ambulatorial para acompanhamento com profissional da mesma equipe que realizou o atendimento durante a hospitalização pode fornecer, ao paciente e seus familiares, segurança quanto à continuidade do cuidado. Entretanto, geralmente, o acompanhamento ambulatorial no próprio hospital é realizado apenas em casos selecionados e durante curto período de tempo, sendo posteriormente encaminhados para atendimento ambulatorial em Unidades Básicas de Saúde. A maioria dos pacientes recebe encaminhamento para a rede de atenção básica já no momento da alta hospitalar, não sendo, portanto, acompanhados nos ambulatórios do hospital. O intervalo de tempo entre a alta hospitalar e o acompanhamento na rede é variável, podendo ocorrer descontinuidade do cuidado imediatamente após alta, especialmente para pacientes que residem em áreas não cobertas pela Estratégia Saúde da Família.

Nestas situações de transição do atendimento, onde o paciente fica mais vulnerável a danos, a segurança do paciente pode depender, em parte, da expansão das responsabilidades do hospital por meio do fornecimento de serviços domiciliares, por um período de tempo após alta, para reduzir os riscos de resultados negativos (MAMON, 1992).

4.2.2.2 Seguimento por meio de visita domiciliar - O Programa de Assistência Domiciliária do Hospital Universitário da Universidade de São Paulo (PAD-HU/USP)

Desde o ano de 2000, o hospital mantém o PAD, que presta atendimento ambulatorial no domicílio do paciente. O programa é destinado a pacientes do HU/USP que atendem aos seguintes critérios de 
elegibilidade: não apresentar condições clínicas e de locomoção para se deslocar até o hospital, residir no subdistrito do Butantã, e contar com um cuidador familiar responsável.

Durante os doze anos de existência, o PAD atendeu mais de duas mil pessoas, sendo a maioria de idosos, acamados, com doenças crônicas degenerativas, geralmente com sequelas de Acidente Vascular Cerebral, demenciados por Parkinson, demência vascular ou Alzheimer, além de pacientes com Doença Pulmonar Obstrutiva Crônica, Insuficiência Cardíaca Congestiva, e neoplasias. Atualmente, $10 \%$ dos pacientes atendidos são crianças que, na maioria dos casos, nasceram com alguma doença sindrômica e necessitam de ventilação mecânica, com diagnóstico de neuropatia crônica e doença pulmonar crônica.

Dentro da hierarquização da assistência domiciliar, o PAD realiza atendimento secundário, mais complexo, pois geralmente envolve pacientes em coma, paraplégicos ou tetraplégicos, pacientes com traqueostomia, gastrostomia, úlcera por pressão grave, uso de sondas, entre outras situações. Em geral, o atendimento primário, menos complexo, é realizado pelas Unidades de Saúde da Família (USFs). No entanto, o representante do PAD ressalta que este perfil está mudando, devido ao suporte fornecido pela equipe multiprofissional dos Núcleos de Apoio à Saúde da Família (NASFs), que possibilita atendimento a casos de maior complexidade.

No PAD, há vários subprogramas, como o de oxigenoterapia domiciliar (POD), coleta domiciliar de exames laboratoriais, empréstimo de equipamentos e materiais auxiliares (cama hospitalar, cadeira de rodas, cadeira de banho, etc), fornecimento de materiais de consumo (materiais para curativos, sondas, etc) atendimento à família enlutada (PROAFE), suporte de voluntários às famílias e pacientes (VOPAD). Há, também, o programa de gerenciamento de pacientes crônicos (PROGEC), no qual pacientes relativamente mais estáveis, embora acamados, são monitorados por contato telefônico, além de visitas domiciliares espaçadas, geralmente a 
cada seis meses. Atualmente, dos cem pacientes em atendimento no PAD, vinte e cinco estão no PROGEC.

Um programa de atendimento telefônico 24 horas (ATEPAD) funcionou durante um ano, prestando orientação a partir de um fluxograma de queixas padronizado, como forma de suporte aos pacientes vinculados ao PAD e seus familiares em caso de dúvidas e, também, em situações de estresse frequentemente vivenciadas pelos familiares de pacientes graves. Durante o funcionamento do ATEPAD observou-se redução de $80 \%$ na vinda de pacientes do PAD ao Pronto Socorro, em função das orientações recebidas sobre como proceder e devido ao suporte emocional aos familiares. Também foi observado, neste período, aumento da média de óbito no domicílio de $36 \%$ para $66 \%$, entre os pacientes em fase terminal, com o óbito ocorrendo na própria casa, junto aos familiares e, como ressalta o médico, sem as intervenções desnecessárias nos momentos finais da vida, que geralmente ocorrem quando da procura de atendimento de emergência. Entretanto, apesar destes indicadores, o programa foi desativado devido à dificuldade burocrática de pagamento do serviço prestado, uma vez que o atendimento era feito na forma de plantão à distância, com um celular de referência, fora do horário de funcionamento do PAD no hospital. Atualmente, o paciente ou familiar entra em contato com o PAD e as dúvidas são anotadas pela secretária em livro de recados, para que sejam respondidas posteriormente.

Como estratégia para otimizar o serviço prestado, foi desenvolvido um vídeo que é entregue a cada família de paciente atendido pelo PAD. A elaboração deste manual contou com participação multidisciplinar (médico, enfermeiro, farmacêutico, nutricionista, fonoaudiólogo, fisioterapeuta, terapêuta ocupacional) disponibilizando orientações necessárias ao cuidado do paciente no domicílio. Novos capítulos estão programados para a elaboração de novo vídeo, sobre sonda, ostomia, prevenção de quedas, estresse e depressão, final da vida e luto. 
Além do apoio diário ao cuidador por meio do acolhimento realizado quando do atendimento às chamadas telefônicas, o suporte psíquico é fornecido pelo médico psiquiatra e, quando ocorre óbito do paciente, são realizadas visitas domiciliares aos familiares cuidadores, por meio do PROAFE. Foram relatados casos em que cuidadores familiares foram acompanhados por psicólogos, no PAD, de seis meses a um ano após a morte do paciente. Entretanto, o PAD não conta mais com o serviço de psicologia, que foi muito atuante neste tipo de demanda.

Atualmente, são promovidos encontros semestrais com cuidadores, onde há depoimentos e confraternização. Com relação à capacitação de cuidadores, o PAD oferece um curso de 60 horas, incluindo aulas práticas, para formação de cuidadores informais.

O PAD conta com um médico clínico, três enfermeiras e uma assistente social, como equipe exclusiva do programa. Os outros profissionais que atuam no PAD dividem a carga horária de trabalho entre atividades desenvolvidas em unidades de atendimento do hospital e atividades desenvolvidas no domicílio de pacientes, tais como médico psiquiatra, médico pediatra, fisioterapeuta, fonoaudiólogo, terapeuta ocupacional. Embora psicólogos e farmacêuticos também já tenham atuado dessa forma no PAD, ou inclusive fora do horário de trabalho, atualmente 0 programa não conta com a participação destes profissionais, que voltaram a dedicar-se exclusivamente às atividades de seus setores, em função da demanda de trabalho.

Como destaca o representante do PAD, o retorno financeiro, à instituição, do atendimento domiciliar realizado é muito baixo, em função do valor pago pelo SUS às visitas domiciliares multidisciplinares (cerca de $\mathrm{R} \$ 3,00$ por profissional). Além disso, não há possibilidade de recebimento de recursos provenientes do programa federal de assistência domiciliária Melhor em Casa - uma vez que o convênio é firmado apenas com as prefeituras municipais. 
Pacientes que necessitam de atendimento domiciliar e moram no subdistrito Butantã, mas não apresentam o grau de complexidade dos pacientes atendidos pelo PAD, são encaminhados para atendimento por equipes do Programa Saúde da Família, assim como pacientes que moram em outras regiões da cidade.

Fluxo do atendimento realizado pelo PAD, com foco no processo de uso de medicamentos:

Os pacientes são encaminhados ao PAD pelas equipes das enfermarias, Pronto Socorro e ambulatório do HU/USP. Dentro de cinco dias úteis após alta hospitalar, e geralmente após visita realizada pelo assistente social, é realizada a primeira visita domiciliar multidisciplinar. A periodicidade das visitas depende da avaliação clínica. A necessidade de ajuste de tratamentos específicos, como anticoagulação, diabetes e hipertensão é um dos critérios utilizados para a classificação da periodicidade de visitas, pois o seguimento exigido nestes casos demanda menor intervalo de tempo entre as visitas e maior número de visitas.

Na primeira visita, de posse do resumo de alta e do prontuário, vários aspectos do cuidado ao paciente são avaliados, por todos os componentes da equipe, resultando em ampla gama de informações fornecidas ao paciente e cuidador. Como ressalta o representante do PAD, a situação do processo de uso de medicamentos no domicílio também é verificada, porém sem uma abordagem específica.

Em geral, na primeira visita domiciliar verifica-se a receita de alta e solicita-se que sejam mostrados todos os medicamentos em uso. Um problema frequentemente observado é o armazenamento inadequado dos medicamentos, às vezes em armários de banheiro, ou em caixas, misturados com medicamentos de familiares. São encontrados medicamentos com prazo de validade expirado, e até retirados de blísteres ("para facilitar", segundo os pacientes), portanto, sem possibilidade de 
verificar o prazo de validade, além de mal conservados. Outro problema citado como frequente é a observação de desperdício devido à existência de grandes estoques de medicamentos fornecidos gratuitamente pela rede pública de saúde, e que foram posteriormente suspensos.

O armazenamento inadequado de medicamentos também foi verificado por SCHENKEL et al. (2005), em estudo realizado em 101 residências no sul do Brasil, onde a maior parte dos medicamentos (55\%) não estava sendo utilizada, era armazenada na cozinha (43\%) ou no banheiro (14\%), e estava exposta ao calor e umidade (56\%). Além disso, o prazo de validade foi encontrado em $83 \%$ dos medicamentos, e em $16 \%$ estava expirado.

A constatação, in loco, do problema demonstra a importância da realização de visitas domiciliares, e ressalta a necessidade de orientação ao paciente e seus familiares, numa abordagem de educação em saúde.

Durante $O$ atendimento domiciliar realizado pela equipe do PAD, também é frequente a ocorrência de dúvidas de pacientes e/ou cuidadores sobre a necessidade ou não de continuidade do tratamento que era realizado antes da hospitalização. O médico estima que é questionado sobre o tema por cerca de $50 \%$ dos pacientes, na primeira visita após alta.

(...) na primeira visita você resolve, porque eles perguntam mesmo: "e esses aqui que eu estava tomando?" Aí você tem que ver tudo (M4).

A ocorrência de dúvidas, no domicílio, sobre o tratamento a ser utilizado após alta hospitalar, observada frequentemente nas visitas domiciliares realizadas pelo PAD, confirma dados obtidos em outros estudos. POMPEO et al. (2007), em estudo realizado no Brasil, verificaram que os pacientes estão deixando o hospital com dúvidas, especialmente aquelas relacionadas à prescrição de medicamentos na alta e ao cuidado para reabilitação e independência, em casa. Estudo realizado por MARIN et al. (2010), no interior do Estado de São Paulo, revelou que cerca de $30 \%$ 
dos pacientes idosos tiveram dúvidas ou dificuldades na continuidade dos cuidados após a alta.

KERZMAN et al. (2005), em entrevista com 341 pacientes, 7 a 14 dias após alta hospitalar, verificaram que $73 \%$ conheciam o motivo de uso de novos medicamentos prescritos, $80 \%$ destes informaram a correta indicação. Menos de $20-25 \%$ dos entrevistados tinham algum conhecimento sobre efeitos colaterais, testes necessários para monitorização da farmacoterapia e alterações necessárias no estilo de vida (por exemplo, dieta específica, aumento ou redução da ingestão de líquidos, diminuição da exposição ao sol). Além disso, $60 \%$ dos pacientes relataram não ter recebido nenhuma orientação sobre novos tratamentos prescritos durante a hospitalização. Estes dados reforçam a necessidade de realização de reconciliação medicamentosa na alta e de orientações sobre as alterações realizadas no plano farmacoterapêutico, na alta hospitalar, e sugerem a importância do seguimento domiciliar.

Outra constatação bastante frequente no atendimento domiciliar realizado pela equipe do PAD é a ocorrência de discrepâncias entre a receita de alta e os medicamentos que o paciente realmente está utilizando no domicílio, ou seja, recebimento de tratamento diferente do prescrito, por inclusão ou interrupção de uso de medicamentos por conta própria, necessitando pronta intervenção durante a visita domiciliar.

Acho que metade das vezes está mudado. (...) geralmente, não são coisas muito importantes, mas, às vezes, parou de tomar remédios importantes. Aí você chama a atenção (M4).

Diferenças entre o tratamento prescrito na alta e o tratamento em uso podem ser decorrentes da falta de entendimento do esquema terapêutico, decisão própria do paciente quanto à inclusão de medicamentos por automedicação, exclusão ou alteração na forma de utilizar os medicamentos, inclusive por falta de recursos financeiros (CUA e KRIPALANI, 2008) ou, 
ainda, devido a alterações realizadas por outros médicos, durante atendimento ambulatorial após alta.

SCHNIPPER et al. (2006), em seguimento realizado dentro de 3 a 5 dias após alta de 79 pacientes, verificaram que 12 pacientes não estavam utilizando um dos medicamentos da receita de alta, 11 utilizavam dose ou frequência diferente da prescrita, e dois estavam utilizando medicamentos diferentes de mesma classe terapêutica. Além disso, dois pacientes apresentavam efeitos colaterais, 14 estavam com dificuldades em encontrar os medicamentos prescritos e 9 apresentavam dificuldades com o preço dos medicamentos.

Em estudo realizado por SMITH et al. (1997), em que 53 idosos receberam visita domiciliar 7 a 10 dias após alta, verificou-se que 31 pacientes apresentaram alteração no esquema farmacoterapêutico prescrito na alta hospitalar. A intervenção, após contato com o médico prescritor, possibilitou prevenir 7 readmissões hospitalares.

A ocorrência destes problemas demonstra a importância do seguimento domiciliar e da realização de reconciliação medicamentosa também após alta hospitalar.

Nas visitas domiciliares, o médico do PAD procura orientar o paciente quanto ao tratamento adequado, avaliando as discrepâncias entre o tratamento prescrito e o tratamento em uso, e esclarecendo as dúvidas no momento do atendimento, embora reconheça que não é um procedimento sistematizado, como a reconciliação medicamentosa.

Durante as visitas domiciliares, são feitas orientações pontuais sobre os medicamentos, por médicos ou enfermeiros, e quando se observa que a utilização de medicamentos está confusa são preenchidas planilhas específicas contendo nome do medicamento, dose, e horário de administração. Com relação à abordagem sobre eventos adversos 
relacionados a medicamentos, geralmente, depende da manifestação do paciente, questionando a equipe.

Como ressalta o representante do $\mathrm{PAD}$, não há procedimento sistematizado para $\mathrm{O}$ atendimento do paciente quanto ao uso de medicamentos, e a participação de farmacêutico na visita domiciliar realizada pelo PAD possibilitaria prestar assistência com foco no uso de medicamento, com realização de anamnese farmacológica, orientação detalhada sobre utilização dos medicamentos, e organização dos medicamentos para melhorar a identificação, condições de armazenamento e controle do prazo de validade, conforme observado em trabalho realizado por farmacêuticos, no PAD, durante alguns períodos.

A valorização e o reconhecimento da necessidade de participação de farmacêutico nas visitas domiciliares do PAD-HU/USP se devem, em parte, conforme mencionado, às atividades desenvolvidas anteriormente no programa. TAKAHASHI (2009), em pesquisa realizada durante atuação em visitas domiciliares realizadas junto ao PAD-HU/USP, demonstrou que, além do desenvolvimento de atividades relacionadas ao estoque domiciliar de medicamentos, foi possível identificar situações que requerem pronta intervenção da equipe de saúde: entre os 87 pacientes visitados, $62 \%$ apresentaram pelo menos um resultado negativo relacionado a medicamento. Além de problemas de segurança do tratamento, verificado em $14,8 \%$ dos pacientes, sendo $3,4 \%$ devido à utilização de dose ou frequência superior à indicada, também foram identificadas outras situações, como problema de saúde não tratado $(20,6 \%)$, efeito de medicamento não necessário $(9,1 \%)$ e inefetividade terapêutica $(37,4 \%)$.

\subsubsection{Seguimento domiciliar por contato telefônico}

Com exceção do monitoramento de pacientes crônicos atendidos pelo PAD, e de eventuais contatos telefônicos para seguimento de casos de suspeitas de reações adversas a medicamentos, pela farmacêutica da 
Farmacovigilância, no HU/USP não é realizado seguimento do paciente por contato telefônico, após alta hospitalar.

Ensaio clínico controlado, envolvendo 221 pacientes, avaliou impacto de contato telefônico realizado, por farmacêuticos, dois dias após a alta hospitalar. Durante o contato, os pacientes do grupo sob intervenção foram questionados sobre seus tratamentos, incluindo se tinham conseguido obter todos os medicamentos, se entenderam como tomá-los, se tinham apresentado algum efeito colateral, e se tinham algum questionamento ou preocupação. Quando necessário, o farmacêutico realizou intervenção para corrigir o problema relacionado a medicamento e notificou a equipe do hospital. O prontuário dos pacientes foi analisado quanto a atendimento no serviço de emergência ou readmissão hospitalar em trinta dias após a alta. Cerca de 1 em cada 5 pacientes (19\%) não tinha conseguido obter todos os medicamentos prescritos na alta. Doze pacientes (15\%) relataram novos problemas ou preocupações, tais como rash cutâneo, febre, tontura, vômito, diarreia, constipação, dor abdominal, elevação da pressão arterial e taquicardia, sendo encaminhados à equipe. O seguimento por contato telefônico foi associado com aumento da satisfação do paciente, resolução de problemas relacionados a medicamentos, e menor número de atendimento em serviço de emergência ( $10 \%$ versus $24 \%$ ), em relação ao grupo controle. Além disso, foi observada tendência para redução de readmissão hospitalar (15\% versus $25 \%$ ). Considerando-se o custo do atendimento realizado pelos farmacêuticos e a economia devido à redução dos atendimentos pelo serviço de emergência, houve economia total de aproximadamente 12 mil dólares (DUDAS et. al, 2001).

Estudo de coorte retrospectiva, envolvendo usuários de plano de saúde que receberam alta de um hospital em 2008, foi realizado para avaliar o impacto de intervenção telefônica sobre a readmissão em 30 dias. 0 contato telefônico foi realizado por enfermeira especialmente treinada para verificar se o paciente ou cuidador recebeu orientações na alta hospitalar, se 
não recebeu prescrição de medicamentos duplicados ou contraindicados e se entendeu as próximas etapas a seguir, tais como consulta médica de seguimento, para evitar eventos agudos adicionais ou exacerbações. Pacientes que receberam contato telefônico dentro de 14 dias após alta foram considerados do grupo sob intervenção. Este período foi escolhido porque as primeiras 2 ou 3 semanas após alta são consideradas críticas para prevenção de readmissões. O tempo médio para a realização do contato telefônico foi de 7 dias. A probabilidade de readmissão hospitalar entre os 6773 pacientes que receberam contato telefônico foi $23,1 \%$ menor em relação aos pacientes do grupo controle (HARRISON et al., 2011).

Outros ensaios clínicos controlados demonstraram que a associação de contatos telefônicos após alta a outras estratégias desenvolvidas pela equipe hospitalar, como reconciliação medicamentosa, orientação ao paciente ou visita domiciliar, pode ter reflexos positivos na segurança do paciente após alta hospitalar, tais como redução do número de eventos adversos relacionados a medicamentos e dos atendimentos em serviços de urgência (SCHNIPPER et al., 2006), e redução da taxa de readmissão hospitalar (COLEMAN et al., 2006; HUANG e LIANG, 2005; NAYLOR et al., 1999).

GREENWALD et al. (2007) recomendam a realização de contato telefônico dentro de 2 a 3 dias após a alta, para reforçar o plano de alta e resolver problemas.

NAFFE (2012) recomenda que todos os hospitais adotem a política de seguimento por contato telefônico após alta para pacientes em risco de readmissão.

Com relação ao cuidado ao paciente após alta hospitalar, verifica-se que o PAD-HU/USP demonstra ser um importante serviço de seguimento domiciliar para pacientes críticos, contribuindo para a segurança do processo de uso de medicamentos no domicílio. Entretanto, o atendimento é 
restrito a pacientes com problemas de locomoção e, por isso, não abrange atendimento aos demais pacientes em risco de apresentar eventos adversos relacionados a medicamentos.

Verifica-se, também, a existência de lacunas no cuidado ao paciente após hospitalização, decorrentes da ausência de seguimento telefônico.

\subsubsection{O ACESSO A MEDICAMENTOS PRESCRITOS NA ALTA HOSPITALAR}

No momento da alta, o HU/USP não fornece medicamentos para uso no domicílio. Embora o hospital já tenha fornecido medicamentos anteriormente, especialmente antibióticos, para uso até obtenção na rede pública, essa rotina foi excluída, em função de falta de farmácia ambulatorial, na instituição.

A existência de farmácias ambulatoriais em hospitais possibilita o fornecimento de medicamentos prescritos na alta hospitalar, reduzindo os receios de pacientes e familiares sobre a continuidade do tratamento, e viabiliza o estabelecimento de vínculo do hospital com o paciente, necessário ao acolhimento de dúvidas relacionadas ao tratamento que possam surgir no domicílio.

Ressalte-se que a demora no início do tratamento e a interrupção ou uso irregular de medicamentos podem comprometer o estado de saúde do paciente e gerar agravos que resultem em atendimento ambulatorial ou em serviço de urgência, ou readmissão hospitalar.

BARRETO et al. (2008), analisando a redução da mortalidade no primeiro ano de seguimento de pacientes com insuficiência cardíaca, destacam o fornecimento gratuito dos medicamentos, iniciado na alta hospitalar e prosseguindo-se mensalmente, realizado pela instituição 
estudada, uma vez que, segundo os autores, a principal causa das hospitalizações é o tratamento inadequado, quer por não adesão quer por prescrição não-otimizada.

Após despender esforços para fornecer o tratamento adequado durante a hospitalização (em várias etapas desenvolvidas nos "bastidores"), prescrever medicamentos necessários à continuidade do tratamento e orientar o paciente sobre o uso destes medicamentos, incluindo os riscos associados à falta ou inadequação de sua utilização, a possibilidade de falta de acesso ao medicamento é uma preocupação incorporada à prática diária da equipe de saúde comprometida com a obtenção de resultados farmacoterapêuticos positivos e com a segurança do paciente.

A preocupação quanto ao acesso aos medicamentos prescritos na alta hospitalar foi manifestada frequentemente, neste estudo, e foram descritas várias estratégias para viabilizar a continuidade do tratamento, envolvendo toda a equipe multiprofissional.

4.2.3.1 Acesso aos medicamentos disponibilizados gratuitamente na rede pública de saúde

Essa é uma preocupação frequente, quando da elaboração da receita de alta:

A gente normalmente procura manter a medicação que é disponivel nas UBSs (...) porque não adianta a gente falar que existe uma droga mais moderna se ele não vai comprar. Aqui a disponibilidade é muito maior do que existe na rede básica. Então, para a compensação do paciente foi utilizada uma droga que não estava usando lá, mas na alta procura voltar e adequar àquela que ele vai conseguir (M2).

Em algumas situações, há necessidade de adequação da prescrição, no momento da alta, como, por exemplo, a heparina de baixo peso molecular padronizada na UBS é diferente daquela padronizada no HU/USP. 
Assim, a receita de alta é feita com o nome e a dose preconizada para o medicamento disponibilizado na UBS.

Em função de diferenças entre fármacos selecionados para compor a relação de medicamentos padronizados no HU/USP e a relação de medicamentos da rede básica, farmacêuticos de ambas as equipes mobilizam-se para promover, futuramente, a atuação conjunta das equipes responsáveis pelo processo de seleção de fármacos.

São realizados contatos constantes entre farmacêuticos e assistentes sociais do HU/USP e das UBSs, para confirmar a disponibilidade de medicamentos, devido à desatualização da relação dos medicamentos da rede básica, disponibilizada on line, e devido à possibilidade de desabastecimento temporário, provocando falta de produtos.

Farmacêuticos do HU/USP mantêm estreito contato com o Serviço de Assistência Especializada (SAE) e a Secretaria de Vigilância em Saúde (SVS) para liberação de medicamentos como antirretrovirais, tuberculostáticos, quimioprofilaxia para meningite, entre outros.

Em caso de necessidade de uso de medicamentos injetáveis após alta, o paciente pode dar continuidade ao tratamento em unidades da rede pública de saúde ou no Hospital Dia do HU/USP:

No caso de prescrição de determinados medicamentos injetáveis para uso após alta hospitalar - em particular, heparina de baixo peso molecular, geralmente para prevenção de trombose após cirurgias ortopédicas, e antibiótico de uso hospitalar, para tratamento de osteomielite - as equipes de UBSs ou USFs administram o medicamento durante a semana e, aos finais de semana e feriados, os pacientes são atendidos pelo Hospital Dia do HU/USP.

Nestes casos, o medicamento pode ser fornecido pelas próprias unidades ou, quando não disponível, o HU/USP pode fornecer o 
medicamento para as unidades, para que seja administrado ao paciente. A comunicação entre as equipes de Farmácia do hospital e das unidades ocorre de forma estreita, permitindo o gerenciamento de estoque dos medicamentos, de forma a evitar interrupção do tratamento.

Ao receber alta do HU/USP, o paciente é orientado sobre a administração do medicamento em UBS próxima ao domicílio ou, em caso de necessidade, em sua própria casa, além do acompanhamento do tratamento pelas equipes da atenção primária, uma vez que todas as providências já terão sido tomadas durante a hospitalização, caso a caso.

Além da parceria estabelecida com unidades da região oeste do Município de São Paulo, onde está localizado o HU/USP, o contato também é realizado no caso de pacientes vinculados a unidades de saúde de outras regiões da capital e da região metropolitana.

Quando necessário, o Serviço Social auxilia na identificação e localização da unidade básica de referência, e realiza o primeiro contato, colocando o Serviço de Farmácia em contato com a UBS, seja em bairros da capital ou em outros municípios.

Quando a alta é condicionada à administração do medicamento injetável no Hospital Dia do HU/USP, o Serviço Social é acionado sempre que alguma dificuldade é sinalizada, pelo paciente ou familiar, sobre a ida ao hospital diariamente durante o período de tratamento. Após avaliação, a assistente social apresenta sugestões para resolução do problema, que pode variar desde a definição do acompanhante até o pagamento do transporte, por meio do fornecimento de passes de ônibus, da quota de passes que o hospital fornece mensalmente para o Serviço Social.

Atuação multiprofissional da equipe do HU/USP também ocorre para viabilizar acesso a medicamentos de alto custo distribuídos gratuitamente pelo SUS, para doenças como parkinson, alzheimer, artrite reumatóide, 
asma grave, esclerose múltipla, osteoporose, dislipidemias, hepatite B e C, epilepsia refratária, entre outras:

A farmácia faz o contato, providencia toda a documentação e a gente entra na parte de orientação, como chegar e aonde ir (AS).

Também foi citada atuação do Serviço Social em caso de falta de documento de identificação do paciente, exigido para a liberação destes medicamentos.

(...) pediram um relatório social, justificando, (...) e a gente conseguiu que essa medicação fosse dispensada, assegurando a alta dessa paciente com a medicação (AS).

Quando, durante a internação, ocorre diagnóstico de doenças como tuberculose, HIV, diabetes, hipertensão, a equipe do Serviço Social auxilia no acesso a medicamentos distribuídos gratuitamente em serviços públicos de saúde.

Quando o diagnóstico de tuberculose ocorre durante a hospitalização, a equipe do Serviço Social atua para evitar a interrupção do tratamento.

(...) na alta, a gente sabe da importância e da necessidade de ele tomar a medicação por seis meses, não interromper a medicação porque, senão, a doença volta. A gente vê qual é a UBS mais próxima, faz o contato com a unidade, tenta assegurar essa medicação (AS).

PERRECHI e RIBEIRO (2009) alertam que os pacientes internados por tuberculose devem ser monitorados após alta hospitalar até a sua chegada à UBS, uma vez que podem se considerar curados ao receber alta hospitalar, não dando continuidade ao tratamento.

Em situações específicas, como em casos sociais de não adesão ao tratamento, quando há envolvimento de alcoolismo, o Serviço Social realiza avaliação juntamente com a equipe, podendo sugerir internação em Campos 
do Jordão. ${ }^{13}$ Uma vez aceita a internação pelo paciente, o Serviço Social entra em contato com a central de vagas responsável, encaminha a documentação preenchida pela equipe médica e o relatório social.

A resposta da Central, cedendo a vaga, vem para o Serviço Social, e toda essa alta, roupa, transporte, tudo isso é visto pelo Serviço Social para viabilizar a ida dele para lá, para que a gente tenha certeza de que realmente ele vai fazer esse tratamento (AS).

As assistentes sociais também realizam trabalho de conscientização e sensibilização, junto aos pacientes e familiares, tanto nas enfermarias como no Pronto Socorro, abordando a importância do tratamento para evitar complicações, intercorrências e melhorar a qualidade de vida.

Muitas vezes o diagnóstico acontece na enfermaria. (...) nessa internação é diagnosticado um HIV, um diabetes, uma hipertensão. Então, a gente trabalha muito: "são doenças crônicas que não têm cura, mas que têm tratamento e o Estado disponibiliza o tratamento" (AS).

No Pronto Socorro Infantil tem criança diabética que vem para cá por uma descompensação, criança com epilepsia que vem para cá com convulsão. Então, sempre a gente é acionada para avaliar esses casos e ver até que ponto essa medicação está sendo dada corretamente, no horário, tudo direitinho. Às vezes, deixa acabar a medicação e não providencia. Hoje a gente tem todo um trabalho com essa família (AS).

\subsubsection{Acesso a medicamentos na rede privada}

Frequentemente, na clínica pediátrica, berçário e UTIs neonatal e pediátrica, são prescritos medicamentos que necessitam ser preparados em farmácia de manipulação, devido à indisponibilidade de especialidades farmacêuticas industrializadas em apresentação adequada a pacientes pediátricos.

\footnotetext{
${ }^{13}$ Cidade próxima a São Paulo, onde há hospital de referência para doenças pulmonares, conveniado ao SUS.
} 
Quando prescritos na alta hospitalar, para assegurar que os pacientes receberão os medicamentos no domicílio e possam ser adequadamente orientados sobre sua administração, ainda no hospital, a equipe multidisciplinar é envolvida no processo de aquisição do medicamento. A farmacêutica avalia a estabilidade da formulação, a fim de verificar o volume mais adequado a ser manipulado, considerando a duração do tratamento e o preço por frasco.

De posse da prescrição, a assistente social entra em contato com farmácia de manipulação e solicita orçamento por fax. É feita avaliação sobre as condições financeiras da família em pagar o medicamento manipulado. Caso possua condições, a família realiza o pagamento diretamente ao entregador, que traz o medicamento no próprio hospital. Caso contrário, o Serviço Social realiza o pagamento do medicamento manipulado adquirido.

Nós temos esse corpo de voluntários aqui que tem várias atividades dentro do hospital, e uma delas é um bazar, um brechó que vende coisas usadas que nós ganhamos, recebemos em doação. Com isso, então, a gente consegue ter uma verba para suprir essas necessidades (AS).

A verba arrecadada com o bazar também é utilizada para suprir outras necessidades específicas, como pagamento de taxi para alta ou aquisição de material prescrito na alta, sempre mediante avaliação das condições socioeconômicas da família.

Em outros casos em que haja comprometimento do acesso aos medicamentos prescritos, sejam eles de distribuição gratuita ou não, ocorre intermediação do Serviço Social. Por exemplo, após retorno ao domicílio, em situações onde os medicamentos prescritos não são encontrados para aquisição ou apresentam preço acima das condições financeiras da família, ou estão temporariamente indisponíveis na rede pública, o Serviço Social é procurado pelo paciente ou seus familiares, os quais são encaminhados à 
enfermaria que realizou atendimento, a fim de verificar possibilidade de substituição do medicamento ou outra forma de solucionar o problema.

Com relação ao acesso a medicamentos prescritos na alta hospitalar, verifica-se envolvimento da equipe de saúde do HU/USP, de forma intensiva e integrada. Este envolvimento é justificado por vários estudos realizados no Brasil, que abordam os problemas de acesso aos medicamentos frequentemente associados com dificuldades econômicas do paciente e irregularidade na disponibilização de medicamentos na rede pública de saúde (PANIZ et al. 2008; PERINI, 2009; ÁVILA et al., 2011; LUZ et al., 2009, SANTA-HELENA et al., 2010; ARRAIS et al., 2005).

Estudo realizado na região do Butantã, onde se localiza o HU/USP, além de desvelar sentimentos de impotência e humilhação vivenciados frequentemente por pacientes de baixa renda, pela dependência de terceiros ou necessidade de, muitas vezes, realizar "peregrinação" de UBS em UBS para encontrar o medicamento prescrito, destaca a falta de divulgação sobre como acessar os programas governamentais de distribuição gratuita de medicamentos (BELLO, 2009).

Os resultados destes estudos demonstram a importância do desenvolvimento de estratégias para promover o acesso dos pacientes aos medicamentos prescritos na alta, contribuindo para 0 atendimento humanizado dos pacientes em alta hospitalar. 


\subsection{ARTICULAÇÃO ENTRE O HOSPITAL E DEMAIS SERVIÇOS DE SAÚDE}

O HU/USP é um hospital de média complexidade, porém a clientela atendida apresenta graus variáveis de complexidade, em função de problemas de referência e contrarreferência. Grande parte dos pacientes atendidos no hospital apresenta risco muito baixo e poderia ser atendida em unidades básicas de saúde (UBSs). Por outro lado, há casos de hospitalização de pacientes graves, por dificuldade de encaminhá-los a hospitais de alta complexidade, em função de falta de vagas.

(...) é muito comum, a gente aqui com um caso grave, um caso terciário (M3).

Além disso, muitos pacientes poderiam realizar acompanhamento em UBS imediatamente após alta hospitalar, mas são acompanhados no ambulatório do próprio HU/USP até que seja possível efetivar o encaminhamento de forma segura, para a continuidade do atendimento ao paciente na rede básica de saúde.

Acho que melhorou. Antes a gente nem conseguia fazer algumas devoluções. Antes os pacientes voltavam para cá e a gente assumia isso como um cuidado. Até ele realmente se recuperar, ele ficava no nosso ambulatório e depois ele voltava. Agora não, agora isso está um pouco melhor estruturado, mas ainda não é muito tranquilo. Tem situações que você não consegue (E3).

Não raro, o encaminhamento para atendimento em ambulatórios de especialidades é dificultado pela demora no agendamento de consultas.

(...) precisa de um especialista para daqui um mês, não daqui seis meses. Como é que vai fazer nesse meio do caminho? Essa que é a dificuldade (M3). 
Em geral, verificam-se diferenças entre as UBSs, quanto à receptividade do contato e a agilidade na resolução das questões encaminhadas pela equipe hospitalar.

Depende muito da região que o paciente está, com qual UBS que ele está vinculado. Tem UBS que tem uma resposta muito pronta. Se você liga, passa, solicita, isso a gente sabe que não vai ser um problema. Outras, não. Têm uma dificuldade maior nessa articulação (E3).

Alguns serviços funcionam melhor que outros, (...) alguns ambulatórios de especialidades, algumas UBSs, a gente consegue retorno rápido (E2)

Foram citados casos de pacientes diabéticos que permaneceram hospitalizados apenas porque houve demora no fornecimento, pela UBS, dos aparelhos para monitorização da glicemia capilar.

Teoricamente, as unidades de saúde de menor complexidade deveriam resolver a maior parte dos problemas hoje tratados pelos hospitais universitários, mas, na prática, para parcela significativa da população brasileira, os serviços de emergência continuam sendo a porta de entrada do sistema de saúde (MACHADO e KUCHENBECKER, 2007).

Além disso, o HU/USP também encontra dificuldade de realizar o encaminhamento dos pacientes para unidades de maior ou menor grau de complexidade. Em pesquisa realizada junto a treze equipes da Estratégia Saúde da Família do Sudeste do Brasil sobre acompanhamento de usuários portadores de câncer, cerca de $70 \%$ dos profissionais referiram não ter conhecimento de usuários com contrarreferência, quando o diagnóstico foi realizado em outra unidade de saúde (SIMINO et al., 2010). No estudo realizado por MARIN et al. (2010), apenas $28,4 \%$ dos idosos foram contrarreferenciados para a Unidade de Saúde da Família de origem. Também no tratamento de tuberculose, segundo PERRECHI e RIBEIRO (2009), parece não ocorrer uma perfeita integração entre a rede hospitalar e as UBS que tratam a doença. 
Além de problemas relacionados à referência e contrarreferência, quando o encaminhamento pelo HU/USP é efetivado, na maioria dos casos não há comunicação entre as equipes dos diferentes serviços de saúde, tanto na admissão como na alta hospitalar, exceto pelo formulário de encaminhamento para o SUS e resumo de alta, emitidos pelo hospital.

Em situações muito específicas, ocorre contato telefônico entre equipes do HU/USP e UBSs para troca de informações e articulação para continuidade do atendimento ao paciente. Por exemplo, em casos que envolvem pacientes com problemas sociais graves, que podem apresentar falta de adesão ao tratamento, recidiva de tuberculose, ou quando é verificada a necessidade de materiais específicos para realização de curativos após alta hospitalar.

Quando verificada a necessidade na unidade de internação, este contato ocorre, geralmente, por meio do Serviço Social, tanto para obtenção de informações necessárias ao atendimento durante a hospitalização e ao planejamento da alta, como para articular a continuidade do atendimento, inclusive quanto à possibilidade de acompanhamento por USF, quando indicado. No entanto, ainda são poucos os casos de contato entre os serviços, não sendo rotina diária para a equipe do HU/USP.

Verifica-se que eventual articulação no atendimento ocorre mais por iniciativa das equipes envolvidas que pela existência de um processo estruturado, sistematizado, entre os serviços de saúde de diferentes níveis de complexidade.

Em revisão sistemática da literatura (KRIPALANI et al., 2007b), verificou-se que a comunicação direta entre as equipes hospitalar e de atenção primária não é frequente (3\% a $20 \%)$.

Para KRIPALANI et al. (2007a), a forma unilateral de transferência de informação sobre o paciente, na alta, deveria ser substituída por diálogo entre as equipes hospitalar e da atenção primária, tanto no momento da 
hospitalização como na alta. Uma das estratégias recomendadas é envolver a equipe da atenção primária no processo de planejamento da alta, para a formulação de um plano de seguimento coeso, incluindo planos de contingência (ou seja, o que é mais provável de dar errado e o que deveria ser feito), além de necessidades específicas de seguimento (o que deve ser feito nas primeiras consultas após alta).

BERNARDINO et al. (2010), em estudo realizado em hospital universitário brasileiro, verificaram que a realização de contato telefônico, para transferência de informações para a equipe da unidade de saúde responsável pelo seguimento do paciente após alta, trouxe satisfação ao paciente, ao perceber-se melhor acolhido na unidade de saúde. As autoras sugerem a implantação da função de "enfermeira de ligação", para viabilizar a integração do hospital à rede de serviços de saúde e, assim, promover a continuidade do cuidado ao paciente.

FRATINI et al. (2008) descrevem experiência exitosa de articulação em hospital do sul do país, onde pacientes foram encaminhados às unidades de atenção básica, mediante contato prévio realizado pelo coordenador do programa de altas especiais ou pela assistente social. Cópias de informações detalhadas sobre a situação do paciente e suas necessidades, contendo telefone de contato da instituição, foram fornecidas ao usuário e à unidade de saúde, que se comprometia a dar seqüência ao tratamento, na própria unidade ou em domicílio. A parceria incluiu, ainda, o acompanhamento pela equipe multidisciplinar hospitalar no caso de necessidades especiais, como cuidados fisioterápicos e o fornecimento de antibioticoterapia injetável. Nos casos mais críticos, a equipe hospitalar realizou contato telefônico no $3^{\circ}$ dia após a alta para se certificar de que o tratamento estava sendo realizado. Entre os resultados positivos, verificouse humanização do atendimento, com a manutenção do vínculo entre paciente, família e sistema de saúde; redução do tempo de internação e de 
exposição às complicações daí decorrentes; maior disponibilização de leitos e diminuição dos custos do atendimento.

Destacam-se, nos dois estudos realizados no Brasil, a preocupação e importância de designar um profissional para coordenar o processo de alta, realizando a "ponte" necessária entre o hospital e o serviço de saúde que dará continuidade ao atendimento ao paciente, visando à integralidade do cuidado.

No que se refere à articulação entre as equipes de farmacêuticos do HU/USP e de outros serviços de saúde, eventualmente ocorre troca de informações, na admissão hospitalar, sobre o uso de medicamentos pelos pacientes. Por outro lado, para o Serviço de Farmácia há resultados significativos quanto ao estabelecimento de parcerias entre o hospital e demais serviços da rede pública de saúde para o fornecimento de medicamentos, visando à continuidade do tratamento após alta hospitalar.

Segundo o representante do PAD, existe articulação entre as equipes de atendimento domiciliar da região do subdistrito do Butantã e, além do PAD-HU/USP, há diversos serviços públicos que prestam assistência domiciliar, como USFs com suporte de Núcleos de Apoio à Saúde da Família (NASFs); a Unidade de Atendimento Domiciliar (UAD) da prefeitura; e a Atenção Primária Domiciliar (APD) do Centro de Saúde-Escola Samuel Pessoa, ligado à Faculdade de Medicina da USP. Quanto ao programa federal recém-lançado, Melhor em Casa, ainda não há conhecimento, pelo PAD, sobre sua implantação na região.

Até alguns anos atrás, além dos pacientes atendidos pelo HU/USP, o PAD recebia encaminhamentos das UBSs. Entretanto, com o surgimento da $U A D$, estes pacientes não foram mais encaminhados ao PAD.

A articulação entre a equipe do PAD e as equipes dos demais serviços de atendimento domiciliar foi citada tanto com relação ao encaminhamento de pacientes atendidos no HU/USP como em 
intermediação para agendamento de consultas ou fornecimento de medicamentos.

O processo de uso de medicamentos após alta hospitalar, com foco na segurança do paciente, é complexo e envolve múltiplas ações, além de atuação interdisciplinar e interinstitucional. A articulação entre os serviços de saúde pode possibilitar o desenvolvimento de uma linha de cuidado para a segurança do paciente no processo de uso de medicamentos, contribuindo para a integralidade do cuidado.

Verifica-se que, especificamente com relação ao processo de uso de medicamentos após alta hospitalar, foram demonstradas iniciativas de articulação entre o HU/USP e outros serviços de saúde quanto ao acesso a medicamentos prescritos na alta. Entretanto, não há relatos de atuação conjunta na interface do atendimento, para a promoção do uso seguro de medicamentos no domicílio. 


\subsection{FATORES FACILITADORES E BARREIRAS PARA IMPLANTAÇÃO E DESENVOLVIMENTO DAS ESTRATÉGIAS E PARA ARTICULAÇÃO ENTRE OS SERVIÇOS}

\section{FATORES FACILITADORES}

Com relação às atividades atualmente desenvolvidas no hospital, quanto ao cuidado ao paciente em alta hospitalar com foco no processo de uso de medicamentos, nas entrevistas foram apontados como facilitadores vários aspectos relacionados à equipe hospitalar, tais como iniciativa, comprometimento, responsabilidade por resultados e qualificação.

A gente entende que não dá para você só dispensar medicamento e o paciente não saber utilizar. Então acho que tem esse comprometimento mesmo da equipe em resolver o problema, e a gente se sente como responsável por este paciente (F1).

O 'staff' da enfermaria, a chefia da enfermaria e as pessoas que trabalham lá têm esse envolvimento de uma maneira muito forte (M3).

A atuação multiprofissional, que ocorre em todas as unidades de internação, foi bastante valorizada nas entrevistas e, especificamente na clínica pediátrica, a integração entre os componentes da equipe multiprofissional foi destacada como facilitador.

O que facilita acho que é a integração que já existe dos profissionais com os seus pares, (...) com a equipe multiprofissional. A gente se sente bem trabalhando com 0 pessoal, se sente acolhido, respeitado (F3). 
Com relação às atividades que ainda devem ser desenvolvidas, o apoio da alta administração à Gerência de Risco e a priorização da questão da segurança no uso de medicamentos na instituição foram citados como fatores facilitadores.

Um ponto muito positivo é que existe uma preocupação do hospital, tanto que foi criada a comissão, pela própria superintendência, para gerenciamento de risco, e os profissionais que compõem entenderam que medicamentos é um item que nós demos prioridade, que nós entendemos que precisa haver uma melhora, precisa aumentar a segurança (E3).

Quanto aos facilitadores para a articulação entre o hospital e demais serviços de saúde, verifica-se articulação facilitada com unidades básicas de saúde (UBSs) e unidades de saúde da família (USFs) onde os médicos residentes do HU/USP ou acadêmicos dos cursos da área de saúde desenvolvem atividades, como parte de programas de residência ou estágios.

(...) se aluno passa ali no estágio de rede básica e depois ele vem para cá, e volta, sempre tem esse ciclo, (...) facilita aproximação. (...) as universidades, neste sentido, favorecem um pouco essa articulação (E3).

Também há grande expectativa, neste sentido, em função do início de desenvolvimento de atividades em UBSs pelos farmacêuticos residentes.

A "ponte" entre os serviços é observada não somente durante o desenvolvimento das atividades acadêmicas propiciadas pelo vínculo com a universidade. A articulação também é facilitada com profissionais da rede básica que já fizeram parte dos programas de residência ou estágios no HU/USP, além de profissionais de UBSs ou USFs que também trabalham, ou trabalharam, no HU/USP.

(...) tem farmacêuticos, nestas unidades (UBSs), que foram nossos alunos, então (...) obter informações é mais fácil, e integrar também. (...) tem projetos da faculdade nestes locais $(F 1)$. 
Eu já fui orientador de residente do PSF, então eu sei que em determinado posto tem um chefe que eu conheço. Então quando é um paciente, por exemplo, com tuberculose, (...) é uma recidiva, precisaria ter uma atenção especial, aí a gente liga e fala: "olha, este paciente está saindo de alta hoje e eu gostaria que vocês fossem fazer a visita domiciliar" (M2).

\section{BARREIRAS}

Algumas dificuldades relacionadas às atividades atualmente desenvolvidas foram apontadas como barreiras para o desenvolvimento de atividades relacionadas ao cuidado ao paciente em alta hospitalar:

- Falha na comunicação da equipe médica, com antecedência, sobre quais medicamentos os pacientes deverão fazer uso no domicílio é uma das dificuldades encontradas por enfermeiros e farmacêuticos para realizar orientação mais detalhada durante o período de hospitalização, para melhor assimilação de conteúdos pelos pacientes e cuidadores.

- A dinâmica da rotina de alta, que é iniciada pela manhã e termina à tarde, gera acúmulo de altas no período da tarde, dificultando a organização e realização das atividades relacionadas à alta, tanto para a equipe de enfermagem como para a equipe de farmácia. Ressaltou-se que essa situação pode inviabilizar ou comprometer a qualidade do serviço prestado, uma vez que, além do pouco tempo disponível ao final do dia, existe a pressão de familiares e pacientes que querem ser liberados para ir para casa, e a pressão da urgência de liberação da vaga para possibilitar a admissão de paciente proveniente do Pronto Socorro.

- A ausência de prontuário eletrônico e de prescrição eletrônica é considerada importante barreira para a implantação e desenvolvimento de atividades relacionadas ao cuidado ao paciente em alta hospitalar, 
pois dificulta a otimização do tempo utilizado na execução de tarefas rotineiras e o compartilhamento, entre as equipes, de informações sobre o atendimento ao paciente, comprometendo também a articulação entre os serviços de saúde.

A necessidade de ampliação do quadro de profissionais foi a barreira mais apontada, e de mais difícil transposição, para a ampliação/implantação de atividades:

- A ampliação da atuação de enfermeiros no cuidado ao paciente em alta hospitalar requer ampliação do quadro de funcionários, especialmente para seguimento após alta, por meio de contato telefônico ou visita domiciliar. Por outro lado, há reconhecimento de que o planejamento de alta para todos os pacientes possibilitaria reorganização de rotinas de atendimento nas unidades, e, mesmo com o quadro atual de enfermeiros, viabilizaria a inclusão de algumas atividades, tais como atuação na reconciliação medicamentosa na alta e ampliação da orientação aos pacientes e/ou cuidadores durante a hospitalização.

- Embora o início do programa de residência em Farmácia tenha contribuído com a expansão da atuação em algumas atividades, o número reduzido do quadro de farmacêuticos é considerado a principal barreira à ampliação de sua participação em atividades diversas, tais como realização de entrevista na admissão hospitalar; orientação a pacientes e cuidadores em todas as unidades de internação, durante a hospitalização e no momento da alta; e realização de reconciliação medicamentosa. Embora existam procedimentos padronizados e farmacêuticos treinados para realizar orientação ao paciente em alta hospitalar, não há número de farmacêuticos suficiente para o desenvolvimento da atividade em todas as unidades de internação.

- Ampliação do quadro de profissionais também é considerada barreira para disponibilização de farmacêuticos para atuação junto ao PAD, e 
para realização de seguimento de pacientes em risco de apresentar eventos adversos relacionados a medicamentos após alta hospitalar, por meio de contato telefônico ou visita domiciliar.

- A necessidade de ampliação de recursos humanos é apontada, também, por médicos, como barreira para a realização de seguimento domiciliar do paciente, seja por meio de contato telefônico ou por visita domiciliar. Um grupo de trabalho da clínica pediátrica realiza, eventualmente, visitas domiciliares, especialmente a pacientes crônicos com hospitalizações frequentes. Entretanto, não é realizado seguimento domiciliar sistemático destes pacientes, após alta, por falta de pessoal. Pelo mesmo motivo, não é possível ampliar a participação de médicos pediatras em visitas domiciliares junto ao PAD.

- A necessidade de contratação de recursos humanos para proporcionar ampliação de categorias profissionais na equipe fixa, já é uma realidade vivenciada pelo $P A D$, independente de implantação de novas atividades.

- A realização de visitas domiciliares a pacientes sem restrição de locomoção, após alta hospitalar, é percebida pelo PAD como atribuição das Unidades de Saúde da Família, embora haja reconhecimento de que a maior parte da população da região não está coberta pela Estratégia Saúde da Família.

- Quanto à implantação, pelo PAD, de atendimento telefônico a pacientes que não apresentem restrições de locomoção, foi citada como barreira a falta de conhecimento das informações sobre o paciente, a intercorrência que resultou na internação e o atendimento realizado durante a hospitalização, especialmente pela falta de prontuário eletrônico. 
A falta de tempo e a necessidade de ampliação do quadro de funcionários para realização/ampliação de atividades relacionadas ao cuidado do paciente em alta hospitalar ficam evidentes nas falas da equipe:

A gente vem 'brigando' pela implantação de 'tablets', para otimizar o tempo, para tentar ganhar mais tempo nessa rotina, para ver se a gente consegue fazer mais coisas durante o turno da manhã (F2).

A maioria das altas ocorre à tarde e só tem dois farmacêuticos clínicos (F3).

Eu não tenho hoje, por mais que eu queira e saiba que é importante, como tirar uma enfermeira da assistência para que ela vá à casa do paciente (...), porque senão ela vai deixar de assistir alguém que está aqui dentro (E3).

O próprio sistema de ligar parece que é mais simples, porque consigo, por exemplo, atender uma quantidade maior de pessoas do que se tivesse que ir à casa. Mas, mesmo assim, se tirar uma enfermeira agora para que ela faça ligação (...) ela também vai descumprir alguma atividade para algum dos pacientes que estão internados (E3).

Sem dúvida, se nós tivéssemos um 'fôlego' para ligar para todo mundo, para ver se está usando o medicamento corretamente, se está tendo alguma dúvida no pós-alta imediato, ajudaria muito. (..) como a gente tem o dia corrido dentro da enfermaria, eu não sei como isso seria possível (M2).

(visita domiciliar) nós temos uma limitação muito grande, a gente não tem horário de médico para fazer tudo isso (M3).

Com relação à articulação entre o hospital e demais serviços de saúde, a barreira mais frequentemente citada foi falta de contato entre as equipes, pelo entendimento de que o isolamento de cada equipe em sua unidade de atendimento resulta na falta de conhecimento da estrutura, do fluxo de trabalho, da complexidade, das dificuldades vivenciadas no dia a dia, enfim, da realidade do outro.

Eu acho que as pessoas que atuam nessas outras unidades têm pouco contato com as pessoas que atuam no hospital (...). 
Não se conversa, não tem reuniões, nada. É só o paciente que vai lá, e vem cá, mas não tem nenhum vínculo entre as pessoas (M1).

Os profissionais trabalham lá e aqui, nenhum daqui vai lá para ver e nenhum de lá vem aqui para ver como que é (M2).

Se a gente pudesse ter o telefone da UBS (...) para falar com o médico daquela região... seria excelente para você passar o caso. Mas o negócio é escrito, entendeu? Então, pode se perder e a gente não tem esse retorno (M2).

Isso pode melhorar, acho que deveria ter reuniões sistemáticas, em que um encontrasse o outro, um conhecesse melhor a realidade do outro, que eu soubesse... esse paciente é de tal região, então ele vai voltar para essa UBS, a enfermeira é tal, então eu vou ter contato com ela, vou dizer o que aconteceu na internação, acho que seria perfeito (E3).

Barreiras para a implantação e desenvolvimento de atividades relacionadas ao cuidado ao paciente em alta hospitalar foram apontadas por estudos realizados em outros países (PEDERSEN et al., 2007; SPINEWINE et al., 2006; GRIFFITH et al., 1998; BARNSTEINER, 2008; ASHP, 2005; ALIBHAl et al., 1999) e incluem: falta de apoio da alta administração, inadequação da equipe (quantitativa ou falta de treinamento específico), falta de programa sistematizado, falta de notificação prévia sobre o plano de alta, falta de tempo dos profissionais, necessidade de uso de tecnologias da informação de forma integrada.

Embora a maioria das barreiras citadas nos estudos seja semelhante às barreiras citadas nesta pesquisa, no HU/USP não houve referência à falta de apoio da alta administração para a implantação de estratégias relacionadas à segurança do paciente. Pelo contrário, o apoio foi citado como fator facilitador. Este apoio é imprescindível, tanto pelo incentivo à equipe para o desenvolvimento de práticas seguras, como pelo comprometimento da organização em garantir recursos humanos, materiais, de informação, e instrumentos normativos, necessários ao desenvolvimento de processos adequados e, consequentemente, para obtenção dos resultados desejados com relação à segurança do paciente. Para SAMMER 
et al. (2010), o engajamento da liderança é um elemento crítico para o sucesso do desenvolvimento da cultura de segurança em uma organização.

A transposição da barreira relacionada à ampliação de recursos humanos requer que o tema seja trabalhado junto ao Governo do Estado, por meio de argumentação técnica, a partir de levantamento das necessidades dos serviços e dos benefícios gerados pela implantação/ampliação das atividades relacionadas ao cuidado ao paciente em alta hospitalar. Vale ressaltar que os benefícios podem ser relacionados ao paciente (redução de sofrimento ao evitar a ocorrência de eventos adversos), ao hospital (redução de despesas associadas à readmissão hospitalar e atendimentos de emergência), e às equipes de saúde (satisfação com a assistência prestada), conforme demonstrado ao longo deste trabalho, em vários estudos.

Com relação às tecnologias de informação, o uso de várias intervenções envolvendo sistemas de informação tem demonstrado redução de erros de medicação, tais como prescrição eletrônica, sistemas informatizados de suporte à decisão clínica, código de barras, entre outros (BATES, 2000). Enquanto no Brasil tais recursos estão indisponíveis para a maioria dos hospitais, em alguns países a prescrição eletrônica e o prontuário eletrônico, entre outros, são recursos utilizados já há alguns anos para o desenvolvimento de estratégias voltadas à segurança do paciente (PEDERSEN et al., 2007). Além destas, soluções mais sofisticadas têm sido desenvolvidas e as tecnologias de informação têm contribuído no cuidado ao paciente em alta de várias formas: produção automática de relatos de alta a partir de informações já disponíveis no sistema, substituindo a transcrição da informação por meio de digitação e, consequentemente, evitando falhas no processo; produção automática de materiais informativos contendo planos de alta personalizados (brochuras) para uso pelo paciente, e disponibilização de "enfermeira virtual" para orientação personalizada ao paciente no momento da alta (JACK e BICKMORE, 2010/2011). 
Os recursos da tecnologia de informação, nos dias de hoje, são uma importante ferramenta para o compartilhamento intra e interinstitucional de informações sobre o paciente, possibilitando a continuidade informacional (CUNHA e GIOVANELLA, 2011). O estabelecimento de um banco de dados para uso comum é considerado um dos principais passos para a continuidade do atendimento no manejo de medicamentos, no sentido de garantir a efetiva comunicação entre profissionais e serviços que atendem ao paciente (ASHP, 2005).

Vale ressaltar que, embora tais sistemas integrados facilitem 0 desenvolvimento das atividades, sua ausência não deve representar barreira para a integração da informação entre os serviços, já que a troca de informações pode ser realizada por contato telefônico, como já ocorre em situações eventuais, entre profissionais do HU/USP e outros serviços de saúde, além do encaminhamento de resumo de alta contendo as informações necessárias à continuidade do tratamento. BATES (2000) ressalta que as tecnologias de informação não são uma panaceia e que seu uso deve permitir às pessoas fazer o que elas fazem melhor, como tomar decisões complexas e comunicarem-se umas com as outras.

Embora não confiram poder de decisão à equipe hospitalar sobre barreiras estruturais, as quais dependem da alta administração, os fatores facilitadores relacionados à equipe de saúde (iniciativa, comprometimento, responsabilidade por resultados e qualificação) são essenciais tanto para a identificação das barreiras estruturais na instituição como para a transposição das barreiras relacionadas ao processo de alta, citadas pelos entrevistados. A atuação interdisciplinar na identificação de pontos críticos do processo de alta e na análise de indicadores, em curso na instituição, é essencial para o sucesso de futuras iniciativas relacionadas ao cuidado ao paciente em alta hospitalar, na instituição.

Devido a necessidades adicionais de infraestrutura, parece remota a possibilidade de ampliação da clientela atendida pelo PAD-HU/USP, sendo 
recomendável a busca de outros mecanismos para a implantação de seguimento domiciliar, com foco no processo de uso de medicamentos, bem como a integração do atendimento hospitalar ao seguimento realizado pelas USFs, para o desenvolvimento de transição efetiva e segura do cuidado após alta hospitalar.

Com relação à articulação entre o hospital e os demais serviços de saúde, as "pontes" resultantes das atividades acadêmicas e profissionais apontam para um possível mecanismo de transposição das barreiras que determinam a fragmentação e isolamento do atendimento, visando à aproximação dos profissionais, de forma a possibilitar a integração das equipes no processo de alta hospitalar. Por outro lado, a articulação depende, também, da receptividade da iniciativa e da disponibilização da infraestrutura necessária, pelos demais serviços de saúde. SAITO (2010), em estudo realizado na zona leste de São Paulo, destaca a falta de avanço na estruturação de rede de serviços para atendimento às demandas de saúde nos diferentes níveis de atenção. Aponta, entre outros problemas, insuficiência de recursos humanos, despreparo dos profissionais para atividades que exigem qualificação específica, e dificuldades operacionais dos sistemas de informação.

Embora não tenha sido elencada como barreira, a fala de um dos entrevistados demonstra uma barreira potencial e pode traduzir a importância da discussão sobre o tema desta pesquisa para o desenvolvimento de estratégias voltadas à segurança do paciente:

Essa preocupação que você está trazendo, talvez não esteja na cabeça das pessoas. Nunca vi alguém aqui no hospital levantar a questão da preocupação na segurança da alta. Então, como nunca se preocupou, não se criou também. Precisa haver o interesse ou a preocupação. Não é porque ninguém queira fazer, acho que é porque desconhece e não sabe da importância (M2). 
Conchusões 
Com base nas informações fornecidas pela equipe de saúde do Hospital Universitário da Universidade de São Paulo, entre as atividades desenvolvidas, relacionadas à segurança do paciente após hospitalização, com foco no processo de uso de medicamentos, destaca-se a orientação de alta ao paciente e/ou cuidador, realizada de forma diferenciada, em casos selecionados, principalmente na Pediatria e Berçário.

A reconciliação medicamentosa, em fase de implantação, e a mobilização da equipe multidisciplinar para viabilizar o acesso a medicamentos prescritos na alta, em casos específicos, completam o quadro de atividades desenvolvidas durante o período de hospitalização, visando contribuir com a segurança do paciente após alta hospitalar.

A visita domiciliar após alta hospitalar apresenta limitações, quanto ao enfoque desta pesquisa, pois é desenvolvida apenas junto a pacientes críticos com problemas de locomoção, e ocorre sem a participação de farmacêuticos.

Com relação à articulação entre o hospital e outros serviços de saúde, com foco no uso de medicamentos, ocorre eventualmente, e em geral é restrita à viabilização de acesso aos medicamentos prescritos na alta, não abrangendo iniciativas de integração para transferência de informações acuradas e completas para a continuidade do tratamento, nem para o seguimento do paciente.

Assim, os principais desafios identificados para a melhoria do cuidado ao paciente hospitalizado no HU/USP, com foco na segurança do processo de uso de medicamentos após alta hospitalar são:

- Desenvolvimento de reconciliação medicamentosa na admissão hospitalar, e implantação de reconciliação na transferência do paciente entre setores e na alta hospitalar;

- Ampliação da orientação de alta realizada por farmacêuticos, na rotina diária; 
- Realização de sessões de orientação ao paciente e/ou cuidador, durante o período de hospitalização, além das orientações pontuais fornecidas pela equipe multidisciplinar;

- Fornecimento de medicamentos prescritos na alta;

- Realização de seguimento telefônico e visitas domiciliares a pacientes selecionados em função do risco de apresentar eventos adversos relacionados a medicamentos após alta hospitalar, com participação de farmacêuticos;

- Desenvolvimento de atividades integradas com as equipes da atenção básica, para evitar descontinuidade do cuidado em relação ao tratamento, na transição do atendimento.

A falta de recursos humanos e de tecnologias de informação e a necessidade de alterações no procedimento de alta são percebidas como as principais barreiras para implantação, desenvolvimento e ampliação de atividades consideradas estratégicas para a segurança do paciente após alta hospitalar. Por outro lado, características da equipe hospitalar e apoio da alta administração são considerados fatores facilitadores à implantação e desenvolvimento destas estratégias.

Enquanto a falta de contato entre as equipes é considerada a principal barreira para a articulação do hospital e demais serviços de saúde, o desenvolvimento de atividades acadêmicas junto à atenção básica facilita o estabelecimento de "pontes" entre os serviços, demonstrando o potencial de êxito do uso deste facilitador em iniciativas de integração entre as equipes para o cuidado ao paciente em alta hospitalar.

A condição de hospital de ensino e o desenvolvimento da cultura de segurança podem ter contribuído para a atuação da equipe na implantação e desenvolvimento de atividades relacionadas à segurança do paciente, com foco no processo de uso de medicamentos. 
Portanto, os resultados demonstram que a segurança do paciente no processo de uso de medicamentos após alta hospitalar faz parte da agenda do HU/USP, sendo desenvolvidas algumas estratégias pela equipe hospitalar, porém, ainda, com limitações e sem a articulação adequada com demais serviços de saúde. Dessa forma, pode haver comprometimento da segurança do paciente, após alta hospitalar, o que sugere a necessidade de concentração de esforços para transpor as barreiras identificadas, visando contribuir para a segurança do paciente na interface entre hospital, atenção básica e domicílio. 
Considerações finais 
O presente estudo destaca a importância e os desafios da atuação profissional para a segurança do paciente no processo de uso de medicamentos após alta hospitalar, e apresenta possibilidades de aprofundamento da temática em pesquisas futuras, que emergiram das limitações do estudo realizado e das reflexões sobre as informações coletadas na pesquisa de campo e nos estudos publicados.

A obtenção de relatos de participantes de diferentes categorias profissionais atuantes nas mesmas unidades de internação possibilitou a confirmação, esclarecimento e complementação de informações referentes à descrição de rotinas desenvolvidas na instituição. No entanto, na prática diária, procedimentos podem, eventualmente, ser realizados de forma incompleta ou diferente da padronizada, como pode ser observado em algumas situações descritas neste estudo. Dessa forma, visualiza-se a importância da realização de estudos por meio de observação sistemática das práticas desenvolvidas na instituição, possibilitando o conhecimento aprofundado da dinâmica do processo analisado.

A realização de entrevistas com profissionais que realizam supervisão de atividades desenvolvidas em todas as unidades de internação possibilitou a confirmação sobre a uniformidade dos procedimentos padronizados em unidades cujos profissionais não participaram deste estudo, tais como ginecologia, obstetrícia e berçário. Por outro lado, não foram coletadas opiniões dos profissionais que atuam nestas unidades sobre barreiras e fatores facilitadores para implantação e desenvolvimento das estratégias e para articulação entre o hospital e demais serviços de saúde. Estudos adicionais incluindo estes setores podem ampliar as informações sobre os desafios vivenciados pela equipe hospitalar.

A realização de estudos por meio de entrevistas com pacientes durante a hospitalização e no domicílio pode fornecer subsídios importantes para a compreensão do problema e para a realização de melhorias no processo. 
Estudos envolvendo levantamento e análise do atendimento a pacientes que apresentaram eventos adversos relacionados ao uso de medicamentos após hospitalização na própria instituição podem auxiliar no planejamento de estratégias a serem desenvolvidas.

A despeito das limitações, este trabalho permitiu identificar estratégias, barreiras e fatores facilitadores relacionados à segurança do paciente após alta hospitalar, cuja abordagem pode ser útil a outras instituições, respeitadas as especificidades de cada caso. 
Referências 
AGUIAR, G.; SILVA JÚNIOR, L. A.; FERREIRA, M. A. M. llegibilidade e ausência de informação nas prescrições médicas: fatores de risco relacionados a erros de medicação. Revista Brasileira de Promoção à Saúde, v. 19, n. 2, p. 84-91, 2006.

ALIBHAI, S. M. H.; HAN, R. K.; NAGLIE, G. Medication education of acutely hospitalized older patients. Journal of General Internal Medicine, v. 14, p. 610-616, 1999.

AL-RASHED, S. A. et al. The value of impatient pharmaceutical counseling to elderly patients prior to discharge. British Journal of Clinical Pharmacology, v. 54, p. 657-664, 2002.

ANACletO, T. A. et al. Erros de medicação. Pharmacia Brasileira, Brasília, Janeiro/Fevereiro, 2010. Suplemento, 24 p.

ANDREAZZA, R. S. et al. Causes of drug-related problems in the emergency room of a hospital in southern Brazil. Gaceta Sanitaria, v. 25, n.6, p. 501-506, 2011.

APhA - ASHP. American Pharmacists Association - American Society of Health-System Pharmacists. Improving care transitions: optimizing medication reconciliation. Executive Summary, 2012. 20 p.

ARRAIS, P. S. D. et al. Prevalência e fatores determinantes do consumo de medicamentos no Município de Fortaleza, Ceará, Brasil. Cadernos de Saúde Pública, Rio de Janeiro, v. 21, n. 6, p. 1737-1746, 2005.

ASHP. American Society of Health-System Pharmacists. ASHP guidelines for providing pediatric pharmaceutical service in organized health care systems. American Journal of Health-System Pharmacy, v. 51, p. 16901692, 1994.

ASHP. American Society of Health-System Pharmacists. ASHP guidelines on pharmacist-conducted patient education and counseling. American Journal of Health-System Pharmacy, v. 54, p. 431-434, 1997.

ASHP. American Society of Health-System Pharmacists. Continuity of care in medication management: review of issues and considerations for pharmacy. American Journal of Health-System Pharmacy, v. 62, p. 17141720, 2005.

ASHP. American Society of Hospital Pharmacists. ASHP guidelines on preventing medication errors in hospitals. American Journal of Hospital Pharmacy, v. 50, p. 305-14, 1993. 
ÁVILA, C. W. et al. Adesão farmacológica ao anticoagulante oral e os fatores que influenciam na estabilidade do índice de normatização internacional. Revista Latino-Americana de Enfermagem, Ribeirão Preto, v. 19, n. 1 , 2011. Disponível em: <http://www.eerp.usp.br/rlae>. Acesso em: 08 maio 2012.

BARBOSA, M. S. S.; MAFFEI, F. H. A.; MARIN, M. J. S. Avaliação das orientações pós alta de pacientes em uso de anticoagulante oral. Revista Nursing, v. 10, n. 113, p.471-477, 2007.

BARNSTEINER, J. H. Medication Reconciliation. In: Patient safety and quality: an evidence-based handbook for nurses. Rockville: Agency for Healthcare Research and Quality. Hugues RG (ed.), 2008. Disponível em: <http://www.ahrq.gov/qual/nurseshdbk/docs/BarnsteinerJ_MR.pdf>. Acesso em: 20 nov 2012.

BARNSTEINER, J. H. Medication reconciliation: transfer of medication information across settings - keeping it free from error. American Journal of Nursing, p. 31-36, 2005. Supplement.

BARRETO, L. C. L. et al. Percepções dos profissionais de uma unidade de internação pediátrica sobre a alta de crianças ostomizadas. Revista Gaúcha de Enfermagem, Porto Alegre, v. 29, n. 3, p. 438-445, 2008.

BARRETTO, A. C. P. et al. Re-hospitalizações e morte por insuficiência cardíaca: índices ainda alarmantes. Arquivos Brasileiros de Cardiologia, v. 91, n. 5 , p. $335-341,2008$.

BARROS, J. A. C. Pensando o processo saúde doença: a que responde o modelo biomédico? Saúde e Sociedade, v.11, n.1, p.67-84, 2002.

BATTES, D. W. Using information technology to reduce rates of medication errors in hospitals. British Medical Journal, v. 320, p.788-791, 2000.

BAYLEY, K. B. et al. Evaluation of patient care interventions and recommendations by a transitional care pharmacist. Therapeutics and Clinical Risk Management, v. 3, n. 4, p. 695-703, 2007.

BECK, U. Sociedade de risco: rumo a uma outra modernidade, São Paulo: Ed. 34, 2011.

BELL, C. M. et al. Association of ICU or hospital admission with unintentional discontinuation of medications for chronic diseases. Journal of the American Medical Association, v. 306, n. 8, p. 840-847, 2011.

BELLO, C. B. Acesso a medicamentos: experiência da população de baixa renda na região do Butantã, município de São Paulo, 2009. 2009. 130 p. 
Tese (Doutorado em Saúde Pública) - Faculdade de Saúde Pública, Universidade de São Paulo, São Paulo.

BERGKVIST, A. et al. Improved quality in the hospital discharge summary reduces medication errors-LIMM: Landskrona Integrated Medicines Management. European Journal of Clinical Pharmacology, v. 65, p. 1037-1046, 2009.

BERNARDINO, E. et al. Enfermeira de ligação: uma estratégia de integração em rede. Revista Brasileira de Enfermagem, Brasília, v.63, n.3, p. 459463, 2010.

BERTOLDI, A. D. et al. Utilização de medicamentos em adultos: prevalência e determinantes individuais. Revista de Saúde Pública, São Paulo, v. 38, n.2, p. 228-238, 2004.

BISOGNANO, M.; BOUTWELL, A. Improving transitions to reduce readmissions. Frontiers of Healthcare Services Management, v. 25, 2009. Disponível em: <http://www.ache.org/pdf/secure/gifts/July10-frontiers.pdf>. Acesso em: 20 nov 2011.

BOOCKVAR, K. et al. Adverse events due to discontinuations in drug use and dose changes in patients transferred between acute and long-term care facilities. Archives of Internal Medicine, v. 164, p. 545-550, 2004.

BRASIL. Portaria Interministerial MEC/MS nº 2.400 de 02/10/2007. Estabelece os requisitos para certificação de unidades hospitalares como Hospitais de Ensino, 2007. Diário Oficial da União, Brasília, DF.

BRASIL. Anvisa. RDC n 2, de 25 de Janeiro de 2010. Dispõe sobre o gerenciamento de tecnologias em saúde em estabelecimentos de saúde, 2010. Diário Oficial da União, Brasília, DF.

BRASIL. Portaria MS/GM no 675 de 30 de março de 2006. Aprova a Carta dos Direitos dos Usuários da Saúde. Diário Oficial da União, Brasília, DF.

BROWN, P. et al. Cost of medical injury in New Zealand: a retrospective cohort study. Journal of the Health Services Research \& Policy, v.7, n.1, p. 29-34, 2002.

BUDNITZ, D. S. et al. National surveillance of Emergency Department visits for outpatient adverse drug events. Journal of the American Medical Association, v. 296, p. 1858-1866, 2006.

CALABRESE, A. T. et al. Pharmacist involvement in a multidisciplinary inpatient medication education program. American Journal of HealthSystem Pharmacy, v. 60, p. 1012-1018, 2003. 
CAMPOS, C. E. A. O desafio da integralidade segundo as perspectivas da vigilância da saúde e da saúde da família. Ciência \& Saúde Coletiva, v. 8 , n. 2, p. 569-584, 2003.

CAMPOS, G. W. S.; DOMITTI, A.C. Apoio matricial e equipe de referência: uma metodologia para gestão do trabalho interdisciplinar em saúde.

Cadernos de Saúde Pública, Rio de Janeiro, v. 23, n. 2, p. 399-407, 2007.

CANO, F. G; ROZENFELD, S. Adverse drug events in hospitals: a systematic review. Cadernos de Saúde Pública, Rio de Janeiro, v. 25, p. S360-S372, 2009. Suplemento 3.

CAPUCHO, H. C. Atividade de Farmacovigilância: fundamentos práticos para a obtenção das informações, realização da investigação e tomada de decisões. In: CAPUCHO, H. C.; CARVALHO, F. D.; CASSIANI, S. H. B. (Org.) Farmacovigilância: gerenciamento de riscos da terapia medicamentosa para a segurança do paciente. São Caetano do Sul: Yendis Editora, 2011. p. 127-148.

CAPUCHO, H. C. Sistemas manuscrito e informatizado de notificação voluntária de incidentes como base para a cultura de segurança. 2012. 155 f. Tese (Doutorado) - Escola de Enfermagem de Ribeirão Preto, Universidade de São Paulo, Ribeirão Preto.

CARDOZO-GONZALES, R. I.; VILLA, T. C. S.; CALIRI, M. H. L. O processo da assistência ao paciente com lesão medular: gerenciamento de caso como estrategia de organização da alta hospitalar. Medicina, Ribeirão Preto, v. 34, p. 325-333, 2001.

CASSIANI, S. H. B.; FREIRE, C. C.; GIMENES, F. R. E. A prescrição médica eletrônica em um hospital universitário: falhas de redação e opiniões de usuários. Revista da Escola de Enfermagem da USP, São Paulo, v. 37, n. 4, p. 51-60, 2003.

CASSIANI, S. H. B. (Org.). Os eventos adversos relacionados aos medicamentos: um problema global e nacional. In: Hospitais e medicamentos: impacto na segurança dos pacientes. São Caetano do Sul: Yendis Editora, 2010a. p. 21-34.

CASSIANI, S. H. B. (Org.). Gerenciamento de riscos e comitês de segurança do paciente. In: Hospitais e medicamentos: impacto na segurança dos pacientes. São Caetano do Sul: Yendis Editora, 2010b. p. 95-122.

CECILIO, L. C. O.; MERHY, E. E. A integralidade do cuidado como eixo da gestão hospitalar, 2003. Disponível em: <http://www.uff.br/saudecoletiva/professores/merhy/capitulos-07.pdf>. Acesso em 10 nov 2011. 
CESAR, A. M.; SANTOS, B. R. L. Percepção de cuidadores familiares sobre um programa de alta hospitalar. Revista Brasileira de Enfermagem, Brasília, v. 58, n. 6, p. 647-652, 2005.

CHEN, D.; BURNS, A. Summary and Recommendations of ASHP-APhA Medication Reconciliation Initiative Workgroup Meeting, 2007.

Disponível em:

$<$ http://www.ashp.org/s_ashp/docs/files/MedRec_ASHP_APhA_Wkgrp_MtgS ummary.pdf>. Acesso em 03 ago 2012.

CLASSEN, D. C; METZGER, J. Improving medication safety: the measurement conundrum and where to start. International Journal for Quality in Health Care. v. 15, p. i41-i47, 2003. Supplement 1.

COLEMAN, E. A. et al. The care transitions intervention: results of a randomized controlled trial. Archives of Internal Medicine, v. 166, p. 18221828, 2006.

COLEMAN, E. A.; BERENSON, R. A. Lost in transition: challenges and opportunities for improving the quality of transitional care. Annals of Internal Medicine, v.140, p. 533-536, 2004.

CORNISH, P. L. et al. Unintended medication discrepancies at the time of hospital admission. Archives of Internal Medicine, v.165, p. 424-429, 2005.

CORRY, M. et al. Hospitals do not inform GPs about medication that should be monitored. Family Practice, v. 17, p. 268-271, 2000.

CRESTANA, G. B.; SILVA, J. H. Fármacos residuais: panorama de um cenário negligenciado. Revista Internacional de Direito e Cidadania, n. 9, p. 55-65, 2011.

CUA, Y. M.; KRIPALANI, S. Medication use in the transition from hospital to home. Annals of Academy of Medicine Singapore, v. 37, p. 136-141, 2008.

CUNHA, E. M.; GIOVANELLA, L. Longitudinalidade/continuidade do cuidado: identificando dimensões e variáveis para a avaliação da Atenção Primária no contexto do sistema público de saúde brasileiro. Ciência \& Saúde Coletiva, v.16, p. 1029-1042, 2011. Suplemento 1.

DONIHI, A.C. et al. Scheduling of pharmacist-provided medication education for hospitalized patients. Hospital Pharmacy. v. 43, n. 2, p. 121-126, 2008.

DUDAS, V. et al. The impact of follow-up telephone calls to patients after hospitalization. The American Journal of Medicine, v.111, n. 9B, p. 26S30S, 2001. 
ETCHELLS, E. Admitting medication errors: five critical concepts. Quality and Safety in Health Care, v.19, n. 5, p. 369-370, 2010.

FERNER R. E.; ARONSON J. K. Clarification of terminology in medication errors definitions and classification. Drug Safety, v. 29, n. 11, p. 1011-1022, 2006.

FITZGERALD, R. J. Medication errors: the importance of an accurate drug history. British Journal of Clinical Pharmacology, v. 67, n. 6, p. 671-675, 2009.

FOSTER, A. J. et al. Adverse drug events occurring following hospital discharge. Journal of General Internal Medicine, v. 20, p. 317-323, 2005.

FOSTER, A. J. et al. Adverse events among medical patients after discharge from hospital. Canadian Medical Association Journal. v. 170, n. 3, p. 345349, 2004.

FOSTER, A. J. et al. The incidence and severity of adverse events affecting patients after discharge from the hospital. Annals of Internal Medicine, v. 138, p. 161-167, 2003.

FOX, K.; GRAY, C.; RECK, J. Improving medication management: a review of the evidence. Augusta, ME: Maine Health Access Foundation, 2007. Disponível em:

<https://webapp.usm.maine.edu/MuskieWebDBfrontend/publicationView.acti on;jsessionid=BEEC6531676152E0CEFE794A58A10963? publicationld=498 9>. Acesso em 20 out 2012.

FRANCO, T. B.; MAGALHÃES JÚNIOR, H.M. Integralidade na assistência à saúde: a organização das linhas do cuidado, 2004. Disponível em: <http://www.hc.ufmg.br/gids/anexos/integralidade_assistencia_saude.pdf>. Acesso em 20 nov 2012.

FRATINI, J. R. G.; SAUPE, R.; MASSAROLI, A. Referência e contra referência: contribuição para a integralidade em saúde. Ciência, Cuidado e Saúde, Maringá, v. 7, n.1, p. 065-072, 2008.

GEBHART, F. Setting up a medication reconciliation system. Drug Topics, 2005. Disponível em:

$<$ http://drugtopics.modernmedicine.com/drugtopics/article/articleDetail.jsp?id =143478>. Acesso em 09 jun 2012.

GANZELLA, M.; ZAGO, M. M. F. A alta hospitalar na avaliação de pacientes e cuidadores: uma revisão integrativa da literatura. Acta Paulista de Enfermagem, São Paulo, v. 21, n. 2, p. 351-355, 2008. 
GEMELLI, L. M. G.; ZAGO, M. M. F. A interpretação do cuidado com o ostomizado na visão do enfermeiro: um estudo de caso. Revista LatinoAmericana de Enfermagem, v. 10, n. 1, p. 34-40, 2002.

GIL, A. C. Métodos e técnicas de pesquisa social. São Paulo: Atlas, 2007.

GIOVANELLA, L. et al. Saúde da família: limites e possibilidades para uma abordagem integral de atenção primária à saúde no Brasil. Ciência \& Saúde Coletiva, v.14, n.3, p.783-794, 2009.

GIZZI, L. A. et al. Assessment of a safety enhancement to the hospital medication reconciliation process for elderly patients. The American Journal of Geriatric Pharmacotherapy, v. 8, p. 127-135, 2010.

GLANZNER, C. H.; ZINI, L. W.; LAUTERT, L. Programa de atendimento de enfermagem na admissão hospitalar. Revista Gaúcha de Enfermagem, v. 27, n. 1, p. 92-99, 2006.

GLEASON, K. M. et al. Reconciliation of discrepancies in medication histories and admission orders of newly hospitalized patients. American Journal of Health-System Pharmacy, v. 61, p. 1689-1695, 2004.

GLEASON, K. M. et al. Results of the Medications At Transitions and Clinical Handoffs (MATCH) Study: an analysis of medication reconciliation errors and risk factors at hospital admission. Journal of General Internal Medicine, v. 25, n. 5, p. 441- 447, 2010.

GLINTBORG, B; ANDERSEN, S. E.; DALHOFF, K. Insufficient communication about medication use at the interface between hospital and primary care. Quality and Safety Health Care, v.16, p.34-39, 2007.

GOUVÊA, C. S. D. Desenvolvimento de indicadores de segurança do paciente para hospitais de pacientes agudos. 2011. $270 \mathrm{f}$. Tese (Doutorado em Ciências) - Escola Nacional de Saúde Pública Sergio Arouca, Rio de Janeiro.

GREENWALD, J. L.; DENHAM, C. R.; JACK, B. W. The hospital discharge: a review of a high risk care transition with highlights of a reengineered discharge process. Journal of Patient Safety, v. 3, n. 2, p. 97-106, 2007.

GRIMES T. C. et al. Medication details documented on hospital discharge: cross-sectional observational study of factors associated with medication non-reconciliation. British Journal of Clinical Pharmacology, v. 7, n. 3, p. 449-457, 2011.

GRIFFITH, N. L.; SCHOMMER, J. C.; WIRSCHING, R. G. Survey of inpatient counseling by hospital pharmacists. American Journal of Health-System Pharmacy, v. 55, p. 1127-1133, 1998. 
GUALTERO S. M. Pollution prevention measures for unwanted pharmaceuticals. Industrial Ecology, p. 01-23, 2005.

HARRISON, P. L. et al. The impact of postdischarge telephonic follow-up on hospital readmissions. Population Health Management, v. 14, n. 1, p. $27-$ 32, 2011.

HELLSTRÖM, L. M. et al. Errors in medication history at hospital admission: prevalence and predicting factors. BioMed Central Clinical Pharmacology, v.12, n. 9, p. 01-09, 2012.

HOONHOUT, L. H. F. et al. Direct medical costs of adverse events in Dutch hospitals. BioMed Central Health Services Research, v. 9, 2009.

Disponível em: <http://www.biomedcentral.com/1472-6963/9/27>. Acesso em 20 nov 2011.

HUANG, T-T.; LIANG, S-H. A randomized clinical trial of the effectiveness of a discharge planning intervention in hospitalized elders with hip fracture due falling. Journal of Clinical Nursing. v. 14, p. 1193-1201, 2005.

HUGHES, R. G.; ORTIZ, E. Medication errors: why they happen, and how they can be prevented. American Journal of Nursing, p. 14-24, 2005. Supplement.

IMS HEALTH. Pharmaceutical Market Brazil. Cham, Suiza, 2011.

ISMP. Institute for Safe Medication Practices. Medication reconciliation in the hospital and beyond. ISMP Canada Safety Bulletin, v. 6, n. 3, p. 1-3, 2006.

JACK, B.; BICKMORE, T. The re-engineered hospital discharge program to decrease rehospitalization. Care Management, p.12-15, Dec 2010/Jan 2011.

KABOLI, P.J. et al. Clinical pharmacists and inpatient medical care - a systematic review. Archives of Internal Medicine v.166, p. 955-963, 2006.

KERZMAN, H.; BARON-EPEL, O.; TOREN, O. What do discharged patients know about their medication? Patient Education and Counseling, v. 56, p. 276-282, 2005.

KLÜCK, M. M.; GUIMARÃES, J. R. Sumário eletrônico de alta: garantindo a continuidade da assistência ao paciente através da informação. Informática Pública, Belo Horizonte, p. 123-137, 1999. Disponível em:

<http://www.ip.pbh.gov.br/ANO1_N2_PDF/ip0102kluck.pdf>. Acesso em: 03 nov 2012.

KOHN, L. T.; CORRIGAN, J. M., DONALDSON, M. S. To err is human: building a safer health system. Washington: National Academy Press, 2000. 
KONGKAEW, C; NOYCE, P. R; ASHCROFF, D. M. Hospital admissions associated with adverse drug reactions: a systematic review of prospective observational studies. The Annals of Pharmacotherapy, v. 42, n. 7/8, p.1017-1025, 2008.

KRIPALANI, S. et al. Promoting effective transitions of care at hospital discharge: a review of key issues for hospitalists. Journal of Hospital Medicine. v. 2, n. 5, p. 314-322, 2007a.

KRIPALANI, S. et al. Deficits in communication and information transfer between hospital-based and primary care physicians implications for patient safety and continuity of care. Journal of the American Medical

Association, v. 297, p. 831-841, 2007b.

LAPORTE, J-R. TOGNONI, G. Epidemiologia do medicamento: princípios gerais. São Paulo: Hucitec/Abrasco, 1989.

LEFÈVRE, F. A oferta e a procura de saúde através do medicamento: proposta de um campo de pesquisa. Revista de Saúde Pública, São Paulo, v. 21, p. 64-67, 1987.

LEWIS, P. J. et al. Prevalence, incidence and nature of prescribing errors in hospital inpatients: a systematic review. Drug Safety, v. 32, n. 5, p. 379-389, 2009.

LIEBER, R. R.; ROMANO-LIEBER, N. S. O conceito de risco: Janus reinventado. In: MINAYO, M. C. S.; MIRANDA, A. C. Saúde e ambiente: Estreitando nós. Rio de Janeiro: Ed. Fiocruz, 2002. p. 69-112.

LUZ, T. C. B.; LOYOLA FILHO, A. I.; LIMA-COSTA, M. F. Estudo de base populacional da subutilização de medicamentos por motivos financeiros entre idosos na Região Metropolitana de Belo Horizonte, Minas Gerais, Brasil. Cadernos Saúde Pública, Rio de Janeiro, v. 25, n. 7, p.1578-1586, 2009.

MACHADO, S. P.; KUCHENBECKER, R. Desafios e perspectivas futuras dos hospitais universitários no Brasil. Ciência \& Saúde Coletiva, v.12, n.4, p. 871-877, 2007.

MALTA, D. C.; MERHY, E. E. O percurso da linha do cuidado sob a perspectiva das doenças crônicas não transmissíveis. Interface -

Comunicação, Saúde, Educação, Botucatu, v.14, n. 34, p.593-605, 2010.

MAMON, J. et al. Impact of hospital discharge planning on meeting patient needs after returning home. Health Services Research, v. 27, n. 2, p. 155174, 1992. 
MARIN, M. J. S. et al. Características sócio-demográficas do atendimento ao idoso após alta hospitalar na Estratégia da Saúde. Revista da Escola de Enfermagem da USP, São Paulo, v. 44, n. 4, p. 962-968, 2010.

MARQUES, L. F. G. Farmacovigilância Hospitalar: uma pesquisa sobre programas desenvolvidos em hospitais universitários. 2002. 29p. Monografia de conclusão de curso (Especialização em Farmacologia) - Universidade Estadual de Maringá, Maringá.

MARQUES, L. F. G.; ROMANO-LIEBER, N. S. Tendências da produção científica brasileira sobre segurança do paciente em alta hospitalar. In: IV Fórum Internacional sobre Segurança do Paciente, 2012, Belo Horizonte. Anais. Belo Horizonte: ISMP Brasil, 2012. p. 120.

MARRA, C. C. et al. Orientação planejada de enfermagem na alta hospitalar. Acta Paulista de Enfermagem, São Paulo, v. 2, n. 4, p. 123-127, 1989.

MARTINS, M. et al. Hospital deaths and adverse events in Brazil. BioMed Central Health Services Research, v. 11, 2011. Disponível em: <http://www.biomedcentral.com/1472-6963/11/223>. Acesso em: 20 nov 2011.

MENDES, W. et al. Revisão dos estudos de avaliação da ocorrência de eventos adversos em hospitais. Revista Brasileira de Epidemiology, v. 8, n. 4, p. 393-406, 2005.

MENDES, W. et al. The assessment of adverse events in hospitals in Brazil. International Journal for Quality in Health Care, v. 21, n. 4, p. 279-284, 2009.

MEREDITH, P. A. Generic drugs: therapeutic equivalence. Drug Safety, v.15, n. 4 p. 233-242, 1996.

MEYER, C. et al. How reliable are patient-completed medication reconciliation forms compared with pharmacy lists? American Journal of Emergency Medicine, v. 30, n. 7, p. 1048-1054, 2011.

MIASSO, A. I.; CASSIANI, S. H. D. B. Administração de medicamentos: orientação final de enfermagem para alta hospitalar. Revista da Escola de Enfermagem da USP. São Paulo, v. 39, n. 2, p. 136-144, 2005.

MIASSO, A. I. Erros de prescrição em hospitais brasileiros: um estudo exploratório multicêntrico. Cadernos de Saúde Pública, Rio de Janeiro, v. 25, n. 2, p. 313-320, 2009.

MIDLÖV, P. et al. Medication report reduces number of medication errors when elderly patients are discharged from hospital. Pharmacy World \&Science. v. 30, p. 92-98, 2008. 
MINAYO, M. C. S. O desafio do conhecimento. Pesquisa qualitativa em saúde. São Paulo: Hucitec, 2007.

MINISTÉRIO DA SAÚDE. Assessoria de Comunicação. Melhor em Casa leva atenção à casa do brasileiro. Disponível em:

http://portalsaude.saude.gov.br/portalsaude/noticia/3061/162/melhor-emcasa-leva-atencao-a-casa-do-brasileiro.html . Acesso em: 03 nov 2011.

MISTIAEN, P.; FRANCKE, A. L.; POOT, E. Interventions aimed at reducing problems in adult patients discharged from hospital to home: a systematic meta-review. BioMed Central Health Services Research, v.7, 2007. Disponível em:

< http://www.biomedcentral.com/1472-6963/7/47. Acesso em: 18 nov 2012.

MORIEL, M. C. et al. Prospective study on conciliation of medication in orthopaedic patients. Farmacia Hospitalaria. v. 32, n. 2, p. 65-70, 2008.

MORO, E.L.S. et al. Projeto Cor@gem: o acesso e o uso das TICs entre pacientes hospitalizados e a interação entre ambientes virtuais de aprendizagem. Inclusão Social, v. 2, n. 2, p. 130-141, 2007.

MUELLER, S. K. et al. Hospital-based medication reconciliation practices: a systematic review. Archives of Internal Medicine. Eletronico 2012.

Disponível em: <http://archinte.jamanetwork.com>. Acesso em 26 jun 2012.

NAFFE, A. Post discharge follow up phone call. Heart \& Lung, v. 41, p. 102, 2012. Carta.

NAIR, K. et al. What patients want to know about their medications: focus group study of patient and clinician perspectives. Canadian Family Physician, v. 48, p. 104-110, 2002.

NAPOLEÃO, A. A.; CALDATO, V. G.; PETRILLI FILHO, J. F. Diagnósticos de enfermagem para o planejamento da alta de homens prostatectomizados: um estudo preliminar. Revista Eletrônica de Enfermagem, Goiania, v. 11, n. 2, p. 286-294, 2009. Disponível em:

<http://www.fen.ufg.br/revista/v11/n2/v11n2a08.htm>. Acesso em: 30 out 2012.

NAVARRO, M. B. M. A; CARDOSO, T. A. O. Percepção de risco e cognição: reflexão sobre a sociedade de risco. Ciência \& Cognição, v. 6, p.67-72, 2005.

NAYLOR, M. D. et al. Comprehensive discharge planning and home followup of hospitalized elders: a randomized clinical trial. Journal of the

American Medical Association. v. 281, n. 7, p. 613-620, 1999. 
NOBLAT, A. C. B. et al. Prevalência de admissão hospitalar por reação adversa a medicamentos em Salvador, BA. Revista da Associação Médica Brasileira, São Paulo, v. 57, n.1, p. 42-45, 2011.

NORMAN, A. H; TESSER, C. D. Prevenção quaternária na atenção primária à saúde: uma necessidade do Sistema Único de Saúde. Cadernos de Saúde Pública, Rio de Janeiro, v. 25, n. 9, p. 2012-2020, 2009.

O'HAGAN, J. et al. Self-reported medical errors in seven countries: implications for Canada. Healthcare Quaterly, v. 12, p. 55-61, 2009.

OMS. Organização Mundial da Saúde. A importância da farmacovigilância. Monitorização da segurança dos medicamentos. Brasília: OPAS/OMS; 2005. 48p.

PANIZ, V. M. V. et al. Acesso a medicamentos de uso contínuo em adultos e idosos nas regiões Sul e Nordeste do Brasil. Cadernos de Saúde Pública, Rio de Janeiro, v. 24, n. 2, p. 267-280, 2008.

PEDERSEN, C. A.; SCHNEIDER, P. J.; SCHECKELHOFF, D. J. ASHP national survey of pharmacy practice in hospital settings: monitoring and patient education - 2006. American Journal of Health-System Pharmacy, v. 64 , p. 507-520, 2007.

PEREIRA, A. P. S. et al. Alta hospitalar: visão de um grupo de enfermeiras. R Enferm UERJ. v. 15, n. 1, p. 40-45, 2007.

PERINI, E. P. Acesso a medicamentos. In: BRASIL. Ministério da Saúde. Pesquisa Nacional de Demografia e Saúde da Criança e da Mulher PNDS 2006: Dimensões do processo reprodutivo e da Saúde da Criança. Brasília: Ministério da Saúde, 2009. p. 280-295.

PERRECHI, M. C. T.; RIBEIRO, S. A. Tratamento de tuberculose: integração entre assistência hospitalar e rede básica na cidade de São Paulo. Jornal Brasileiro de Pneumologia, v. 35, n. 11, p. 1100-1106, 2009.

PFAFFENBACH, G.; CARVALHO, O. M.; BERGSTEN-MENDES, G. Reações adversas a medicamentos como determinantes da admissão hospitalar. Revista da Associação Médica Brasileira, São Paulo, v. 48, n. 3, p. 237-241, 2002.

PIPPINS, J.R. et al. Classifying and predicting errors of inpatient medication reconciliation. Journal of General Internal Medicine, v. 23, n. 9, p. 14141419, 2008.

PIRMOHAMED, M. et al. Adverse drug reactions as cause of admission to hospital: prospective analysis of 18820 patients. British Medical Journal, v. 329, p.15-19, 2004. 
POMPEO, D. A. et al. Atuação do enfermeiro na alta hospitalar: reflexões a partir dos relatos de pacientes. Acta Paulista de Enfermagem, São Paulo, v. 20, n. 3, p. 345-350, 2007.

PORTO, S. et al. A magnitude financeira dos eventos adversos em hospitais no Brasil. Revista Portuguesa Saúde Pública, v. 10, p. 74-80, 2010.

PROVONOST, P. et al. Implementing and validating a comprehensive unitbased safety program. Journal of Patient Safety, v. 1, p. 33-40, 2005.

PRONOVOST, P.; SEXTON, B. Assessing safety culture: guidelines and recommendations. Quality and Safety in Health Care, v. 14, p. 231-233, 2005.

RAHMAN, S. et al. Pharmacoenvironmentology - a component of pharmacovigilance. Environmental Health. v. 6, p. 20-22, 2007.

RANTUCCI, M. J. Pharmacists talking with patients: a guide to patient counseling. $2^{\text {nd }}$ ed. Baltimore: Lippincott Williams \& Wilkins, 2007.

RATLIFF, B. W. Leaving the hospital: discharge planning for total patient care. Springfield: Charles C. Thomas, 1981.

REEDER, T. A.; MUTNICK, A. Pharmacist-versus physician-obtained medication histories. American Journal of Health-System Pharmacy, $v$. 65 , p. 857-860, 2008.

RICCI, M. C. S. Atenção farmacêutica em pediatria. In: STORPIRTIS, S. et al. Farmácia Clínica e Atenção Farmacêutica. Rio de Janeiro: Guanabara Koogan, p. 377-393, 2008.

RIGOBELLO, M. C. G. et al. Clima de segurança do paciente: percepção dos profissionais de enfermagem. Acta Paulista de Enfermagem, São Paulo, v. 25, n. 5, p. 728-735, 2012.

RODEHAVER, C.; FEARING, D. Medication reconciliation in acute care: ensuring an accurate drug regimen on admission and discharge. The Joint Commission Journal on Quality and Patient Safety, v. 31, n. 7, p. 406413, 2005.

ROGERS, G. et al. Reconciling medications at admission: safe practice recommendations and implementation strategies. Journal on Quality and Patient Safety, v. 32, n. 1, p. 37-50, 2006.

ROMANO, C. A. Computerized multidisciplinary discharge care planning. Proceedings of the Annual Symposium Computer Application in Medical Care, v. 2, p. 587-589, 1982. 
ROSA, M. B. et al. Erros na prescrição hospitalar de medicamentos potencialmente perigosos. Revista de Saúde Pública, São Paulo, v. 43, n. 3, p.490-498, 2009.

ROTTA, C. S. G. Utilização de indicadores de desempenho hospitalar como instrumento gerencial. 2004. 134 p. Tese (Doutorado em Saúde Pública) - Faculdade de Saúde Pública, Universidade de São Paulo, São Paulo.

ROZENFELD, S. Agravos provocados por medicamentos em hospitais do Estado do Rio de Janeiro, Brasil. Revista de Saúde Pública, São Paulo, p. $1-8,2007$.

ROZENFELD, S. Prevalência, fatores associados e mau uso de medicamentos entre os idosos: uma revisão. Cadernos de Saúde Pública, Rio de janeiro, v.19, n. 3, p. 717-724, 2003.

RUNCIMAN, W. et al. Towards an international classification for patient safety: key concepts and terms. International Journal for Quality in Health Care, v. 21, n. 1, p. 18-26, 2009.

SÁ, M. B.; BARROS, J. A. C.; SÁ, M. P. B. O. Automedicação em idosos na cidade de Salgueiro-PE. Revista Brasileira de Epidemiologia, São Paulo, v.10, n.1, p. 75-85, 2007.

SAITO, R. X. S. Integralidade na perspectiva da integração dos serviços para a formação de redes de atenção: estudo de caso em uma região de saúde do município de São Paulo, Brasil. 2010. 119 p. Tese (Doutorado em Ciências) - Escola de Enfermagem, Universidade de São Paulo, São Paulo.

SAMMER, C. E. et al. What is patient safety culture? a review of the literature. Journal of Nursing Scholarship, v. 42, n. 2, 156-165, 2010.

SANTA-HELENA, E. T.; NEMES M. I. B.; ELUF NETO, J. Fatores associados a não-adesão ao tratamento com anti-hipertensivos em pessoas atendidas em unidades de saúde da família. Cadernos de Saúde Pública, Rio de Janeiro, v. 26, n. 12, p. 2389-2398, 2010.

SCHENKEL, E. P.; FERNÁNDES, L. C.; MENGUE, S. S. Como são armazenados os medicamentos nos domicílios? Acta Farmaceutica Bonaerense, v. 24, n. 2, p. 266-270, 2005.

SCHNIPPER, J. L. et al. Role of pharmacist counseling in preventing adverse drug events after hospitalization. Archives of Internal Medicine, v. 166, p. 565-571, 2006.

SERRA, C. G.; RODRIGUES, P. H. A. Avaliação da referência e contrarreferência no Programa Saúde da Família na Região Metropolitana 
do Rio de Janeiro (RJ, Brasil). Ciência \& Saúde Coletiva, v.15, Supl. 3, p. 3579-3586, 2010.

SILVA, A. E. B. C. et al. Problemas na comunicação: uma possível causa de erros de medicação. Acta Paulista de Enfermagem, São Paulo, v. 20, n. 3 , p. 272-276, 2007.

SILVA, I. J. et al. Cuidado, autocuidado e cuidado de si: uma compreensão paradigmática para o cuidado da enfermagem. Revista da Escola de Enfermagem da USP, São Paulo, v. 43, n. 3, p. 697-703, 2009.

SILVA, I. M. et al. Automedicação na adolescência: um desafio para a educação em saúde. Ciência \& Saúde Coletiva, Rio de janeiro, v. 16, Supl.1, p. 1651-1660, 2011.

SILVA, L. M. G. Breve reflexão sobre autocuidado no planejamento de alta hospitalar pós transplante de medula óssea (TMO): relato de caso. Revista Latino-Americana de Enfermagem, Ribeirão Preto, v. 9, n. 4, p. 75-82, 2001.

SILVA, M. J. P.; GRAZIANO, K. U. A abordagem psico-social na assistência ao adulto hospitalizado. Revista da Escola de Enfermagem da USP, v. 30, n. 2, p. 291-296, 1996.

SILVA, R. C.; RUIZ, T. Os pacientes infartados seguem as recomendações e prescrições no momento da alta hospitalar? Jornal Brasileiro de Medicina, v. 91 , n. 4, p. 49-54, 2006.

SILVA, T.; SCHENKEL, E. P.; MENGUE, S. S. Nível de informação a respeito de medicamentos prescritos a pacientes ambulatoriais de hospital universitário. Cadernos de Saúde Pública, v. 16, n. 2, p. 449-455, 2000.

SIMINO, G. P. R.; SANTOS, C. B.; MISHIMA, S. M. Acompanhamento de usuários, portadores de câncer, por trabalhadores da saúde da família.

Revista Latino-Americana de Enfermagem, Ribeirão Preto, v. 18, n. 5, 2010. Disponível em: <www.eerp.usp.br/rlae >. Acesso em: 20 nov 2011.

SMITH, L. et al. An investigation of hospital generated pharmaceutical care when patients are discharged home from hospital. British Journal of Clinical Pharmacology, v. 44, p. 163-165, 1997.

SOUZA, A. C.; LOPES, M. J. M. Práticas terapêuticas entre idosos de Porto Alegre: uma abordagem qualitativa. Revista da Escola de Enfermagem da USP, São Paulo, v. 41, n. 1, p. 52-56, 2007.

SPINEWINE, A. et al. Implementation of ward-based clinical pharmacy services in Belgium - description of the impact on a geriatric unit. The Annals of Pharmacotherapy. v. 40, p. 720-728, 2006. 
STUFFKEN, R.; EGBERTS, T. C. G. Discontinuities in drug use upon hospital discharge. Pharmacy World \&Science, v. 26, p. 268-270, 2004.

TACHË, S. V.; SÖNNICHSEN, A.; ASHCROFT, D. M. Prevalence of adverse drug events in ambulatory care: a systematic review. Annals of Pharmacotherapy. v. 45, n. 7/8, p. 977-989, 2011.

TAKAHASHI, P. S. K. Atenção farmacêutica para pacientes do Programa de Assistência Domiciliária (PAD) do Hospital Universitário da Universidade de São Paulo. 2009. 131 p. Dissertação (Mestrado em Fármaco e Medicamentos). Faculdade de Ciências Farmacêuticas, Universidade de São Paulo, São Paulo.

TAM, V. C. et al. Frequency, type and clinical importance of medication history errors at admission to hospital: a systematic review. Canadian Medical Association Journal, v. 173, n. 5, p. 510-515, 2005.

TESSER C. D.; BARROS, N. F. Medicalização social e medicina alternativa e complementar: pluralização terapêutica do Sistema Único de Saúde. Revista de Saúde Pública, São Paulo, v. 42, n. 5, p. 914-920, 2008.

TESSER, C. D. Medicalização social (I): o excessivo sucesso do epistemicídio moderno na saúde. Interface - Comunicação, Saúde, Educação, v. 10, n. 19, p. 61-76, 2006.

TESSER, D. C.; POLI NETO, P.; CAMPOS, G. W. S. Acolhimento e (des)medicalização social: um desafio para as equipes de saúde da família. Ciência \& Saúde Coletiva, Rio de Janeiro, v. 15, p. 3615-3624, 2010. Suplemento 3 .

TOUCHETTE, D. R.; SHAPIRO, N. L. Medication compliance, adherence, and persistence: currente status of behavioral and educational interventions to improve outcomes. Journal of Managed Care Pharmacy, v. 14, n. 6, p. S2-S10, 2008. Supplement S-d.

UNROE, K.T. et al. Inpatient medication reconciliation at admission and discharge: a retrospective cohort study of age and other risk factors for medication discrepancies. The American Journal of Geriatric Pharmacotherapy, v. 8, p. 115-126, 2010.

VAN WALRAVEN, C. et al. Effect of discharge summary availability during post-discharge visits on hospital readmission. Journal of General Internal Medicine, v. 17, p. 186-192, 2002.

VARALLO, F. R. Internações hospitalares por reações adversas a medicamentos (RAM) em um hospital de ensino. 2010. 96 f. Dissertação (Mestrado). Faculdade de Ciências Farmacêuticas, Universidade Paulista "Júlio de Mesquita Filho". Araraquara. 
VICTORA, C. G. et al. Condições de saúde e inovações nas políticas de saúde no Brasil: o caminho a percorrer. The Lancet. Série Saúde no Brasil, p. 90-102, 2011.

VIRA, T.; COLQUHOUN, M.; ETCHELLS, E. Reconciliable differences: correcting medication errors at hospital admission and discharge. Quality and Safety in Health Care, v. 15, p.122-126, 2006.

VRIES, E. N. et al. The incidence and nature of in-hospital adverse events: a systematic review. Quality and Safety in Health Care, v.17, p.216-223, 2008.

WACHTER, R. M. Compreendendo a segurança do paciente. Porto Alegre: Artmed, 2010.

WILLIANS, S. What is the High 5s Project? High 5's Project Website. Disponível em: https://www.high5s.org/bin/view/Main/WebHome. Acesso em 19 nov 2012.

WINTER, S. D. et al. Pharmacist- versus physician-acquired medication history: a prospective study at the emergency department. Quality and Safety in Health Care, v. 19, p. 371- 375, 2010.

ZANIRATO, S. H. et al. Sentidos do risco: interpretações teóricas. Revista Bibliográfica de Geografía y Ciencias Sociales, v. 13, n. 785, 2008. Disponível em: http://www.ub.edu/geocrit/b3w-785.htm. Acesso em: 17 abr 2012. 
Qpêndices e anexos 


\section{Apêndice 1}

\section{ROTEIRO DE ENTREVISTA}

1. Em sua opinião, qual o grau de desenvolvimento, na instituição, da cultura de segurança (trabalho em equipe, comunicação clara entre os profissionais e abertura para discussão e análise sobre a ocorrência de erros)?

2. Que medidas são tomadas quando são detectados erros que causam ou têm potencial de causar dano ao paciente?

3. Existe sistema de notificação voluntária de suspeita de reação adversa a medicamento ou de erro de medicação? Como funciona?

4. São realizadas ações pró-ativas para obtenção de informações sobre ocorrência de eventos adversos relacionados a medicamentos ou situações de risco de dano ao paciente? Quais?

5. São desenvolvidos projetos acadêmicos relacionados à segurança do paciente no processo de uso de medicamentos, na instituição?

6. Existem normas e procedimentos específicos para a segurança do paciente no processo de uso de medicamentos, durante a hospitalização? Quais?

7. Como se desenvolve a alta hospitalar do paciente?

(Explorar os seguintes aspectos: existência de planejamento da alta; participação de equipe multiprofissional, de forma colaborativa e integrada no planejamento e operacionalização da alta; documentação do processo, tipo e conteúdo do documento gerado; disponibilização de número de telefone para contato com hospital; existência de uniformidade do procedimento nos diferentes setores assistenciais). 
8. São desenvolvidas estratégias visando à segurança no processo de uso de medicamentos após alta hospitalar? Quais?

(Verificar o desenvolvimento das seguintes atividades: reconciliação medicamentosa na admissão e na alta hospitalar; orientação do paciente elou cuidador; seguimento domiciliar do paciente, e outras atividades que forem citadas).

9. Como as atividades são desenvolvidas?

(Para cada estratégia desenvolvida, explorar os seguintes aspectos: existência de critérios de seleção de pacientes, existência de normas e procedimentos específicos, descrição dos procedimentos realizados).

10. Em sua opinião, quais os fatores facilitadores para a implantação e desenvolvimento das atividades?

11. Em sua opinião, quais são as barreiras para a implantação, desenvolvimento ou ampliação das atividades?

12. Existe articulação entre o hospital e unidades básicas de saúde para a continuidade do cuidado após alta hospitalar, com foco na segurança do paciente no processo de uso de medicamentos?

13. Em sua opinião, quais são os fatores facilitadores para a articulação do cuidado entre os diferentes níveis de assistência à saúde?

14. Em sua opinião, quais são as barreiras para a articulação do cuidado entre os diferentes níveis de assistência à saúde?

15. Gostaria de comentar algum aspecto relacionado ao cuidado ao paciente em alta hospitalar, com foco na segurança do uso de medicamentos, que não tenha sido abordado? 


\section{Apêndice 2}

\section{TERMO DE CONSENTIMENTO LIVRE E ESCLARECIDO}

Eu, Liete de Fátima Gouveia Marques, mestranda da Faculdade de Saúde Pública da Universidade de São Paulo, sob orientação da Prof ${ }^{a}$. Dr ${ }^{a}$ Nicolina Silvana Romano Lieber, estou desenvolvendo uma pesquisa sob o título "USO DE MEDICAMENTOS E A SEGURANÇA DO PACIENTE NA INTERFACE ENTRE HOSPITAL, ATENÇÃO BÁSICA E DOMICÍLIO". Os objetivos deste estudo são: identificar estratégias empregadas pelo hospital para a segurança do paciente no processo de uso de medicamentos após alta hospitalar; verificar articulações entre o hospital e demais serviços de saúde que possibilitem continuidade do cuidado ao paciente; e identificar barreiras e condições facilitadoras para implantação e desenvolvimento de estratégias, assim como para articulação com demais serviços de saúde, analisando alcance e limitações para a segurança de pacientes.

Você está sendo convidado a participar desta pesquisa, voluntariamente, respondendo questões em entrevista que será gravada e transcrita, sendo que as informações serão utilizadas exclusivamente para fins científicos. A participação nesta pesquisa oferece risco mínimo de dano. Caso sinta desconforto com relação a alguma pergunta, não há necessidade de respondê-la, e não haverá prejuízo em sua participação na pesquisa.

Informamos, ainda, que a confidencialidade, o sigilo e a privacidade serão garantidos, assim como seu direito de receber todos os esclarecimentos que se fizerem necessários. A qualquer momento, você poderá retirar seu consentimento e deixar de participar do estudo.

Agradecemos, antecipadamente, sua participação e colocamo-nos à disposição por meio dos seguintes contatos: 1) Liete Marques: Telefones 5532-0720 e 8752-5317 email liete.marques@usp.br; 2) Nicolina S. R. Lieber: Telefone 3061-7768 email nicolina@usp.br.

Os contatos com os comitês de ética são os seguintes:

CEP-HU/USP: Av. Prof. Lineu Prestes, 2565 - Cidade Universitária - CEP: 05508-000 - São Paulo - SP. Telefone: 3091-9457 - Fax: 3091-9452 - email: cep@hu.usp.br.

COEP-FSP/USP: Av. Dr. Arnaldo, 715 - Cerqueira César - CEP: 01246-904 - São Paulo - SP. Telefone: 3061-7779 - email: coep@fsp.usp.br.

Declaro que, após convenientemente esclarecido pelo pesquisador e ter entendido o que me foi explicado, consinto em participar do presente Projeto de Pesquisa.

NOME: RG

FORMAÇÃO/FUNÇÃO:

ASSINATURA: de de 2012. 
ANEXO 1 
Título: USO DE MEDICAMENTOS E A SEGURANÇA DO PACIENTE NA INTERFACE ENTRE HOSPITAL, ATENÇÃO BÁSICA E DOMICÍLIO

Área Temática:

\author{
Pesquisador:LIETE DE FÁTIMA GOUVEIA MARQUES \\ Instituição: Faculdade de Saúde Pública da Universidade \\ de São Paulo - FSP/USP
}

Versão: 2

CAAE: 01260812.0 .0000 .5421

\title{
PARECER CONSUBSTANCIADO DO CEP
}

Número do Parecer: 65433

Data da Relatoria: 22/06/2012

\section{Apresentação do Projeto:}

O projeto de pesquisa foi apresentado em conformidade com os padrões da Resolução do CNS 196/96. O projeto trata da segurança do paciente no processo de uso de medicamentos após alta hospitalar e as estratégias desenvolvidas de forma articulada com demais serviços de saúde. O tema a ser abordado é relevante e a bibliografia apresentada está atualizada e coerente com o assunto. Os pesquisadores descrevem adequadamente a metodologia a ser empregada e o termo de consentimento livre e esclarecido está redigido de forma clara e coerente com a pesquisa em questão.

\section{Objetivo da Pesquisa:}

Os objetivos estão claros e coerentes.

\section{Avaliação dos Riscos e Benefícios:}

O projeto declara haver risco mínimo.

\section{Comentários e Considerações sobre a Pesquisa:}

Nada a declarar.

\section{Considerações sobre os Termos de apresentação obrigatória:}

O TCLE aborda todos os itens a serem desenvolvidos no trabalho de forma clara para convidar e informar aos profissionais sobre sua participação no estudo.

\section{Recomendações:}

Nada a declarar.

\section{Conclusões ou Pendências e Lista de Inadequações:}

Nada a declarar.

\section{Situação do Parecer:}

Aprovado 
Necessita Apreciação da CONEP:

Não

02 de Agosto de 2012

Assinado por:

Claudio Leone 
ANEXO 2 
Título: USO DE MEDICAMENTOS E A SEGURANÇA DO PACIENTE NA INTERFACE ENTRE HOSPITAL, ATENÇÃO BÁSICA E DOMICÍLIO

Área Temática:

\author{
Pesquisador: LIETE DE FÁTIMA GOUVEIA MARQUES \\ Instituição: Faculdade de Saúde Pública da Universidade \\ de São Paulo - FSP/USP
}

Versão: 2

CAAE: 01260812.0 .0000 .5421

\title{
PARECER CONSUBSTANCIADO DO CEP \\ Elaborado pela Instituição Coparticipante
}

Número do Parecer: 51394

Data da Relatoria: 22/06/2012

\section{Apresentação do Projeto:}

O projeto foi redigido de forma clara e com objetivos definidos. O TCLE está adequado; contudo, sugiro que acrescente no TCLE a identificação do profissional entrevistado (farmacêutico, médico, ..)

\section{Objetivo da Pesquisa:}

Apesar de estar claro, o pesquisador irá coletar dados somente de uma instituição sendo que no texto (Objetivo primário) está descrito "identificar estratégias empregadas por hospitais ..... verificar articulações entre hospitais ....". Sugiro revisão pelo pesquisador.

\section{Avaliação dos Riscos e Benefícios:}

Risco mínimo. Esta pesquisa permitirá implementar as estratégias já realizadas com a alta hospitalar no HU/USP.

\section{Comentários e Considerações sobre a Pesquisa:}

Pesquisa relevante.

\section{Considerações sobre os Termos de apresentação obrigatória:}

Adequados.

\section{Recomendações:}

Vide nos itens acima descritos.

\section{Conclusões ou Pendências e Lista de Inadequações:}

Vide nos itens acima descritos.

\section{Situação do Parecer:}

Aprovado 
Necessita Apreciação da CONEP:

Não

\section{Considerações Finais a critério do CEP:}

Concordamos com as observações feitas pelo relator, que será proveitoso identificar a profissão do entrevistado, e correção de Hospitais para hospital; manteremos a aprovação certos das correções serem efetivadas visando um trâmite mais célere.

SAO PAULO, 06 de Julho de 2012

Assinado por:

Mauricio Seckler 
ANEXO 3 

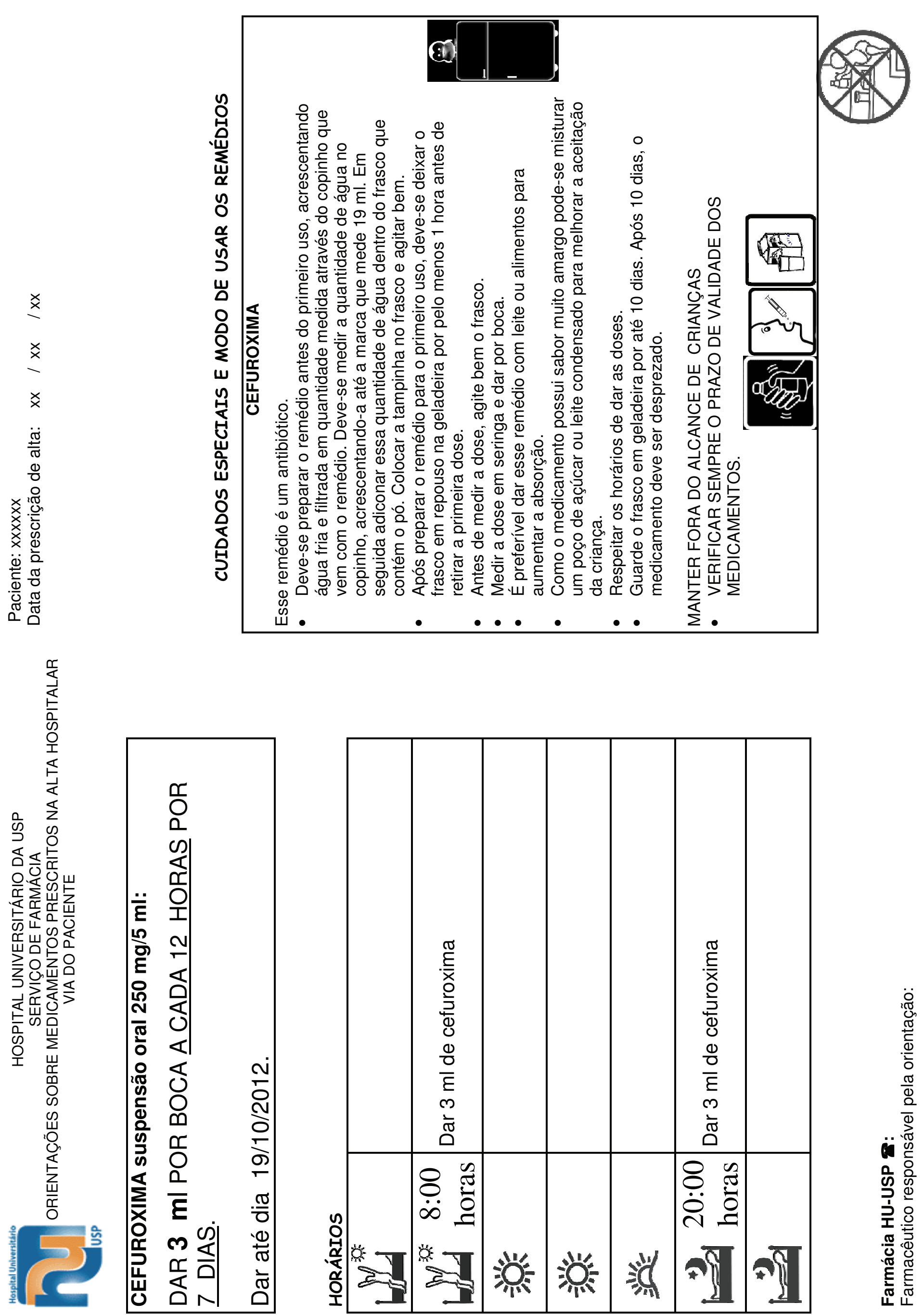
ANEXO 4 
HOSPITAL UNIVERSITÁRIO DA UNIVERSIDADE DE SÃO PAULO SERVIÇO DE FARMÁCIA - ORIENTAÇÃO DE ALTA

\begin{tabular}{|c|l|}
\hline HORÁRIOS & MEDICAMENTOS \\
\hline $\begin{array}{c}6: 00 \\
\text { horas } \\
\text { da } \\
\text { manhã }\end{array}$ & ACIDO VALPRÓICO solução oral $250 \mathrm{mg} / 5 \mathrm{ml}-$ Dar $2,5 \mathrm{ml}$ \\
\hline $\begin{array}{c}18: 00 \\
\text { horas } \\
\text { da } \\
\text { tarde }\end{array}$ & ACIDO VALPRÓICO solução oral $250 \mathrm{mg} / 5 \mathrm{ml}-$ Dar $2,5 \mathrm{ml}$ \\
\hline $\begin{array}{c}22: 00 \\
\text { horas } \\
\text { da noite }\end{array}$ & VIGABATRINA comprimido de $500 \mathrm{mg}-$ Dar um comprimido amassado e \\
diluído com um pouco de água
\end{tabular}

ONDE ENCONTRAR OS MEDICAMENTOS?

MEDICAMENTOS QUE DEVEM SER ADQUIRIDOS EM POSTOS DE SAÚDE:

- ACIDO VALPRÓICO solução oral $250 \mathrm{mg} / 5 \mathrm{ml}$

MEDICAMENTO QUE DEVE SER ADQUIRIDOS EM POSTOS ESPECIAIS (PROGRAMA DE ALTO CUSTO - Maria Zélia):

- VIGABATRINA comprimido de $500 \mathrm{mg}$ 
ANEXO 5 

N. ATEND:
N. MAT, :
RH

NÖME PACIENTE:

SEXO -

DTNASC.:

LEITO:

ENFERMARIA:

DT ADMISSÃO:

DT ALTA:

ESTADIA

CID ADMISSÃO:

DIAG PRINCIPAL

DIAG SECUNDÁRIO

OUTROS DIAGNOSTICOS

HISTORIA/ EVOLUCAO:

DESTINO/ MEDICACAO:

EXAMES RELEVANTES:

PROCEDIM. REALIZ.:

INFEC. HOSP. -

STALTA 
ANEXO 6 
HOSPITAL UNIVERSITÁRIO DA UNIVERSIDADE DE SÃO PAULO

SERVICOO DE FARMÁCIA

ORIENTAÇÃO FARMACÊUTICA NA ALTA HOSPITALAR

Via do prontuário

Dados do cuidador:

Nome:

Parentesco: ( ) pai ( ) mãe ( ) avós ( ) irmã(o) ( ) amigo

( ) outro:
Nome:

RH:

Cole aqui a etiqueta do paciente

Informações sobre os medicamentos prescritos na alta hospitalar

\begin{tabular}{|c|c|c|c|c|}
\hline \multirow[b]{2}{*}{ MEDICAMENTOS / POSOLOGIA / TEMPO DE TRATAMENTO } & \multirow[b]{2}{*}{ HORÁRIOS } & \multicolumn{3}{|c|}{ MODO DE AQUISIÇÃO } \\
\hline & & $\begin{array}{l}\text { Doação do Serviço } \\
\text { Social HU }\end{array}$ & $\begin{array}{l}\text { Retirada } \\
\text { em UBS }\end{array}$ & $\begin{array}{l}\text { Compra pela } \\
\text { familia }\end{array}$ \\
\hline & & & & \\
\hline & & & & \\
\hline & & & & \\
\hline & & & & \\
\hline & & & & \\
\hline & & & & \\
\hline
\end{tabular}

OBSERVAÇÕES DO FARMACÊUTICO

1. Leitura da receita médica: ( ) lê sem dificuldade ( ) lê com dificuldade ( ) não lê

2. Medida de dose no dosador oral:

( ) foi necessário marcar a dose $\quad$ ( ) soube mostrar a dose sem dificuldade

3.Soube informar qual a doença em tratamento? ( ) sim ( ) não. Necessitou esclarecimento.

4. Soube repetir as informações fornecidas na orientação farmacêutica?

( ) $\operatorname{sim}$ ( ) não; foi reorientado.

5. Ocorrência de reação de hipersensibilidade a algum medicamento?

( ) $\operatorname{sim}$.

( ) não.

Observações adicionais: (Ex :histórico de não aderência ao tratamento, eventos adversos, grau de envolvimento dos cuidadores, problemas com aquisição dos medicamentos e questões sociais relevantes) 


\section{Anexo 7}

Example: Reconciling Form That Doubles as an Order Form

UMassMemorial

PREADMISSION MEDICATION LIST

VERIFICATION AND ORDER FORM

(Medication Reconciliation)

Allergies:

LIST BELOW ALL OF THE PATIENTS MEDICATIONS PRIOR TO ADMISSION INCLUDING OTC AND HERBLL MEDS NEW MEDICATHONS OR MEDICATION CHANGIS SHOULD AE WRITEN ON ADMISSION ORDERS

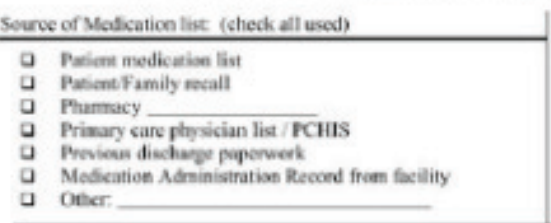

\section{$\square$ CHECK HERE IF THIS IS AN ADDENDUM TOOR REVISION OF PREVIOLSLY COMPLETED MEDICATION LIST}

MEDICATION HISTORY RFCORDFDVERIFIED BY: DATE RECORDED:

\begin{tabular}{|c|c|c|c|c|c|c|c|c|c|c|}
\hline \multicolumn{5}{|c|}{ DATE RECORDHD: } & \multirow{2}{*}{\multicolumn{2}{|c|}{$\begin{array}{c}\text { ORDER } \\
\text { Caatiase } \\
\text { an } \\
\text { Adminsies }\end{array}$}} & \multirow{2}{*}{\multicolumn{2}{|c|}{$\begin{array}{c}\text { ORDize } \\
\text { Centises } \\
\text { on } \\
\text { Trasder }\end{array}$}} & \multirow{2}{*}{\multicolumn{2}{|c|}{ 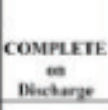 }} \\
\hline $\begin{array}{l}\text { MEDACATON NAME } \\
\text { (WRTELECIBLV) }\end{array}$ & $\begin{array}{c}\text { DOSE } \\
(\mathrm{my}, \mathrm{meg})\end{array}$ & $\begin{array}{l}\text { ROUTE } \\
\text { PO GT, } \\
\text { SC, IV) }\end{array}$ & FREQUENCY & $\begin{array}{l}\text { LAST DOSE } \\
\text { DATETIEE }\end{array}$ & & & & & & \\
\hline 1. & & & & & C & DC & C & DC & & DC \\
\hline 2. & & & & & C & DC & C & DC & C & $D C$ \\
\hline 3. & & & & & C & DC & C & DC & & $D C$ \\
\hline 4. & & & & & C & DC & C & $\mathrm{DC}$ & & DC \\
\hline 5. & & & & & C & DC & C & $D C$ & & $D C$ \\
\hline 6. & & & & & C & DC & C & DC & & $D C$ \\
\hline 7. & & & & & C & DC & C & DC & & $D C$ \\
\hline 8. & & & & & C & DC & C & DC & & $D C$ \\
\hline 9. & & & & & C & DC & C & DC & & DC \\
\hline 10. & & & & & C & DC & C & DC & & $D C$ \\
\hline II. & & & & & C & DC & C & DC & & $D C$ \\
\hline 12. & & & & & C & DC & $\mathrm{C}$ & DC & & $D C$ \\
\hline 13. & & & & & C & DC & C & DC & & $D C$ \\
\hline 14. & & & & & C & DC & C & DC & & $D C$ \\
\hline 15. & & & & & C & DC & $\mathrm{C}$ & DC & & DC \\
\hline
\end{tabular}

M.D. Siganture:

Priat Name:

Reviend and Transcribed

Pager:

DaverTime:

Nurse Sigmature:

Dute/Time:

Sraw to Pharanacy. Fille under Onders wirh the Histery and Phruicel.

Fonte: ROGERS et al. Journal on Quality and Patient Safety, v. 32, n. 1, p. 37-50, 2006. 


\section{Landskrona Hospital \\ SKAंNE}

Department of Medicine, ward 2

Landskrona Hospital

Born: 1 Jan 1921

Name: Clara Carlsson

Physician during hospital care: Mats Matsson

General practitioner: Olle Olsson

Hospital care: 1 Jan 2008 - 11 Jan 2008

\section{DISCHARGE SUMMARY}

You have been in hospital care because you have experienced dizziness for a period of time and finally you fainted. When you fainted you fell and now suffer from back pain. Your blood pressure was found to be too low and this could explain the dizziness. Your medications have therefore been adjusted and your blood pressure is now back to normal. During your hospital care we also found that you had an infection in the urinary tracts, for which you now are receiving antibiotics.

After discharge, you will return to the nursing home Flower garden. Within three weeks you will have an appointment with your General Practitioner, who will measure and follow up on your blood pressure and back pain.

\section{Medication Report}

- Metoprolol has been decreased from 2 to 1 tablets per day, due to low blood pressure.

- Furosemide has been discontinued since you no longer have a problem with swollen ankles.

- Paracetamol has been added because of the back pain from your fall.

- Cefadroxil has been added due to a urinary tract infection.

\begin{tabular}{|l|l|l|l|l|l|l|}
\hline $\begin{array}{l}\text { MEDICINE } \\
\text { preparation and dose }\end{array}$ & Effect & Morning & Noon & Evening & Night & Comments \\
\hline Tabl Metoprolol 25 mg & $\begin{array}{l}\text { Lowers blood } \\
\text { pressure }\end{array}$ & 1 & & & & \\
\hline Tabl Hydrochlorothiazide 50 mg & $\begin{array}{l}\text { Lowers blood } \\
\text { pressure }\end{array}$ & 1 & & & & \\
\hline Tabl Metformin $850 \mathrm{mg}$ & Against diabetes & 1 & & 1 & & \\
\hline Tabl Paracetamol 500 mg & $\begin{array}{l}\text { Against back } \\
\text { pain }\end{array}$ & 2 & 2 & 2 & 2 & On demand \\
\hline Tabl Cefadroxil $500 \mathrm{mg}$ & $\begin{array}{l}\text { Against urinary } \\
\text { tract infection }\end{array}$ & 1 & & 1 & & Until 13 January \\
\hline
\end{tabular}

Fonte: BERGKVIST et al. Eur J Clin Pharmacology, v. 65, p. 1037-1046, 2009. 


\section{GLOSSÁRIO}

\section{ALTA $^{1}$}

Ato médico que determina a finalização da modalidade de assistência que vinha sendo prestada ao paciente, ou seja, a finalização da internação hospitalar. O paciente pode receber alta curado, melhorado ou com seu estado de saúde inalterado. O paciente poderá, caso necessário, passar a receber outra modalidade de assistência, seja no mesmo estabelecimento, em outro ou no próprio domicílio.

\section{DANO $^{2}$}

Deterioração da estrutura ou função do corpo e / ou quaisquer efeitos prejudiciais daí resultantes. Inclui doença, lesão, sofrimento, incapacidade e morte.

\section{$\mathrm{ERRO}^{2}$}

Falha em realizar uma ação planejada ou aplicação de um plano incorreto.

EVENTO ADVERSO ${ }^{2}$

Um incidente que resultou em dano ao paciente.

\section{INTERNAÇÃO HOSPITALAR ${ }^{1}$}

Equivalente à admissão hospitalar. Pacientes que são admitidos para ocupar um leito hospitalar por um período igual ou maior a 24 horas.

\section{REAÇÃO ADVERSA ${ }^{2}$}

Dano inesperado resultante de uma ação justificada, onde o processo correto foi seguido para o contexto no qual o evento ocorreu.

Fontes:

1. MINISTÉRIO DA SAÚDE. Padronização da nomenclatura do censo hospitalar. Série A. Normas e Manuais Técnicos. $2^{a}$ ed. Brasília, 2002.

2. RUNCIMAN, W. et al. Towards an International Classification for Patient Safety: key concepts and terms. International Journal for Quality in Health Care. v. 21, n. 1, p. 18-26, 2009. 


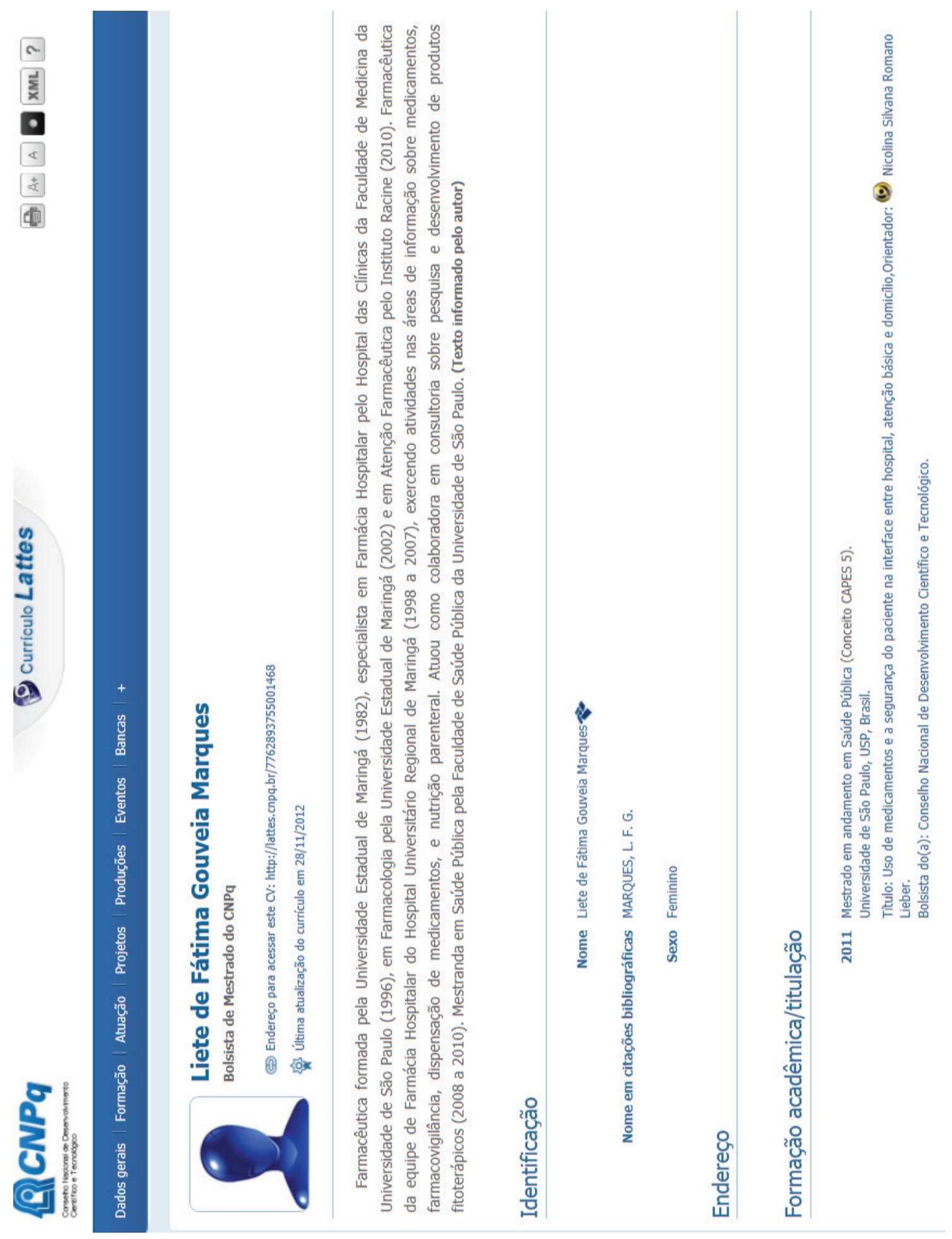




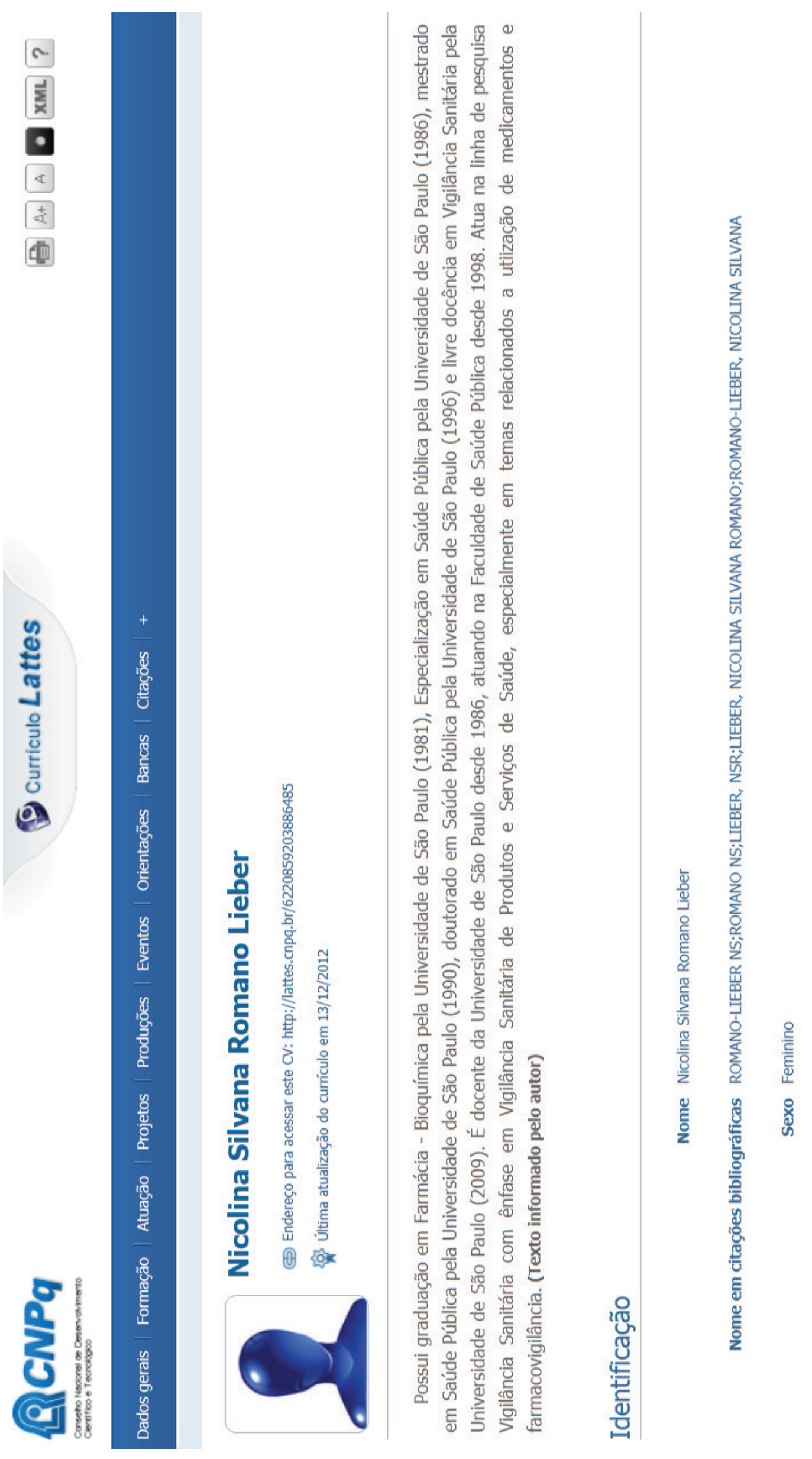

